\title{
Financial Burdens of Cancer Treatment: A Systematic Review of Risk Factors and Outcomes
}

\author{
Grace L. Smith, MD, PhD, MPHa,b; Maria A. Lopez-Olivo, MD, PhDc; Pragati G. Advani, MD, DrPH; Matthew S. Ning, MD;
} Yimin Geng, MS, MSLISe; Sharon H. Giordano, MD, MPH ${ }^{\mathrm{a}}$; ; and Robert J. Volk, PhD

\begin{abstract}
Background: Patients with cancer experience financial toxicity from the costs of treatment, as well as material and psychologic stress related to this burden. A synthesized understanding of predictors and outcomes of the financial burdens associated with cancer care is needed to underpin strategic responses in oncology care. This study systematically reviewed risk factors and outcomes associated with financial burdens related to cancer treatment. Methods: MEDLINE, Embase, PubMed, PsychINFO, and the Cochrane Library were searched from study inception through June 2018, and reference lists were scanned from studies of patientlevel predictors and outcomes of financial burdens in US patients with cancer (aged $\geq 18$ years). Two reviewers conducted screening, abstraction, and quality assessment. Variables associated with financial burdens were synthesized. When possible, pooled estimates of associations were calculated using random-effects models. Results: A total of 74 observational studies of financial burdens in 598,751 patients with cancer were identified, among which $49 \%$ of patients reported material or psychologic financial burdens $(95 \% \mathrm{Cl}, 41 \%-56 \%)$. Socioeconomic predictors of worse financial burdens with treatment were lack of health insurance, lower income, unemployment, and younger age at cancer diagnosis. Compared with patients with health insurance, those who were uninsured demonstrated twice the odds of financial burdens (pooled odds ratio [OR], 2.09; 95\% Cl, 1.33-3.30). Financial burdens were most severe early in cancer treatment, did not differ by disease site, and were associated with worse health-related quality of life ( $\mathrm{HRQ} \mathrm{oL}$ ) and nearly twice the odds of cancer medication nonadherence (pooled OR, 1.70; 95\% Cl, 1.13-2.56). Only a single study demonstrated an association with increased mortality. Studies assessing the comparative effectiveness of interventions to mitigate financial burdens in patients with cancer were lacking. Conclusions: Evidence showed that financial burdens are common, disproportionately impacting younger and socioeconomically disadvantaged patients with cancer, across disease sites, and are associated with worse treatment adherence and HRQoL. Available evidence helped identify vulnerable patients needing oncology provider engagement and response, but evidence is critically needed on the effectiveness of interventions designed to mitigate financial burden and impact.
\end{abstract}

J Natl Compr Canc Netw 2019;17(10):1184-1192 doi: 10.6004/jncen.2019.7305

aDepartment of Radiation Oncology, 'bepartment of Health Services Research, and 'Department of General Internal Medicine, The University of Texas MD

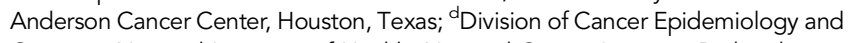
Genetics, National Institutes of Health, National Cancer Institute, Bethesda, Maryland; and ${ }^{e}$ Research Medical Library, and fDepartment of Breast Medical Oncology, The University of Texas MD Anderson Cancer Center, Houston, Texas.

\section{Background}

Although the burden of cancer costs on the US healthcare system is well-recognized, ${ }^{1,2}$ more recently, the personal "financial toxicity" associated with the cost of care has also been identified as a distinct consequence of cancer treatment. ${ }^{3-13}$ A recent systematic review that sought to define the prevalence of the types of financial hardships among patients with cancer showed that $40 \%$ to $50 \%$ of US patients experienced material or psychologic stressors related to the cost of treatment. ${ }^{13}$ The frequency of financial burdens among patients with cancer could also increase, especially for those facing escalating cancer therapy costs and barriers to insurance coverage., 2,12,14,15

As a result, cancer's overall financial burdenincluding the direct costs of care, the indirect costs (eg, lost work, income, and savings), and the distress resulting from these financial stressors of cancer care-is now generally acknowledged as a priority concern faced by US patients as well as the oncology providers caring for them. Yet an effective response to this problem remains lacking, with approximately one-quarter to one-half of patients reporting inadequate oncology provider engagement with their financial burdens. ${ }^{16,17}$ To inform effective response and intervention in vulnerable patients, ${ }^{18}$ a comprehensive synthesis of the risk factors for and outcomes of financial burdens is needed. We therefore conducted a systematic review of these risk factors and outcomes across studies of US patients with cancer to identify the types of burdens in vulnerable patient subgroups and the consequent health impact.

\section{Methods}

\section{Protocol and Registration}

This protocol is registered in PROSPERO (CRD42017054521). Results are reported per the Preferred Reporting Items for Systematic Reviews and Meta-Analyses (PRISMA) statement. $^{19}$

\section{See JNCCN.org for supplemental online content.}




\section{Eligibility Criteria}

Studies were searched that contained primary data analyses examining financial burdens among patients with cancer and the associations of burdens with socioeconomic, demographic, clinical, intervention, and outcome variables. Based on existing conceptual frameworks, ${ }^{12,20}$ studies of both material and psychological financial burdens in patients with cancer were searched. We included English-language, peer-reviewed, full-text studies conducted in US adults (aged $\geq 18$ years) with cancers of any disease site and stage, and in any part of the cancer disease trajectory. Exclusion criteria were as follows: nonUS studies (given major differences in health insurance and employment among countries), no original data analysis, and no patient-level financial burdens reported.

\section{Search, Study Selection, and Data Collection}

MEDLINE, Embase, PsychINFO, and the Cochrane Library were searched from study inception until June 2018, guided by a research librarian (Y. Geng), and reference lists of relevant reviews were manually examined. Search terms and strategy are delineated in eFigure 1 and eAppendix 1 , available with this article at JNCCN.org. Two reviewers (G.L. Smith, P.G. Advani) performed title and abstract screening, full-text review, and consensus resolution of interrater discrepancies for inclusion (kappa, 0.79). Two reviewers for each study (G.L. Smith, P.G. Advani, M.S. Ning) abstracted and cross-checked study characteristics, including design, eligibility, and definition or measure of financial burdens directly reported from the text. Discrepancies were resolved through consensus.

\section{Financial Burden, Risk Factor, and}

\section{Outcome Measures}

We extracted financial burden variables from each study, including measures of direct material burdens (eg, higher out-of-pocket [OOP] costs), indirect burdens (eg, lost savings and increased debt), and psychological burdens (eg, financial worries or distress). Key terms were health expenditures, healthcare costs, cost of illness, financing, fees, charges, bankruptcy, insolvency, economic hardship, economic burden, economic stress or distress, economic difficulty, OOP costs, costs, expenses, and spending. A complete list of search terms is included in supplemental eFigure 1. We extracted reported associations between independent variables (eg, risk factors or interventions) and financial burden variables, and associations between financial burden variables and outcome variables, statistical tests of associations, and magnitude/significance of effects (odds ratios [ORs], risk ratios, hazard ratios [HRs], and $95 \% \mathrm{CI})^{21}$

Risk of Bias Assessment

Reviewers independently ascertained the risk of bias using the NIH Quality Assessment Tool for Observational
Cohort and Cross-Sectional Studies (supplemental eTable 1), ${ }^{22}$ including overall study quality (ie, individual study rated as "good" if it met all applicable quality assessment criteria, "fair" if it met most of the criteria, and "poor" if it met a minority of the criteria). Strength of evidence was evaluated using Grading of Recommendations Assessment, Development, and Evaluation (GRADE) criteria. ${ }^{21}$

\section{Data Synthesis}

For studies reporting the frequency of financial burdens (based on the study's specific measure of material or psychological financial burden), the total sampleweighted prevalence of financial burdens was calculated. Per Cochrane Consumers and Communication Review Group guidelines, ${ }^{21}$ we performed a qualitative synthesis of associations. Quantitative associations were pooled for insurance status and financial burdens, ${ }^{23-27}$ and for financial burdens and medication adherence, ${ }^{5,28,29}$ because these measures could be pooled across multiple studies. We converted reported ORs into $\log$ ORs to quantify the effect, using the generic inversevariance method with a random-effects model to pool ORs. When needed, 1/OR was used for consistency of the referent group in pooled estimates. Adjusted estimates were used where possible for primary analyses to decrease potential confounder bias. Extracted $95 \%$ CIs were transformed into standard errors. Heterogeneity of the data was tested with Cochran's $Q$ test and interpreted using the $I^{2}$ index. When $I^{2}=40 \%$, heterogeneity was explored through sensitivity analyses by eliminating outliers (RevMan 5.3.5 [Reviewer Manager, Copenhagen]). ${ }^{30}$

\section{Results}

\section{Study Selection}

Of 5,711 nonduplicate records screened, with $452 \mathrm{ab}-$ stracts and/or full texts reviewed, 74 studies met the final inclusion criteria per PRISMA (Figure 1). Randomized studies were eligible, but none in the literature met inclusion criteria.

\section{Study and Patient Characteristics}

Studies represented an aggregate sample of 598,751 patients with cancer (Table 1). Of 566,531 patients for whom race/ethnicity was reported, $86 \%$ were categorized as white, non-Hispanic white, or Caucasian. Of 597,575 patients for whom sex was reported, $54 \%$ were female. Weighted mean age was 59.5 years (95\% CI, 57.5-62.3). Additional study characteristics are reported in eAppendix 1 and supplemental eTable 2. In 25 reporting studies (of 20,272 patients), the sample-weighted prevalence was $49 \%$ (95\% CI, $41 \%-56 \%$ ) of patients with cancer with any financial burden (Figure 2). 


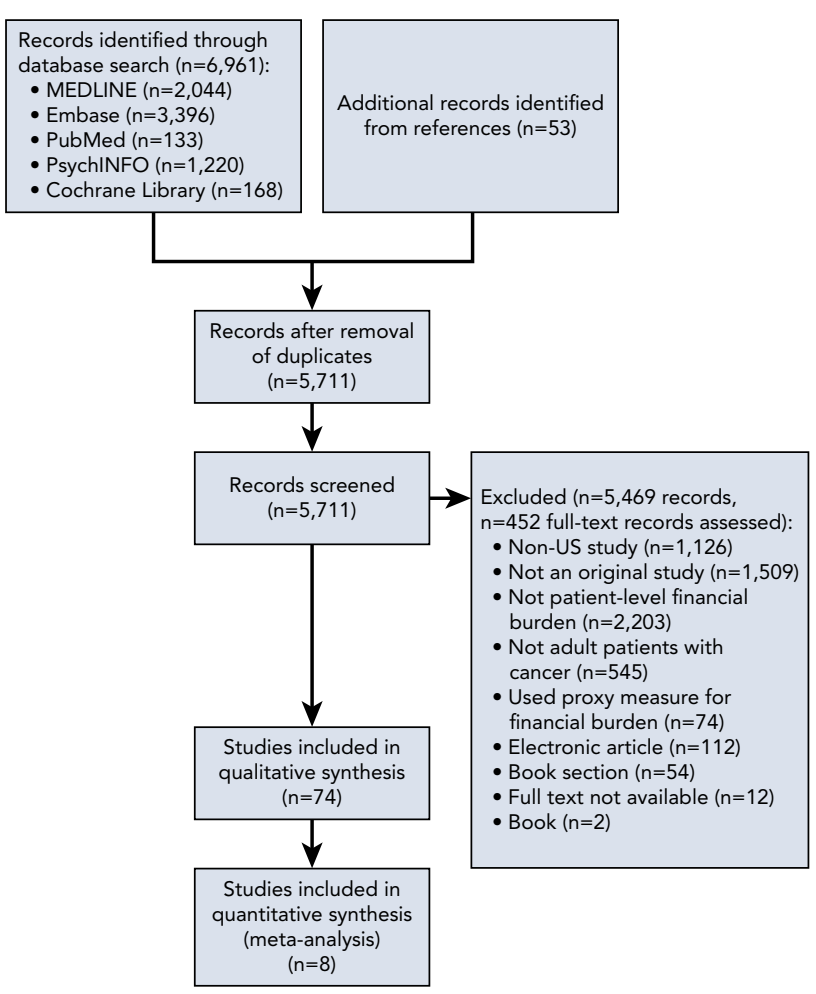

Figure 1. PRISMA flow diagram of study selection.

\section{Financial Burden Measures}

Financial burden measures analyzed across studies were as follows: (1) direct material financial burdens of cancer treatment, such as higher OOP expenses, examined in $19 \%$ of the 74 studies $(n=14)$; (2) indirect financial burdens, such as lost savings, work, and productivity, and inadequacy of financial resources to meet needs for food, housing, and transport as a result of cancer treatment, examined in $57 \%$ of the studies $(n=42)$; and (3) psychological hardships resulting from financial burdens, such as the experience of distress, stress, hardship, and worry, examined in $14 \%$ of the studies $(n=10)$ (Table 1$)$. When grouped by type of financial burden, the prevalence ranged from $39 \%$ to $64 \%$ of patients with direct, indirect, or psychological burden, with no statistically significant difference in prevalence by burden type (see eAppendix 1).

\section{Risk of Bias}

Of 74 studies with observational study designs, the primary sources of bias were recall bias in retrospective and cross-sectional study designs and selection bias (additional details in eAppendix 1 and supplemental eTable 1 ). A total of $72 \%$ of the studies had a "good" quality assessment for risk of bias, with a clearly specified study population, participation by $>50 \%$ of eligible persons, effect estimates provided with variances, a clearly defined

\begin{tabular}{|c|c|}
\hline Study Characteristic & Studies, n (\%) \\
\hline \multicolumn{2}{|l|}{ Financial toxicity measure } \\
\hline Direct material burden & 14 (19\%) \\
\hline Measures & $\begin{array}{l}\text { Higher total OOP expenses, higher OOP } \\
\text { drug expenses, higher OOP-to-income } \\
\text { ratio }\end{array}$ \\
\hline Indirect burden & $42(57 \%)$ \\
\hline Measures & $\begin{array}{l}\text { Lost savings; debt; borrowing; loans; } \\
\text { bankruptcy; losing or selling assets; lost/ } \\
\text { changed housing; inability to meet } \\
\text { needs for food, housing, and transport; } \\
\text { inability to meet financial demands } \\
\text { (medical and insurance coverage, } \\
\text { household finances and bills, daily living } \\
\text { expenses, leisure spending); lost/ } \\
\text { changed work and productivity; } \\
\text { inadequacy of financial support } \\
\text { resources and information; lost/changed } \\
\text { health insurance coverage }\end{array}$ \\
\hline Psychological burden & $10(14 \%)$ \\
\hline Measures & $\begin{array}{l}\text { Distress, stress, hardship, burden, } \\
\text { suffering, worry, difficulty, sacrifice, } \\
\text { uncertainty, anxiety, worsened } \\
\text { circumstances, lack of satisfaction }\end{array}$ \\
\hline \multicolumn{2}{|l|}{ Study design } \\
\hline Prospective cohort & $10(14 \%)$ \\
\hline Retrospective cohort & $9(12 \%)$ \\
\hline Cross-sectional & 55 (74\%) \\
\hline \multicolumn{2}{|l|}{ Study setting } \\
\hline Academic & $21(28 \%)$ \\
\hline Community & $8(11 \%)$ \\
\hline Academic and community & $5(7 \%)$ \\
\hline Population-based & 40 (54\%) \\
\hline
\end{tabular}

Abbreviation: OOP, out-of-pocket.

risk factor and outcome measures consistently measured across study participants, and adjustment for confounders. The strength of pooled evidence ranged from very low to low (additional details in supplemental eTable 3).

\section{Risk Factors Predicting Financial Burdens With Cancer Treatment}

A total of 50 studies evaluated the risk factors for financial burdens, demonstrating similar risk factors for the different types of burdens (direct material, indirect, and psychological burdens) (supplemental eTable 4). Evidence supported multiple socioeconomic factors as independent risk factors. Lack of health insurance was associated with increased odds of (more severe) financial burdens. ${ }^{6,11,23-25,31-46}$ In the pooled analysis (of 4 of 15 studies examining insurance status), ${ }^{23,24,26,27}$ patients lacking any drug or health insurance coverage had 


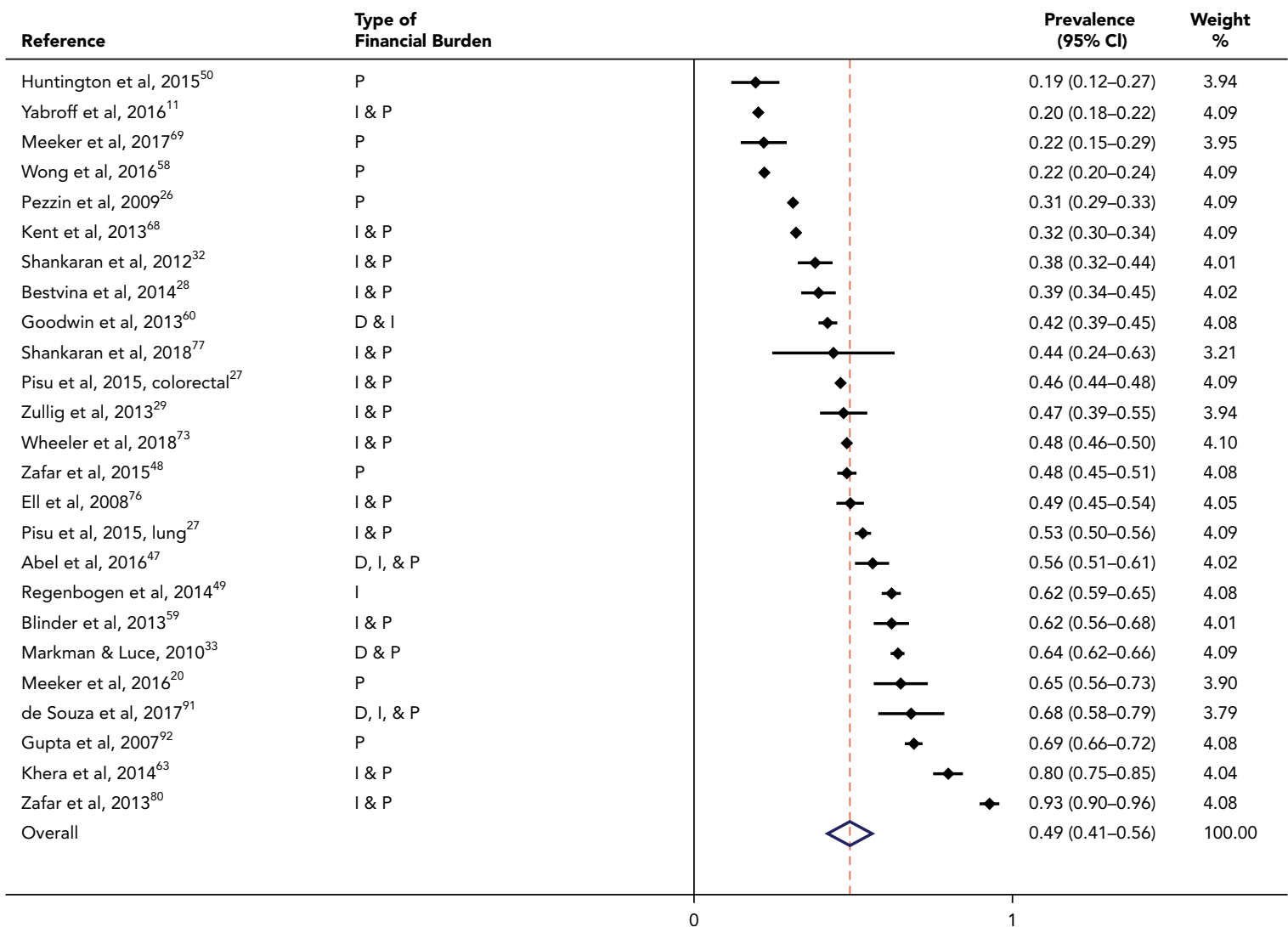

Figure 2. Pooled analyses showing sample-weighted prevalence of financial burdens. Weights are from random-effects analysis. Abbreviations: D, direct burdens; I, indirect burdens; P, psychological burdens.

twice the odds of experiencing financial burdens with cancer treatment, compared with patients who had partial/full insurance coverage (OR, 2.09; 95\% CI, 1.33-3.30) (Figure 3). A limited number of studies evaluated the association by specific insurance type, showing that Medicare, ${ }^{35,38}$ supplemental, ${ }^{6,43}$ and commercial insurance ${ }^{44}$ coverage were associated with decreased financial burdens compared with patients lacking insurance coverage and those with Medicaid.

Lower income was associated with increased odds of financial burdens, ${ }^{6,11,23,24,26,27,31-33,35-37,40-42,47-58}$ with a doseresponse relationship across the income spectrum in a limited number of studies. ${ }^{23,52,53}$ Evidence also indicated that unemployment or job change $\mathrm{e}^{11,24,31,32,36,37,49,51-53,57-65}$ and lower education were independent risk factors for worse financial burdens, ${ }^{23,35,40-42,48,51,61,66}$ although in 2 studies, education was not a risk factor. ${ }^{26,67}$

Demographic risk factors for financial burdens included younger age, which was associated with worse financial burdens across the studies. $^{11,14,24,25,27,31,32,38,40-42,46,48-50,53-55,57,58,61-63,65,68-72}$ Evidence supported a dose-response relationship across the age spectrum. ${ }^{11,31,35,42,49}$ For example, the adjusted probability of "material hardship" decreased from $34 \%$ for patients aged 18 to 54 years to $23 \%$ for those aged 55 to 64 years, $18 \%$ for those aged 65 to 74 years, and $10 \%$ for those aged $\geq 75$ years. ${ }^{11}$ Guy et $\mathrm{al}^{53}$ reported a contrasting finding of worse financial burdens in patients aged 50 to 64 versus those aged 18 to 39 years, but this contrasting finding may have been explained by financial burdens measured as OOP expenses as a percentage of family income instead of absolute OOP alone. ${ }^{11}$ Nonwhite race and Hispanic ethnicity ${ }^{11,68}$ were associated with increased financial burdens compared with white race and non-Hispanic ethnicity, but the effect sizes of associations varied and race/ethnicity categories were heterogeneous across the studies (eg, ORs ranged from 1.41 to 8.0). . $^{11,14,24,25,27,31,32,35,37,41,52,68,71,73,74}$ Female versus male sex was associated with increased financial burdens in a limited number of studies. ${ }^{11,14,25,35,54,58,71}$

Clinical risk factors for financial burdens, including disease and treatment factors, were investigated in multiple studies. Evidence indicated that no single cancer site, histology, or stage at diagnosis emerged as a consistent, independent risk factor for financial burdens 


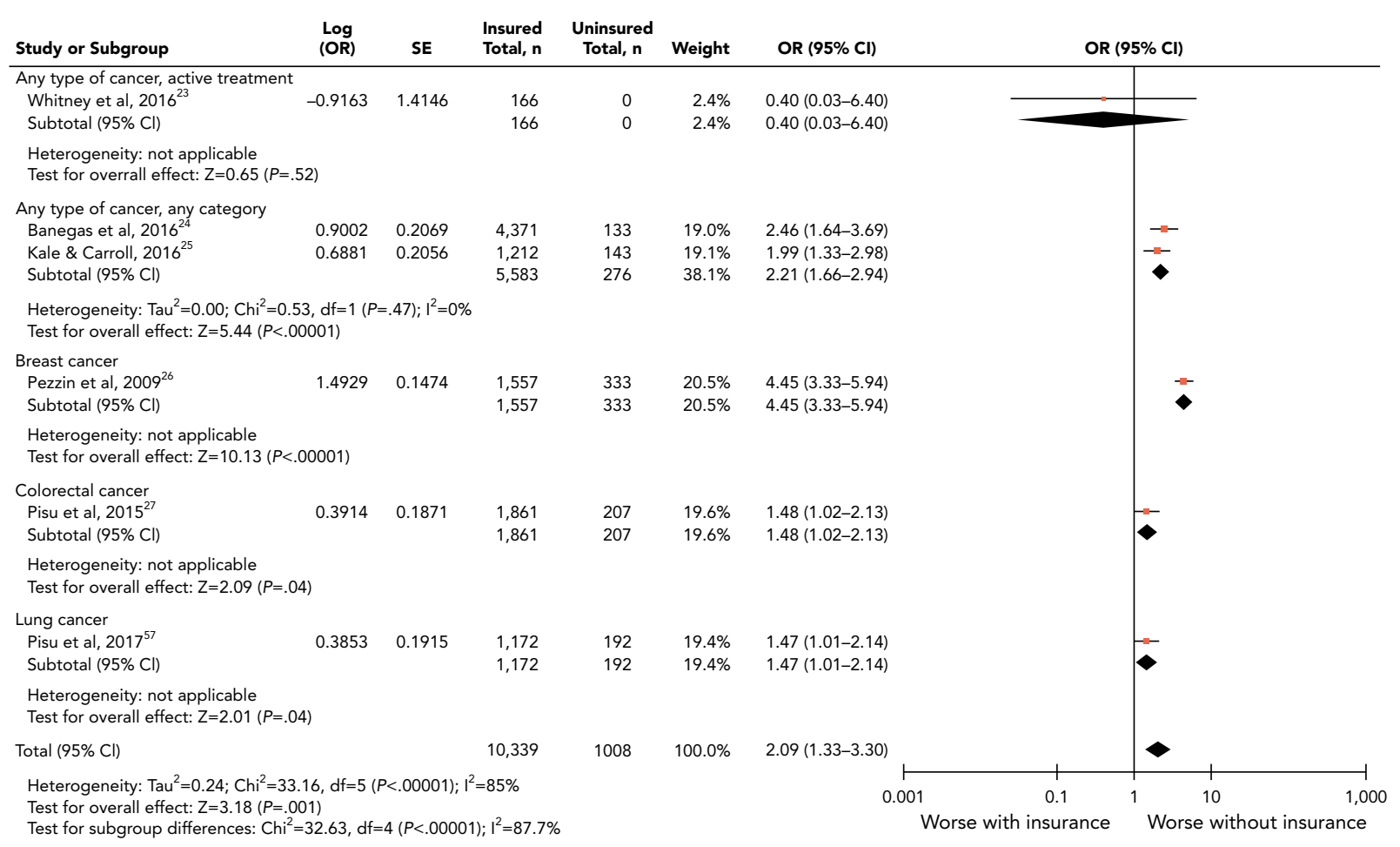

Figure 3. Pooled analyses showing association between insurance status and financial burdens.

Abbreviation: OR, odds ratio.

across the studies. In a limited number of studies, treatment with chemotherapy was associated with increased risk of financial burdens, ${ }^{6,36,37,46,49,60,68}$ whereas receipt of radiation ${ }^{35,75}$ or oncologic surgery were not consistent risk factors. In a limited number of studies, greater treatment duration and intensity were associated with increased financial burdens, ${ }^{45,47,52,60}$ as were cancer recurrence or multiple cancer diagnoses. ${ }^{24,37,68}$ Noncancer comorbidity and worse overall health and functional status were also factors associated with increased financial burdens in a limited number of studies. $6,23,36,63$

Evidence across the studies supported a trajectory of financial burdens, with a greater magnitude (effect size) of burdens at cancer diagnosis/active treatment compared with the magnitude of burdens measured after treatment completion. Financial burdens decreased months to years after cancer treatment was completed. ${ }^{11,24,25,37,55,57,64,68}$ The severity of all types of burdens improved over time, including direct, ${ }^{57,64}$ indirect, and psychological. ${ }^{11,76}$ (supplemental eTable 4).

In a limited number of studies on the long-term trajectory of financial burdens, evidence indicated that certain financial burdens persisted years beyond initial treatment. Ell et al ${ }^{76}$ reported that $49 \%$ of patients had financial stress at least 12 months after diagnosis, and Jagsi et $\mathrm{al}^{37}$ reported that $33 \%$ had persistent financial decline at 4 years after diagnosis. ${ }^{37}$ Huntington et al $^{50}$ reported that a longer time from cancer diagnosis was associated with increased financial burdens in patients with chronic multiple myeloma undergoing long-term treatment. A single study implemented a financial navigation intervention. Among patients enrolled in the program, material financial burdens remained unchanged but psychological financial burdens decreased over time. However, this was a single-arm intervention without a "usual-care" group for statistical comparison. ${ }^{77}$

\section{Health Outcomes Associated With Financial Burdens}

The association of financial burdens with health behaviors was addressed in 23 studies, and with quality of life and survival in another 23 studies (supplemental eTable 5). Financial burdens, including direct, indirect, and psychological burdens, all demonstrated associations with medical nonadherence (ie, delaying, foregoing, or not completing necessary medical care) to cancer-specific treatment and general medical care.

Cancer-specific treatment nonadherence was associated with financial burdens, $5,26,28,29,44,70,75,78,79$ with $2 \%$ to $10 \%$ of patients with higher financial burdens reporting nonadherence to chemotherapy and oncology appointments $\mathrm{s}^{28,33,80}$ and $17 \%$ to $30 \%$ reporting nonadherence to oral maintenance cancer therapies, 
such as imatinib for chronic myeloid leukemia and endocrine therapy for breast cancer. ${ }^{5,50,70}$ In the pooled analysis, patients with higher financial burdens (defined as having greater financial distress, copayments, or direct prescription costs) had nearly twice greater odds of cancer medication nonadherence (OR, 1.70; 95\% CI, 1.13-2.56) (Figure 4; sensitivity analyses in eAppendix 1). Higher financial burdens were also associated with general medical nonadherence in a limited number of studies, including higher frequency of omitted or delayed subsequent cancer screening in patients with cancer and survivors; forgoing or delaying cancer survivorship care and follow-up, dental care, ophthalmologic care, prescription medications, and mental and primary medical care ${ }^{28,36,37,53,68,81,82}$; and lower health selfefficacy and treatment decision-making. ${ }^{58}$

Financial burdens, specifically indirect burdens and psychological burdens, were associated with decreased health-related quality of life (HRQoL) dimensions across the studies (supplemental eTable 5), with more than twice the odds of worse overall physical, mental, emotional, and social function and well-being and increased anxiety, depression, and worry. A dose-response relationship was present, with more severe financial burdens associated with incrementally worse HRQoL scores when measured on continuous scales. ${ }^{25,35,47,76,83,84}$

In a single study of 231,596 patients with cancer, financial burden measured by bankruptcy was independently associated with increased mortality, with nearly twice the mortality risk compared with those not experiencing bankruptcy (HR, 1.79; 95\% CI, 1.64-1.96). ${ }^{71}$ No other study in our review investigated the association of other financial burden measures with mortality.

\section{Discussion}

This systematic review of 74 studies identifying financial burdens associated with cancer treatment in $>500,000$ US patients highlights the ongoing critical need to mitigate this problem. The $49 \%$ frequency of financial burdens associated with cancer treatment reported in this review, derived across a variety of oncology settings, rivaled the burdens from common clinical toxicities associated with cancer treatment-for example, up to $28 \%$ incidence of cardiotoxicity and $34 \%$ to $51 \%$ incidence of peripheral neuropathy attributed to cancer therapies reported in prior studies. ${ }^{85-87}$ Our findings build upon one prior review that identified a $40 \%$ to $50 \%$ prevalence estimate of financial hardships from cancer treatment in US patients ${ }^{13}$ and a $28 \%$ to $73 \%$ prevalence estimate in another review of patients internationally, ${ }^{88}$ validating prior estimates and including contemporary studies. Our study demonstrated that multiple types of burdens-direct material, indirect, and psychological burdens-were uniformly prevalent. This finding underscores the need to assess multidimensional financial burdens in vulnerable patients early in treatment and survivorship, as well as the need for multidimensional interventions to effectively mitigate burdens.

Across the studies, socioeconomic risk factors for direct, indirect, and psychological financial burdens were a lack of health insurance, lower income, and unemployment. Working-aged patients aged $<65$ years and patients without insurance or with Medicaid coverage (compared with private or Medicare coverage) had excess financial burdens. Multiple studies showed excess financial burdens among women (although the strengths of statistical significance in the $P$ values in the studies approached the threshold of .05) and patients of

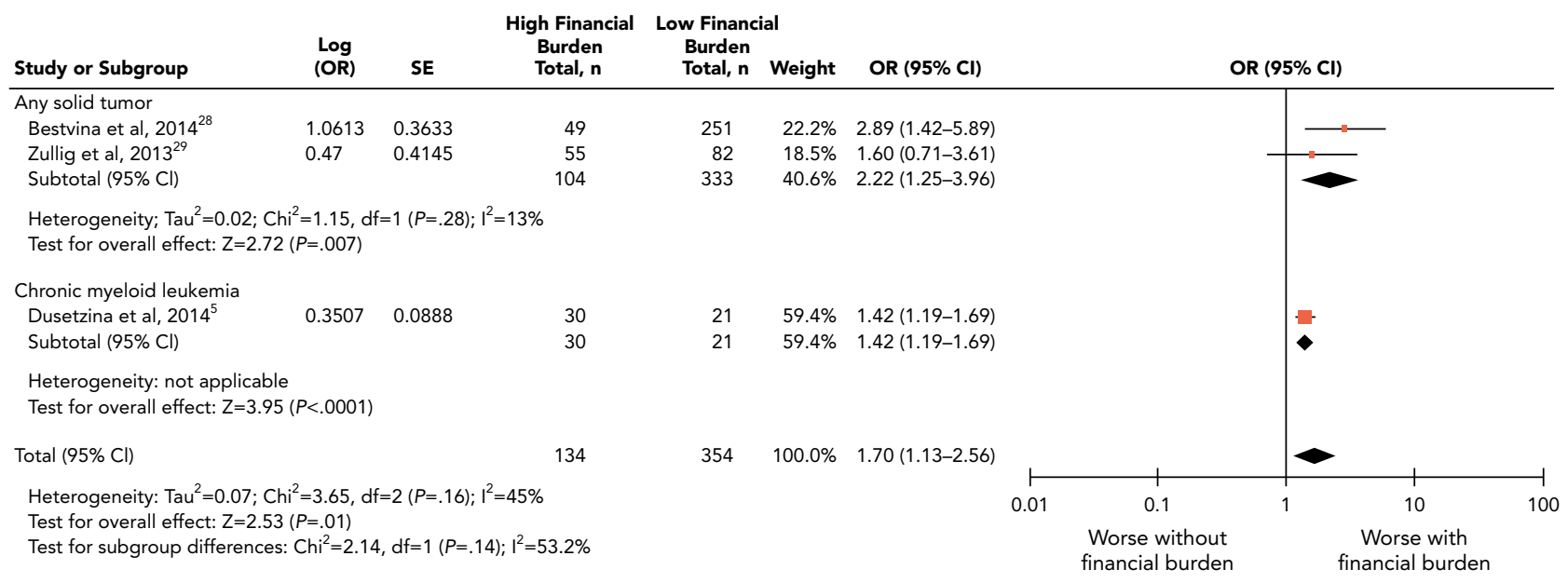

Figure 4. Pooled analyses showing association between financial burdens and cancer medication adherence. Abbreviation: OR, odds ratio. 
nonwhite race and Hispanic ethnicity (although with a varying range of effect sizes in studies). These data identify the disproportionate risk of cancer's financial burdens in vulnerable patient groups and further trigger the hypothesis of whether financial burdens could be a direct and potentially targetable mediator of adherence and mortality disparities in US patients with cancer. Across the studies, the clinical risk factors of initial active treatment, higher treatment intensity, and chemotherapy indicated more severe financial burdens. Evidence did not support the notion that financial burdens differed across cancer disease sites, stages, or histologies, highlighting relevance across patient populations.

The dearth of studies identifying effective interventions reveals a current evidence gap and demonstrates a clinical need for comparative effectiveness studies of interventions to better equip oncology care teams to respond to patients' financial burdens and health impact. Our study's examination of health outcomes demonstrated that direct material, indirect, and psychological financial burdens adversely impacted cancer treatment adherence, including long-term maintenance therapy, and indirect and psychological burdens adversely impacted HRQoL. Additional study is needed on the impact of different types of financial burdens on cancer mortality, given the single study providing evidence of an association between bankruptcy and all-cause mortality.

Our review provides novel insight into the documented gap between patient-reported needs and current oncology practice, wherein oncology provider engagement is not matched with patient-reported financial burdens. In a survey of oncology providers from the iCan Care study, only $34 \%$ regularly had a member of their practice discuss financial burdens with patients. ${ }^{16}$ Of the patients surveyed who desired provider engagement, only $27 \%$ reported that engagement was adequate. Results from our review show that all types of financial burdens and the consequent treatment nonadherence and HRQoL declines could be meaningful targets for direct provider engagement and intervention. Bridging the observed gaps in care would require generalizable interventions implemented across a variety of oncology delivery settings and platforms, including early access to financial counseling, ${ }^{77}$ healthcare and prescription cost assistance programs, enhanced provider cost communication, and patient decision tools.

Limitations of this review reflect those of observational studies. First, causality of associations was not definitively established due to potential attribution or recall bias in retrospective and cross-sectional studies, especially those with solely subjective financial burden measures such a psychological burden. Countering this weakness was the consistency of risk factor and adherence associations with objectively validated measures, such as direct material financial burden measures (eg, OOP expenses). The potential risks of recall, misclassification, and selection and attrition bias of the included studies are further detailed in eAppendix 1 .

Regarding review-level limitations, because authors may be more likely to publish studies and selectively report outcomes that show statistical significance, the findings may overestimate the occurrence of financial burdens or may not reflect other risk factors and outcomes of financial burdens that may be observed in other populations, such as non-US patients. Pooled analyses were limited, since no current standard measure of financial burden has been established, there were only a limited number of studies whose definitions of financial burden could be quantitatively pooled. Our results provide a visual representation of the sign of effect, but the pooled magnitude of association should be interpreted with caution, recognizing the limitations of metaanalysis from observational studies and the pooling of ORs from different types of populations. ${ }^{89,90}$ The very low to low strength of evidence implied uncertainty about the estimates, and further research could have an important impact on our confidence in the estimate of effects.

\section{Conclusions}

Observational evidence supports the findings that cancer treatment's financial burdens are common-experienced in up to half of patients with cancer across disease sites-but that the risks disproportionately affect socioeconomically disadvantaged and working-aged patients. Evidence further shows that financial burdens are associated with worse treatment adherence and HRQoL. Results from a single study also suggest that financial burdens are associated with worse mortality. Synthesized results provide a basis for identifying patients at risk for financial toxicity who would benefit from oncology provider and care team engagement. However, due to the paucity of evidence identifying effective measures to mitigate financial burdens in patients, our results highlight a critical need for ongoing efforts to develop interventions to equip oncology care teams to respond to the meaningful adverse impact of financial burdens in patients with cancer.

Submitted August 1, 2018; accepted for publication March 29, 2019.

Author contributions: Study concept and design: Smith, Lopez-Olivo, Advani, Geng, Giordano, Volk. Data acquisition, analysis, and interpretation: All authors. Manuscript preparation: All authors. Critical revision: All authors. Final approval: All authors.

Disclosures: Dr. Smith has disclosed that she has received grant/research support from the NIH (K07 CA211804-01), the Center for Radiation Oncology Research, and the University Cancer Foundation via the Institutional Research Grant Program at The University of Texas MD Anderson Cancer Center. Dr. Lopez-Olivo has disclosed that she receives grant/research support from the Rheumatology Research Foundation (grant 14119629). Dr. Giordano has 
disclosed that she has received grant/research support from the Susan G. Komen Foundation (SAC 150061). The remaining authors have not received any financial consideration from any person or organization to support the preparation, analysis, results, or discussion of this article.

Funding: This study was supported in part by The University of Texas MD Anderson Cancer Center Duncan Family Institute for Cancer Prevention and
Risk Assessment and the $\mathrm{NCl}$ Cancer Center Support grant, and grant P50 CA016672 (MD Anderson Cancer Center).

Correspondence: Grace L. Smith, MD, PhD, MPH, Department of Radiation Oncology and Department of Health Services Research, The University of Texas MD Anderson Cancer Center, 1400 Pressler Street, Houston, TX 77030. Email: glsmith@mdanderson.org

\section{References}

1. Azzani M, Roslani AC, Su TT. The perceived cancer-related financial hardship among patients and their families: a systematic review. Support Care Cancer 2015;23:889-898.

2. Miller KD, Siegel RL, Lin CC, et al. Cancer treatment and survivorship statistics, 2016. CA Cancer J Clin 2016;66:271-289.

3. Institute of Medicine. Ensuring Patient Access to Affordable Cancer Drugs: Workshop Summary. Washington, DC: National Academies Press; 2014.

4. Soni A. Trends in use and expenditures for cancer treatment among adults 18 and older, U.S. civilian noninstitutionalized population, 2001 and 2011. Statistical Brief \#443. Rockville, MD: Agency for Healthcare Research and Quality; 2014.

5. Dusetzina SB, Winn AN, Abel GA, et al. Cost sharing and adherence to tyrosine kinase inhibitors for patients with chronic myeloid leukemia. J Clin Oncol 2014;32:306-311.

6. Davidoff AJ, Erten M, Shaffer T, et al. Out-of-pocket health care expenditure burden for Medicare beneficiaries with cancer. Cancer 2013; 119:1257-1265

7. Guy GP Jr, Ekwueme DU, Yabroff KR, et al. Economic burden of cancer survivorship among adults in the United States. J Clin Oncol 2013;31: 3749-3757.

8. Yabroff KR, Lamont EB, Mariotto A, et al. Cost of care for elderly cancer patients in the United States. J Natl Cancer Inst 2008;100:630-641.

9. Short PF, Moran JR, Punekar R. Medical expenditures of adult cancer survivors aged $<65$ years in the United States. Cancer 2011;117: 2791-2800.

10. Finkelstein EA, Tangka FK, Trogdon JG, et al. The personal financial burden of cancer for the working-aged population. Am J Manag Care 2009;15:801-806

11. Yabroff KR, Dowling EC, Guy GP Jr, et al. Financial hardship associated with cancer in the United States: findings from a population-based sample of adult cancer survivors. J Clin Oncol 2016;34:259-267.

12. National Cancer Institute. Financial toxicity and cancer treatment (PDQ) health professional version. Available at: https://www.cancer.gov/aboutcancer/managing-care/track-care-costs/financial-toxicity-hp-pdq. Accessed February 14, 2018.

13. Altice CK, Banegas MP, Tucker-Seeley RD, et al. Financial hardships experienced by cancer survivors: a systematic review. J Natl Cancer Inst 2016;109:djw205

14. Ramsey S, Blough D, Kirchhoff A, et al. Washington State cancer patients found to be at greater risk for bankruptcy than people without a cancer diagnosis. Health Aff (Millwood) 2013;32:1143-1152.

15. Congressional Budget Office. Repealing the individual health insurance mandate: an updated estimate. Available at: https://www.cbo.gov/publication/53300. Accessed February 14, 2018.

16. Jagsi $\mathrm{R}$, Ward $\mathrm{KC}$, Abrahamse $\mathrm{PH}$, et al. Unmet need for clinician engagement about financial toxicity after diagnosis of breast cancer. Cancer 2018;124:3668-3676.

17. Shih YT, Chien CR. A review of cost communication in oncology: patient attitude, provider acceptance, and outcome assessment. Cancer 2017; 123:928-939.

18. O'Connor JM, Kircher SM, de Souza JA. Financial toxicity in cancer care. J Community Support Oncol 2016;14:101-106.

19. Moher D, Liberati A, Tetzlaff J, et al. Preferred reporting items for systematic reviews and meta-analyses: the PRISMA statement. Ann Intern Med 2009;151:264-269.

20. Meeker CR, Geynisman DM, Egleston BL, et al. Relationships among financial distress, emotional distress, and overall distress in insured patients with cancer. J Oncol Pract 2016;12:e755-764.

21. Ryan R; Cochrane Consumers and Communication Review Group. Cochrane Consumers and Communication Review Group: data synthesis and analysis. Available at: http://cccrg.cochrane.org/sites/cccrg. cochrane.org/files/public/uploads/Analysis.pdf. Accessed May 9, 2019.
22. National Institutes of Health; National Heart, Lung, and Blood Institute. Study quality assessment tools. Available at: https://www.nhlbi.nih.gov/ health-topics/study-quality-assessment-tools. Accessed February 14, 2018.

23. Whitney RL, Bell JF, Reed SC, et al. Predictors of financial difficulties and work modifications among cancer survivors in the United States. J Cancer Surviv 2016;10:241-250.

24. Banegas MP, Guy GP Jr, de Moor JS, et al. For working-age cancer survivors, medical debt and bankruptcy create financial hardships. Health Aff (Millwood) 2016;35:54-61.

25. Kale HP, Carroll NV. Self-reported financial burden of cancer care and its effect on physical and mental health-related quality of life among US cancer survivors. Cancer 2016;122:283-289.

26. Pezzin LE, O'Niel MB, Nattinger AB. The economic consequences of breast cancer adjuvant hormonal treatments. J Gen Intern Med 2009; 24(Suppl 2):S446-450

27. Pisu M, Kenzik KM, Oster RA, et al. Economic hardship of minority and non-minority cancer survivors 1 year after diagnosis: another long-term effect of cancer? Cancer 2015;121:1257-1264.

28. Bestvina CM, Zullig LL, Rushing $C$, et al. Patient-oncologist cost communication, financial distress, and medication adherence. J Oncol Pract 2014;10:162-167.

29. Zullig LL, Peppercorn JM, Schrag D, et al. Financial distress, use of costcoping strategies, and adherence to prescription medication among patients with cancer. J Oncol Pract 2013;9(Suppl 6):60s-63s.

30. The Cochrane Collaboration. Cochrane Handbook for Systematic Reviews of Interventions. Version 6. Available at: https://training.cochrane.org/ handbook. Accessed May 9, 2019.

31. Veenstra CM, Regenbogen SE, Hawley ST, et al. A composite measure of personal financial burden among patients with stage III colorectal cancer. Med Care 2014;52:957-962.

32. Shankaran $V$, Jolly $S$, Blough $D$, et al. Risk factors for financial hardship in patients receiving adjuvant chemotherapy for colon cancer: a populationbased exploratory analysis. J Clin Oncol 2012;30:1608-1614.

33. Markman M, Luce R. Impact of the cost of cancer treatment: an internetbased survey. J Oncol Pract 2010;6:69-73.

34. Callahan C, Brintzenhofeszoc K. Financial quality of life for patients with cancer: an exploratory study. J Psychosoc Oncol 2015;33:377-394.

35. Fenn KM, Evans SB, McCorkle R, et al. Impact of financial burden of cancer on survivors' quality of life. J Oncol Pract 2014;10:332-338.

36. Jagsi R, Hawley ST, Abrahamse P, et al. Impact of adjuvant chemotherapy on long-term employment of survivors of early-stage breast cancer. Cancer 2014;120:1854-1862.

37. Jagsi R, Pottow JAE, Griffith KA, et al. Long-term financial burden of breast cancer: experiences of a diverse cohort of survivors identified through population-based registries. J Clin Oncol 2014;32:1269-1276.

38. Kircher SM, Johansen ME, Nimeiri HS, et al. Impact of Medicare Part D on out-of-pocket drug costs and medical use for patients with cancer. Cancer 2014; 120:3378-3384.

39. Lathan CS, Cronin A, Tucker-Seeley R, et al. Association of financial strain with symptom burden and quality of life for patients with lung or colorectal cancer. J Clin Oncol 2016;34:1732-1740.

40. Lee M, Khan MM. Gender differences in cost-related medication nonadherence among cancer survivors. J Cancer Surviv 2016;10:384-393.

41. Lee M, Salloum RG. Racial and ethnic disparities in cost-related medication non-adherence among cancer survivors. J Cancer Surviv 2016;10: 534-544.

42. Martin MY, Fouad MN, Oster RA, et al. What do cancer patients worry about when making decisions about treatment? Variation across racial/ethnic groups. Support Care Cancer 2014;22:233-244.

43. Narang AK, Nicholas LH. Out-of-pocket spending and financial burden among Medicare beneficiaries with cancer. JAMA Oncol 2017;3:757-765 
44. Streeter SB, Schwartzberg L, Husain N, et al. Patient and plan characteristics affecting abandonment of oral oncolytic prescriptions. Am J Manag Care 2011;17(Suppl 5):SP38-44.

45. Tucker-Seeley RD, Abel GA, Uno H, et al. Financial hardship and the intensity of medical care received near death. Psychooncology 2015;24 572-578.

46. Wan $Y$, Gao X, Mehta $S$, et al. Indirect costs associated with metastatic breast cancer. J Med Econ 2013;16:1169-1178.

47. Abel GA, Albelda R, Khera N, et al. Financial hardship and patientreported outcomes after hematopoietic cell transplantation. Biol Blood Marrow Transplant 2016;22:1504-1510.

48. Zafar SY, McNeil RB, Thomas CM, et al. Population-based assessment of cancer survivors' financial burden and quality of life: a prospective cohort study. J Oncol Pract 2015;11:145-150.

49. Regenbogen SE, Veenstra CM, Hawley ST, et al. The personal financial burden of complications after colorectal cancer surgery. Cancer 2014;120: 3074-3081.

50. Huntington SF, Weiss BM, Vogl DT, et al. Financial toxicity in insured patients with multiple myeloma: a cross-sectional pilot study. Lancet Haematol 2015;2:e408-416

51. Chongpison Y, Hornbrook MC, Harris RB, et al. Self-reported depression and perceived financial burden among long-term rectal cancer survivors. Psychooncology 2016;25:1350-1356.

52. de Souza JA, Yap BJ, Wroblewski K, et al. Measuring financial toxicity as a clinically relevant patient-reported outcome: the validation of the COmprehensive Score for financial Toxicity (COST). Cancer 2017;123: 476-484.

53. Guy GP Jr, Yabroff KR, Ekwueme DU, et al. Healthcare expenditure burden among non-elderly cancer survivors, 2008-2012. Am J Prev Med 2015; 49(Suppl 5):S489-497.

54. Houts PS, Harvey HA, Simmonds MA, et al. Characteristics of patients at risk for financial burden because of cancer and its treatment. J Psychosoc Oncol 1985;3:15-22.

55. Jones WC, Parry C, Devine S, et al. Prevalence and predictors of distress in posttreatment adult leukemia and lymphoma survivors. J Psychosoc Oncol 2015;33:124-141.

56. Langa KM, Fendrick AM, Chernew ME, et al. Out-of-pocket health-care expenditures among older Americans with cancer. Value Health 2004; 186-194.

57. Pisu M, Azuero A, Benz R, et al. Out-of-pocket costs and burden among rural breast cancer survivors. Cancer Med 2017;6:572-581.

58. Wong YN, Schluchter MD, Albrecht TL, et al. Financial concerns about participation in clinical trials among patients with cancer. J Clin Oncol 2016;34:479-487.

59. Blinder $\mathrm{V}$, Patil S, Eberle $\mathrm{C}$, et al. Early predictors of not returning to work in low-income breast cancer survivors: a 5-year longitudinal study. Breast Cancer Res Treat 2013;140:407-416.

60. Goodwin JA, Coleman EA, Sullivan E, et al. Personal financial effects of multiple myeloma and its treatment. Cancer Nurs 2013;36:301-308.

61. Bernard DSM, Farr SL, Fang Z. National estimates of out-of-pocket health care expenditure burdens among nonelderly adults with cancer: 2001 to 2008. J Clin Oncol 2011;29:2821-2826.

62. Ekwueme DU, Yabroff KR, Guy GP Jr, et al. Medical costs and productivity losses of cancer survivors-United States, 2008-2011. MMWR Morb Mortal Wkly Rep 2014;63:505-510.

63. Khera N, Chang YH, Hashmi S, et al. Financial burden in recipients of allogeneic hematopoietic cell transplantation. Biol Blood Marrow Transplant 2014;20:1375-1381.

64. Meneses K, Azuero A, Hassey L, et al. Does economic burden influence quality of life in breast cancer survivors? Gynecol Oncol 2012;124: 437-443.

65. Francoeur RB. Cumulative financial stress and strain in palliative radiation outpatients: the role of age and disability. Acta Oncol 2005;44:369-381.

66. de Souza JA, Wong YN. Financial distress in cancer patients. J Med Person 2013;11:73-77

67. de Souza JA, Yap BJ, Hlubocky FJ, et al. The development of a financial toxicity patient-reported outcome in cancer: the COST measure. Cancer 2014;120:3245-3253.
68. Kent EE, Forsythe LP, Yabroff KR, et al. Are survivors who report cancerrelated financial problems more likely to forgo or delay medical care? Cancer 2013;119:3710-3717.

69. Meeker CR, Wong YN, Egleston BL, et al. Distress and financial distress in adults with cancer: an age-based analysis. J Natl Compr Canc Netw 2017 15:1224-1233.

70. Neugut Al, Subar M, Wilde ET, et al. Association between prescription co-payment amount and compliance with adjuvant hormonal therapy in women with early-stage breast cancer. J Clin Oncol 2011;29:2534-2542.

71. Ramsey SD, Bansal A, Fedorenko $C R$, et al. Financial insolvency as a risk factor for early mortality among patients with cancer. J Clin Oncol 2016 34:980-986.

72. Zheng Z, Yabroff KR, Guy GP Jr, et al. Annual medical expenditure and productivity loss among colorectal, female breast, and prostate cancer survivors in the United States. J Natl Cancer Inst 2015;108:djv382.

73. Wheeler SB, Spencer JC, Pinheiro LC, et al. Financial impact of breast cancer in black versus white women. J Clin Oncol 2018;36:1695-1701.

74. Palmer NR, Weaver KE, Hauser SP, et al. Disparities in barriers to follow-up care between African American and White breast cancer survivors. Support Care Cancer 2015;23:3201-3209.

75. Farias AJ, Hansen RN, Zeliadt SB, et al. The association between out-ofpocket costs and adherence to adjuvant endocrine therapy among newly diagnosed breast cancer patients. Am J Clin Oncol 2018;41:708-715.

76. Ell K, Xie B, Wells A, et al. Economic stress among low-income women with cancer: effects on quality of life. Cancer 2008;112:616-625.

77. Shankaran $V$, Leahy $T$, Steelquist J, et al. Pilot feasibility study of an oncology financial navigation program. J Oncol Pract 2018;14:e122-129.

78. Farias AJ, Du XL. Association between out-of-pocket costs, race/ethnicity, and adjuvant endocrine therapy adherence among Medicare patients with breast cancer. J Clin Oncol 2017;35:86-95.

79. Bender CM, Gentry AL, Brufsky AM, et al. Influence of patient and treatment factors on adherence to adjuvant endocrine therapy in breast cancer. Oncol Nurs Forum 2014;41:274-285.

80. Zafar SY, Peppercorn JM, Schrag D, et al. The financial toxicity of cancer treatment: a pilot study assessing out-of-pocket expenses and the insured cancer patient's experience. Oncologist 2013;18:381-390.

81. Nipp RD, Zullig LL, Samsa G, et al. Identifying cancer patients who alter care or lifestyle due to treatment-related financial distress. Psychooncology 2016;25:719-725.

82. DiMartino LD, Birken SA, Mayer DK. The relationship between cancer survivors' socioeconomic status and reports of follow-up care discussions with providers. J Cancer Educ 2017;32:749-755.

83. Khera N, Chow EJ, Leisenring WM, et al. Factors associated with adherence to preventive care practices among hematopoietic cell transplantation survivors. Biol Blood Marrow Transplant 2011;17:995-1003.

84. Delgado-Guay M, Ferrer J, Rieber AG, et al. Financial distress and its associations with physical and emotional symptoms and quality of life among advanced cancer patients. Oncologist 2015;20:1092-1098.

85. Yeh ETH, Bickford CL. Cardiovascular complications of cancer therapy: incidence, pathogenesis, diagnosis, and management. J Am Coll Cardio 2009;53:2231-2247.

86. Peng $L, Y e X$, Zhou $Y$, et al. Meta-analysis of incidence and risk of peripheral neuropathy associated with intravenous bortezomib. Suppor Care Cancer 2015;23:2813-2824.

87. Peng $L, B u Z, Y e X$, et al. Incidence and risk of peripheral neuropathy with nab-paclitaxel in patients with cancer: a meta-analysis. Eur J Cancer Care [Br] 2017;26:e12407.

88. Gordon LG, Merolini KMD, Lowe A, et al. A systematic review of financial toxicity among cancer survivors: we can't pay the co-pay. Patient 2017;10: 295-309.

89. Norton EC, Dowd BE. Log odds and the interpretation of logit models. Health Serv Res 2018;53:859-878.

90. Norton EC, Dowd BE, Maciejewski ML. Odds ratios-current best practice and use. JAMA 2018;320:84-85.

91. de Souza JA, Kung S, O'Connor J, et al. Determinants of patient-centered financial stress in patients with locally advanced head and neck cancer. J Oncol Pract 2017;13:e310-318.

92. Gupta D, Lis CG, Grutsch JF. Perceived cancer-related financial difficulty: implications for patient satisfaction with quality of life in advanced cancer. Support Care Cancer 2007;15:1051-1056.

See JNCCN.org for supplemental online content. 
Supplemental online content for:

\section{Financial Burdens of Cancer Treatment: A Systematic Review of Risk Factors and Outcomes}

Grace L. Smith, MD, PhD, MPH; Maria A. Lopez-Olivo, MD, PhD; Pragati G. Advani, MD, DrPH; Matthew S. Ning, MD; Yimin Geng, MS, MSLIS; Sharon H. Giordano, MD, MPH; and Robert J. Volk, PhD

J Natl Compr Canc Netw 2019;17(10):1184-1192

eFigure 1: Search Strategy for MEDLINE (Ovid)

eTable 1: Quality Assessment: Assessing Risk of Bias of Individual Studies

eTable 2: Study and Patient Characteristics and Measures of Financial Toxicity Burdens

eTable 3: Strength of Evidence Assessment Using GRADE Criteria

eTable 4: Risk Factors of Financial Toxicity Burdens

eTable 5: Financial Toxicity Burdens and Health Outcomes

eAppendix 1: Supplementary Results 


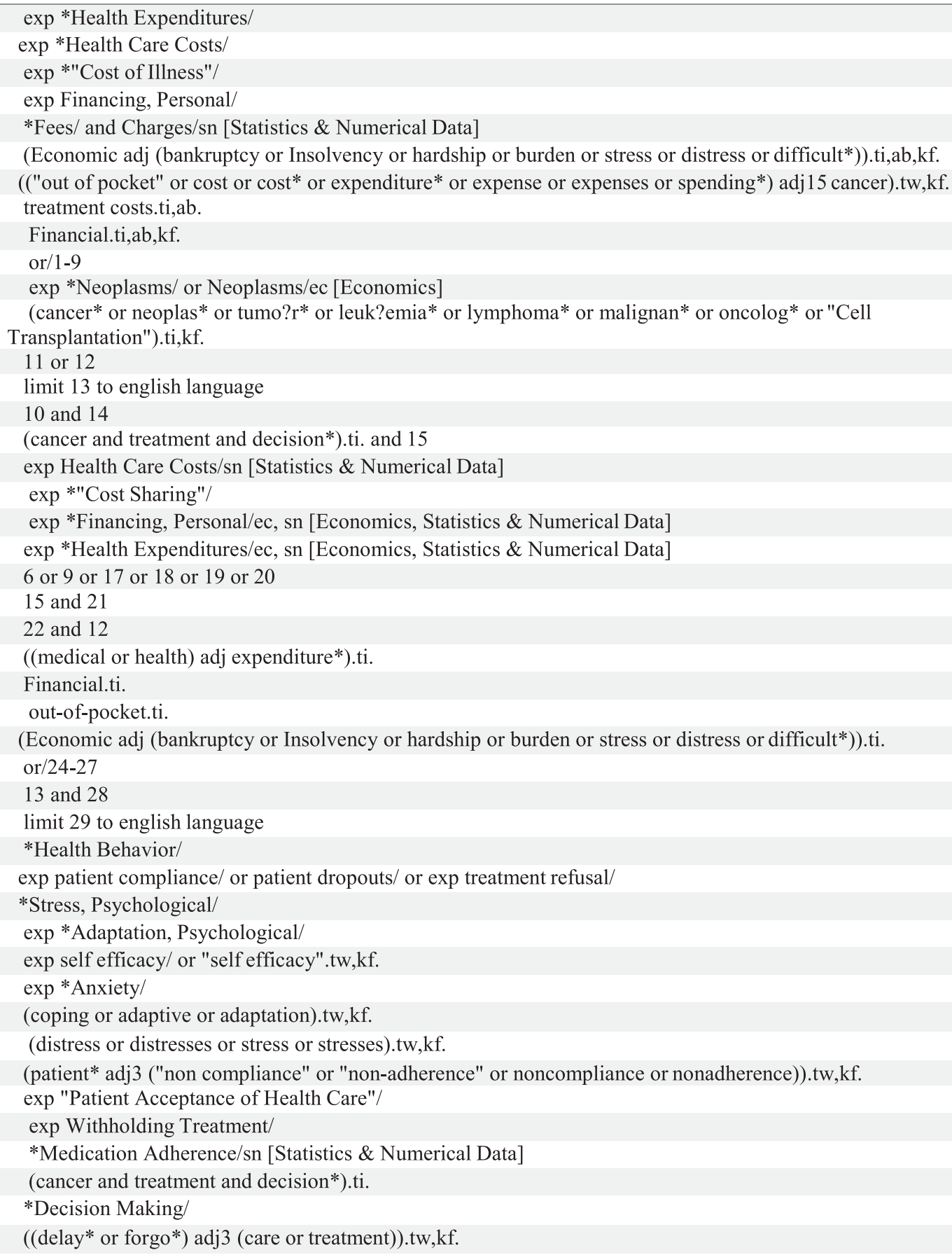

eFigure 1. Search strategy for MEDLINE (Ovid). 


\section{2 - Smith et al}

or $/ 31-45$

23 and 46

remove duplicates from 47

exp Survival Rate/

exp *Survival Analysis/

survival.ti.

exp *Mortality/sn, td [Statistics \& Numerical Data, Trends]

exp *"Quality of Life"/

"Quality of Life".ti,kf.

or/49-54

23 and 55

remove duplicates from 56

57 not 48

exp *insurance, health/

*Insurance Coverage/

exp *Income/

Insurance Carriers/

exp *Socioeconomic Factors/

exp *Demography/

exp "Social Determinants of Health"/

exp *Neoplasms/ec [Economics]

exp *Drug Therapy/ec [Economics]

exp *Antineoplastic Agents/ec [Economics]

exp *Specialties, Surgical/ec [Economics]

Therapeutics/ec [Economics]

exp *Comorbidity/

exp *Radiotherapy/ec [Economics]

exp *Neoplasm Recurrence, Local/ec [Economics]

Recurrence/ and Neoplasms/ and 12

ec.fs.

74 and 75

or/59-73,76

23 and 77

48 or 57 or 78

16 or 79 or 30

remove duplicates from 80

or/1-7,28

"financial relationships to disclose".ab.

Financial Disclosures.ab.

financial conflicts of interest.ab.

financial conflicts of interests.ab.

financial interests.ab.

financial interest.ab.

83 or 84 or 85 or 86 or 87 or 88

81 and 89

81 not 90

82 and 90

91 or 92

eFigure 1. Search strategy for MEDLINE (Ovid). (cont.) 


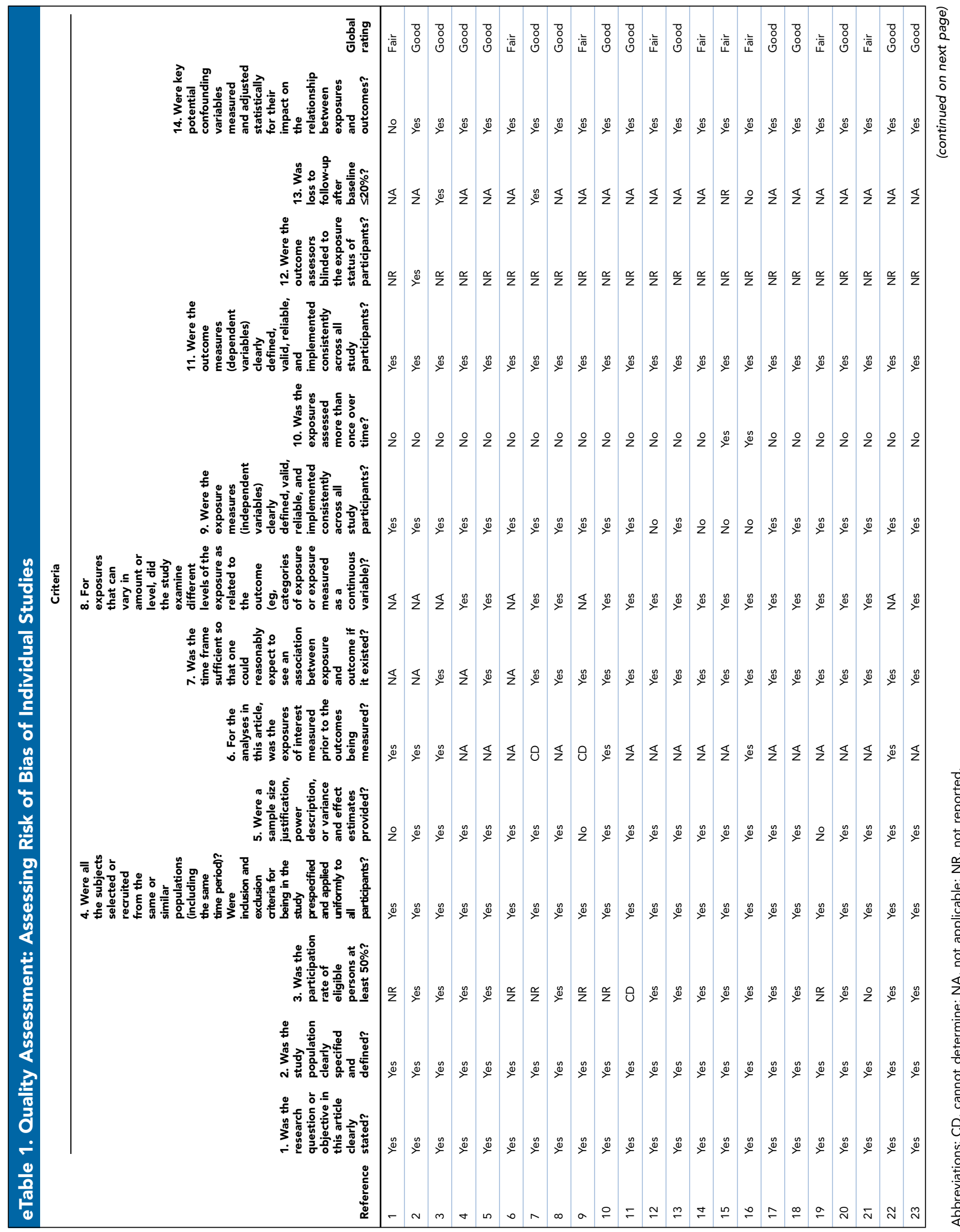




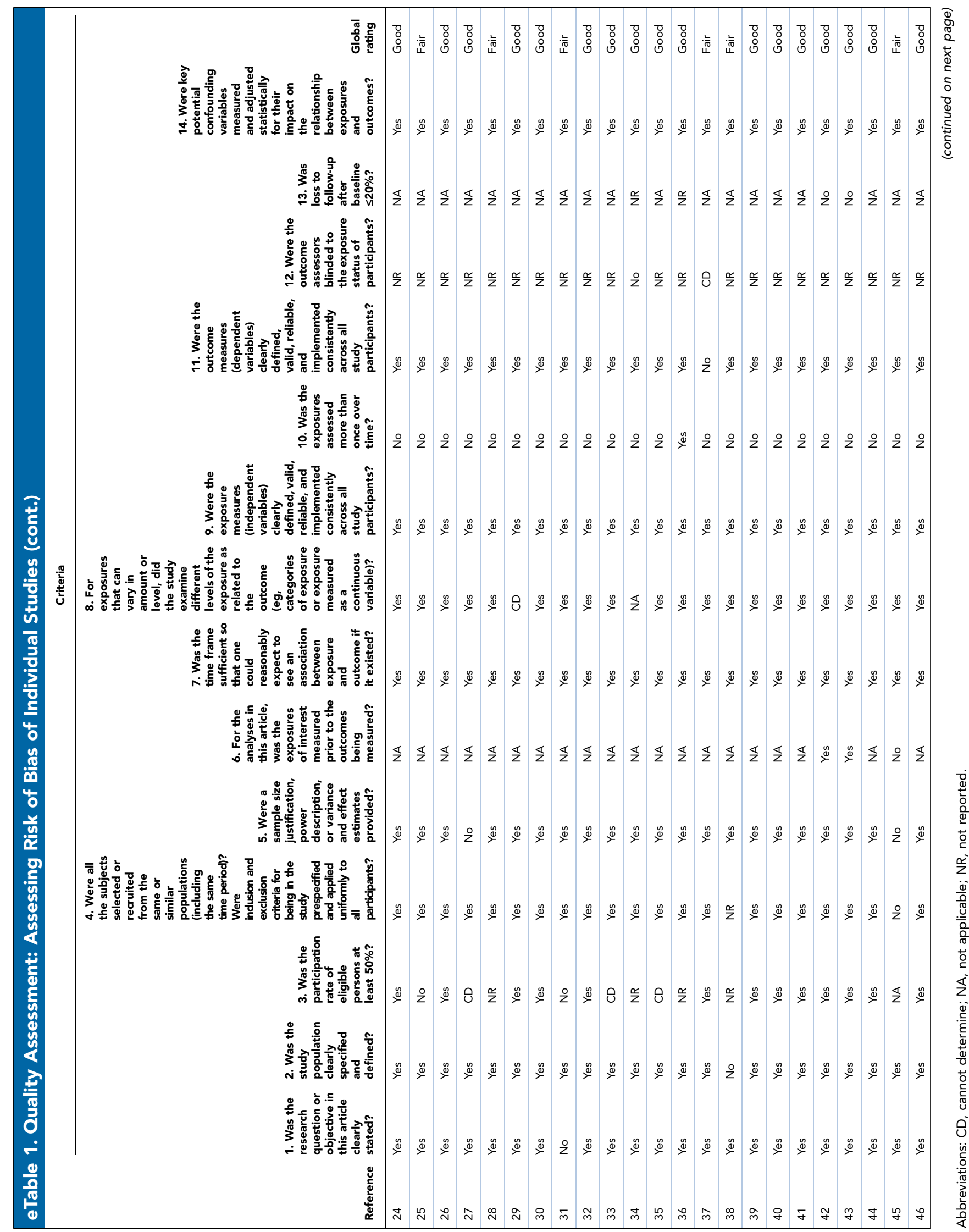




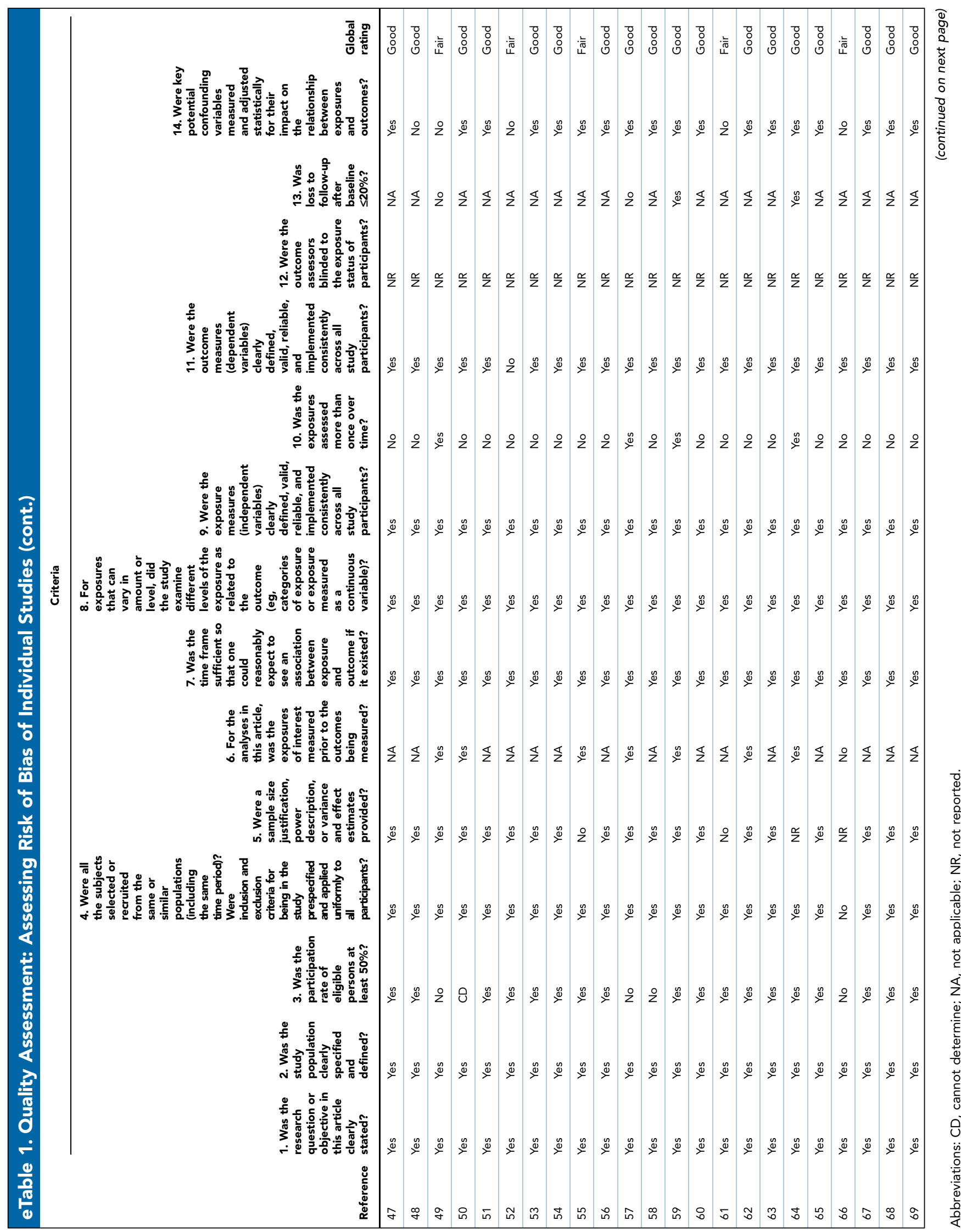




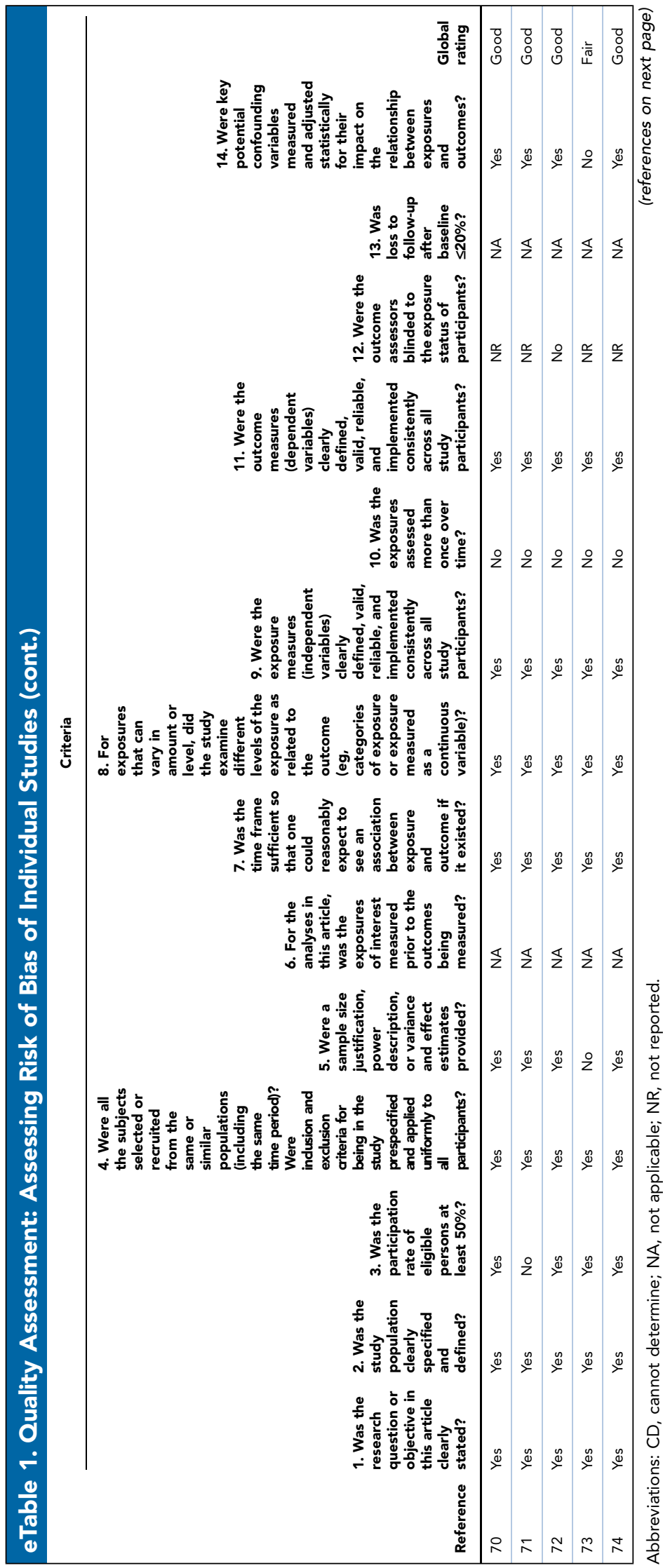



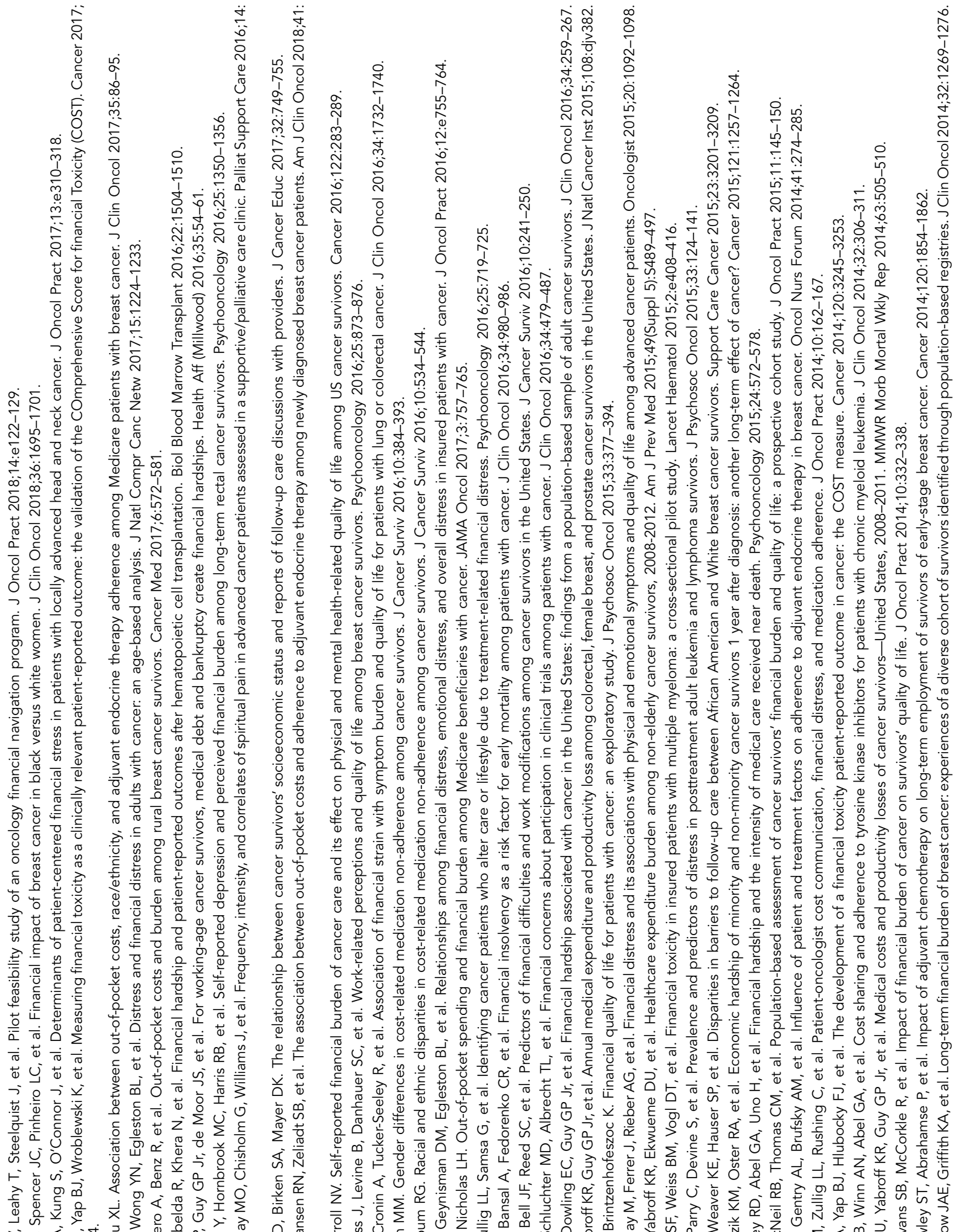

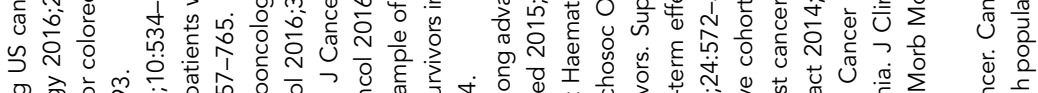

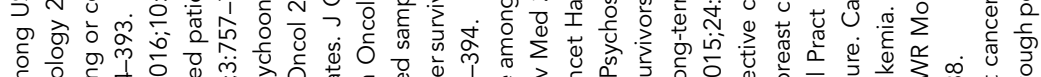

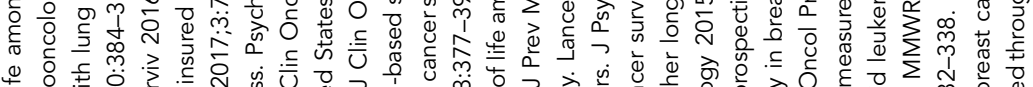

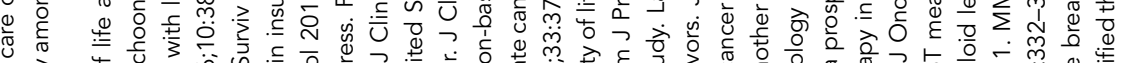

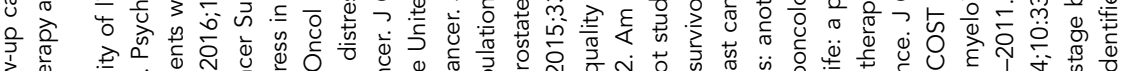

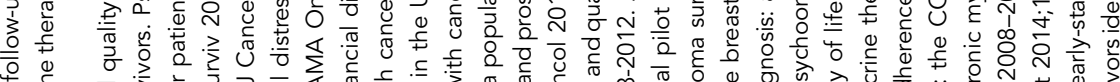

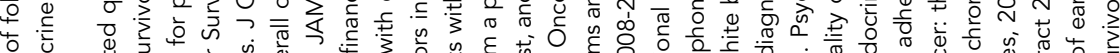

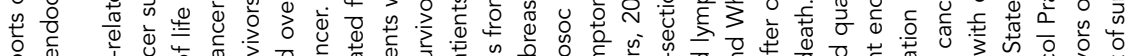

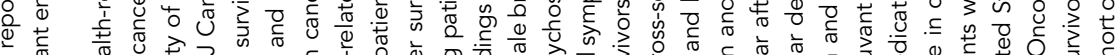

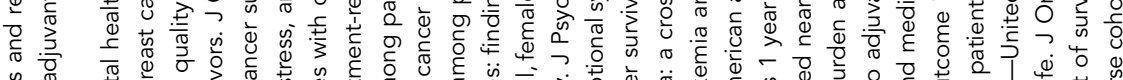

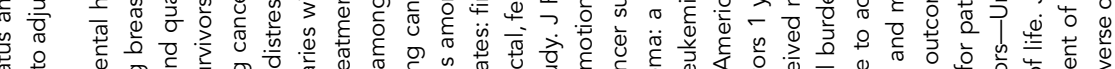

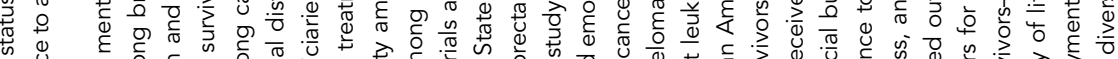

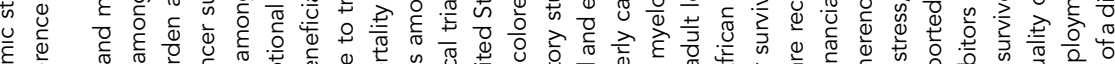
它它

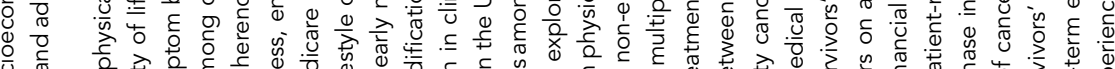

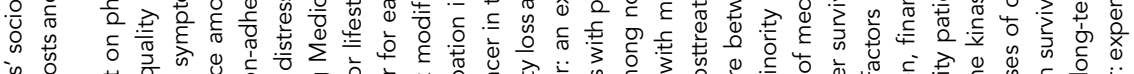

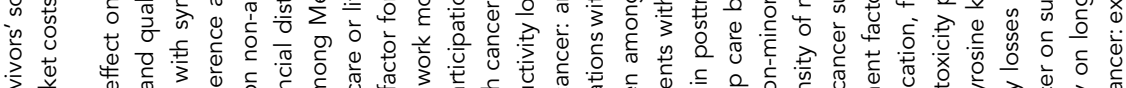

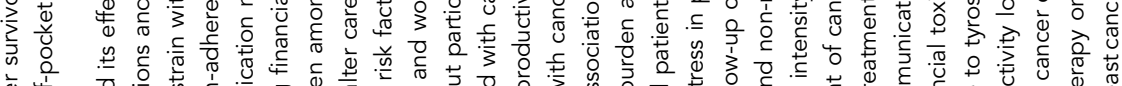

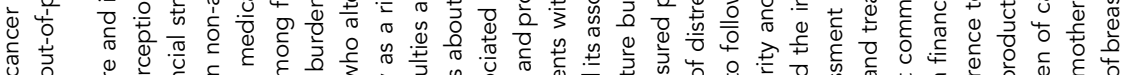

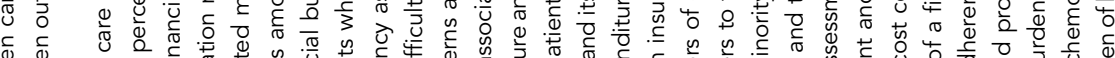

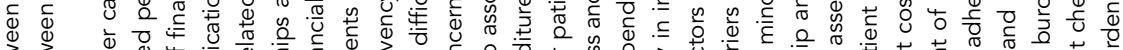

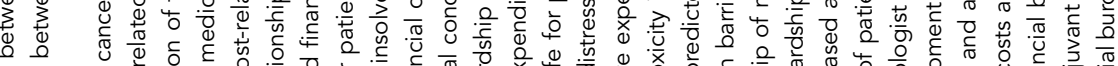

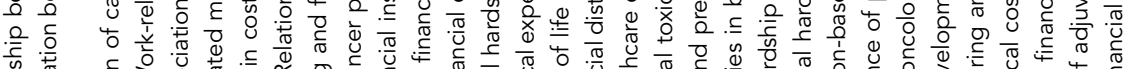

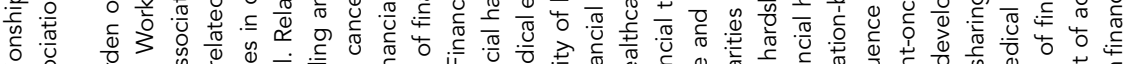

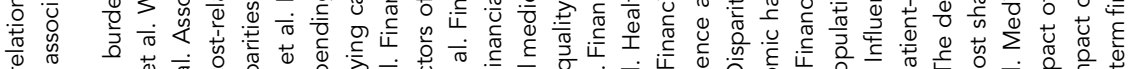

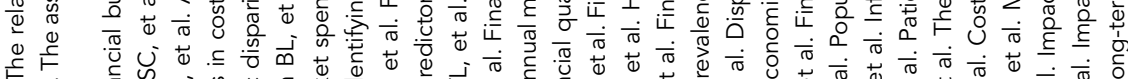

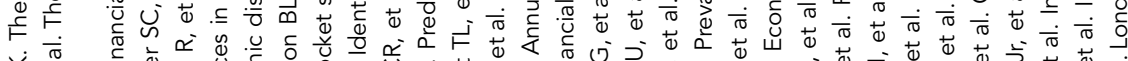

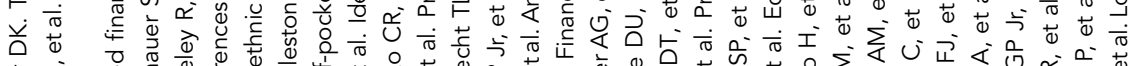

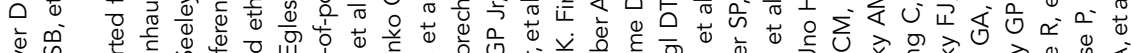

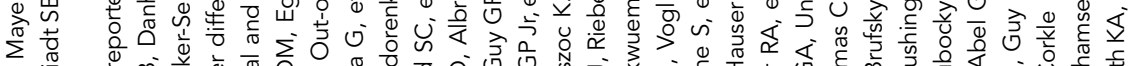

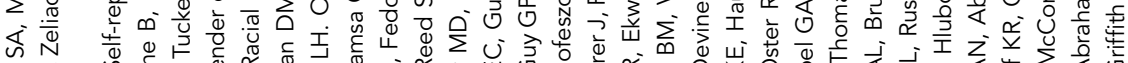

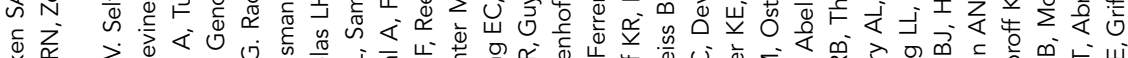

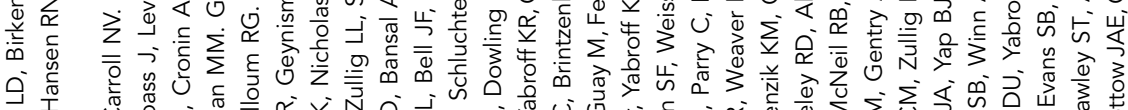

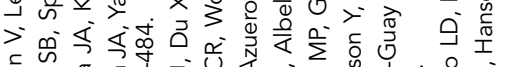

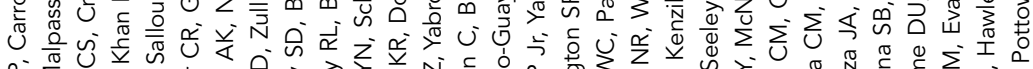

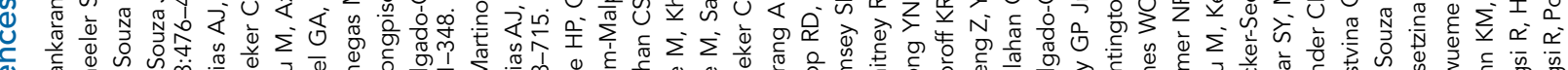

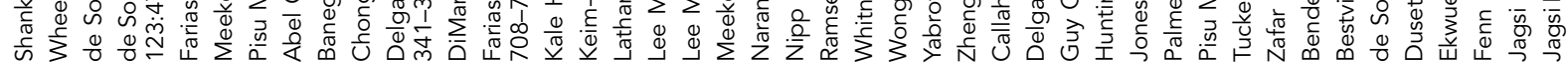

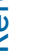




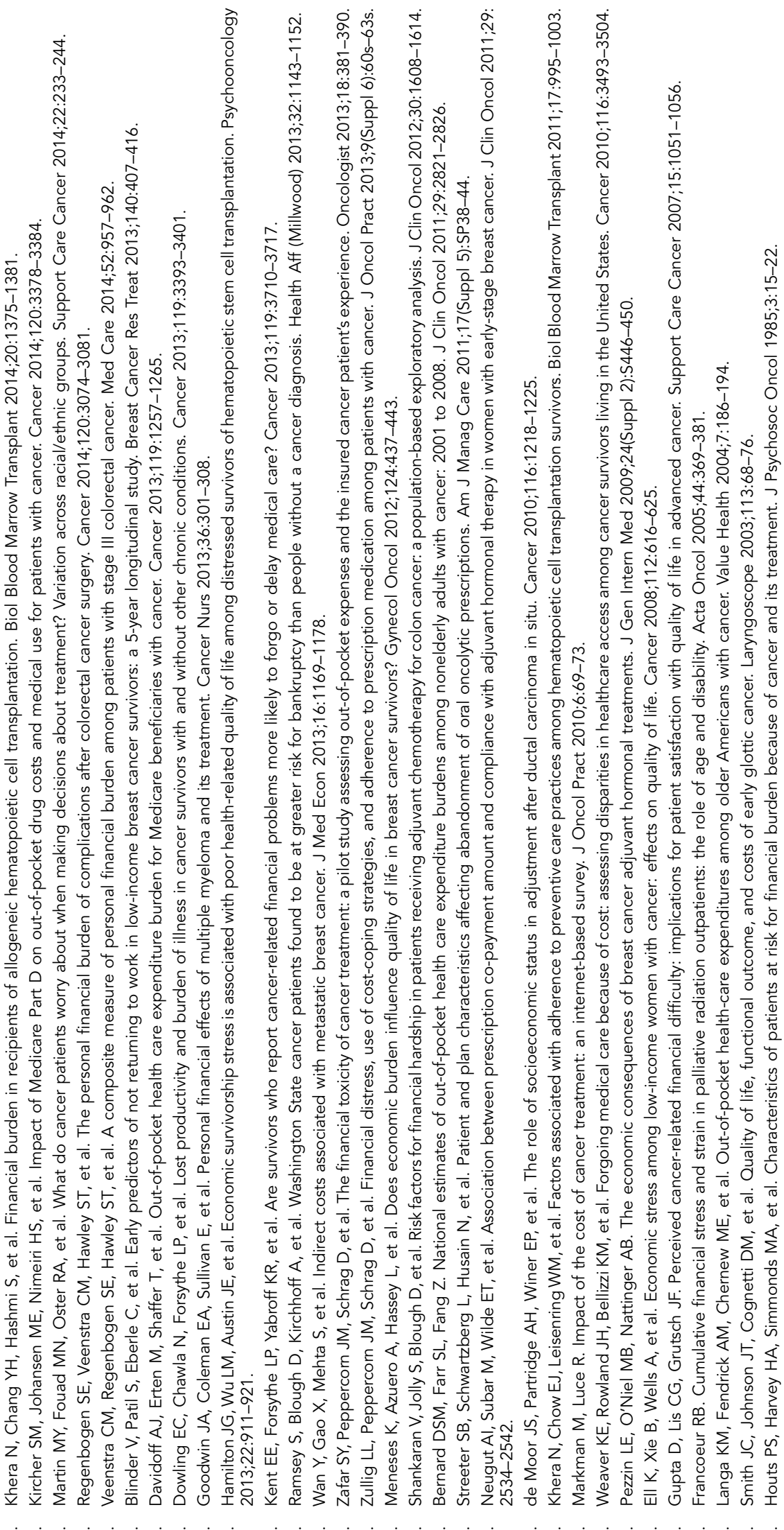




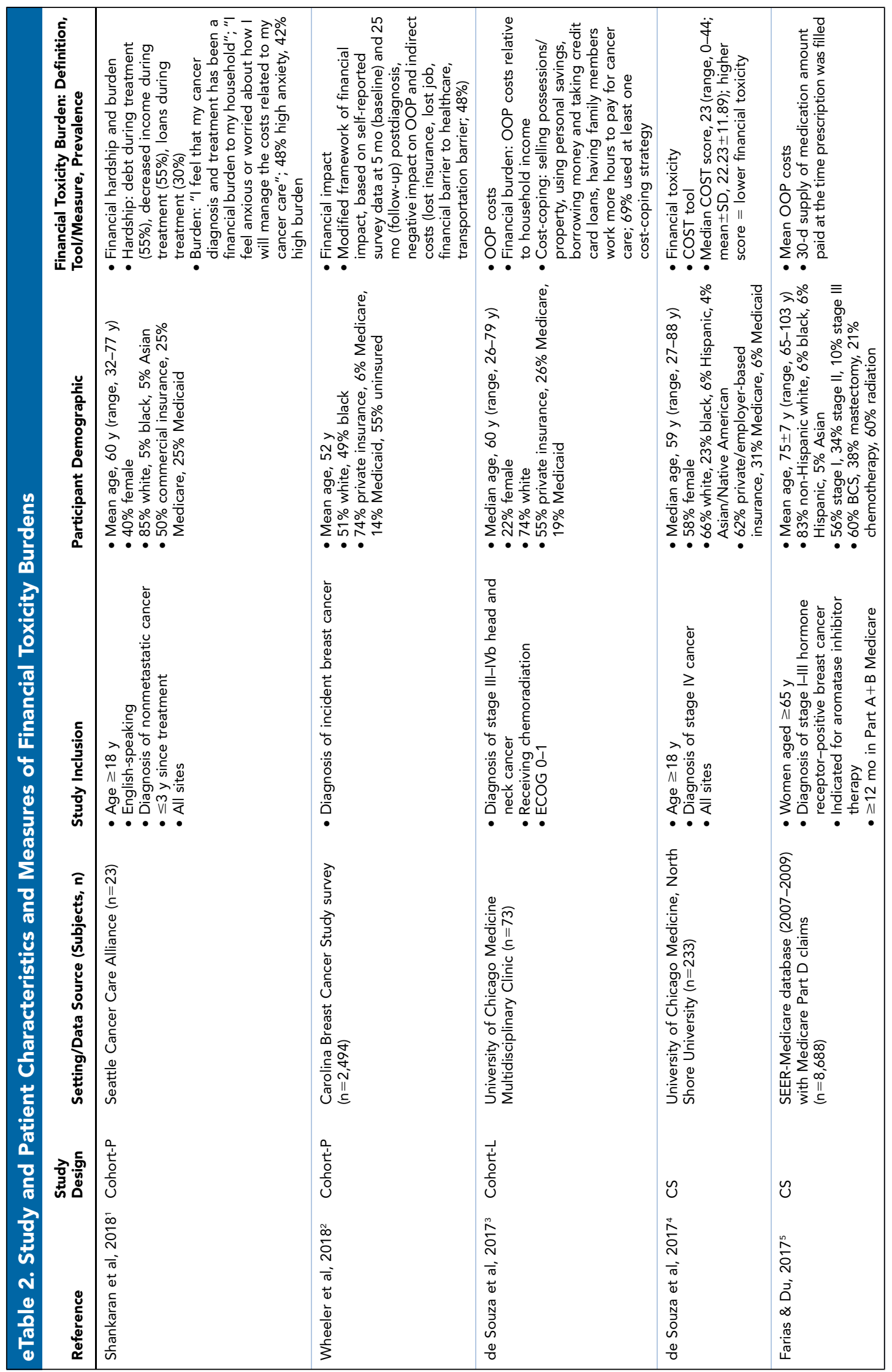

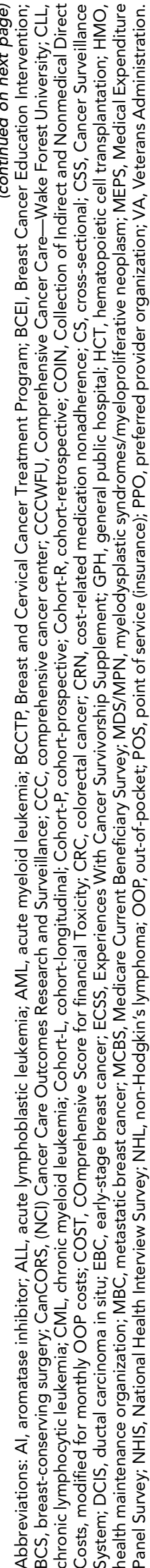




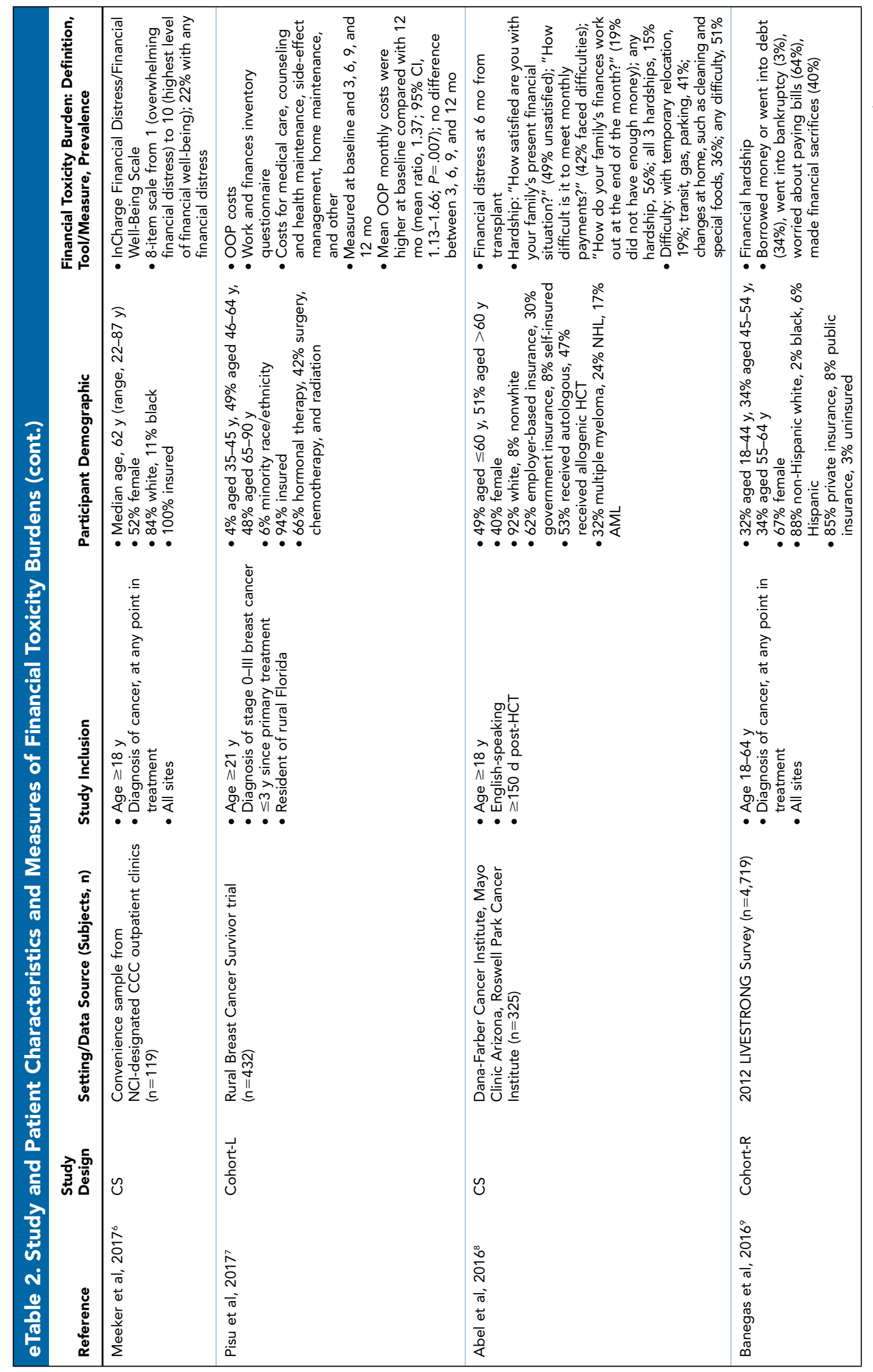

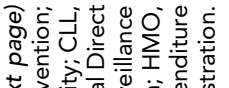

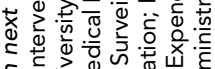

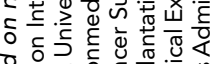

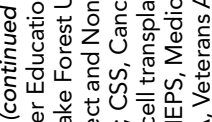

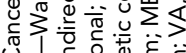
药 $\frac{1}{\pi}$ 论 这市. 西

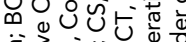
ह 훙웡

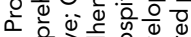

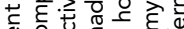
है U 응

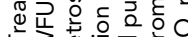

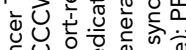

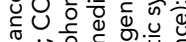
Uับ

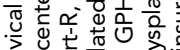
ये⿺辶寸 ठ

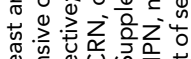

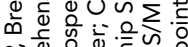

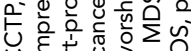

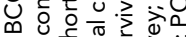
.

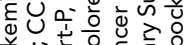
实过

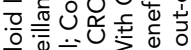
잉

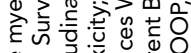

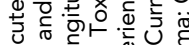
T

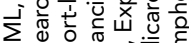
« .0. ब 远 동

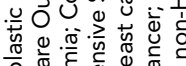
U

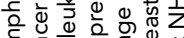
हो. 등

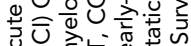
U๖ है

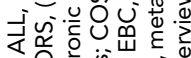

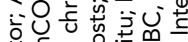

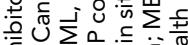

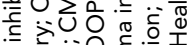
\%

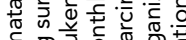

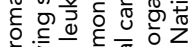
宁这. is  .

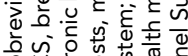

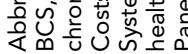




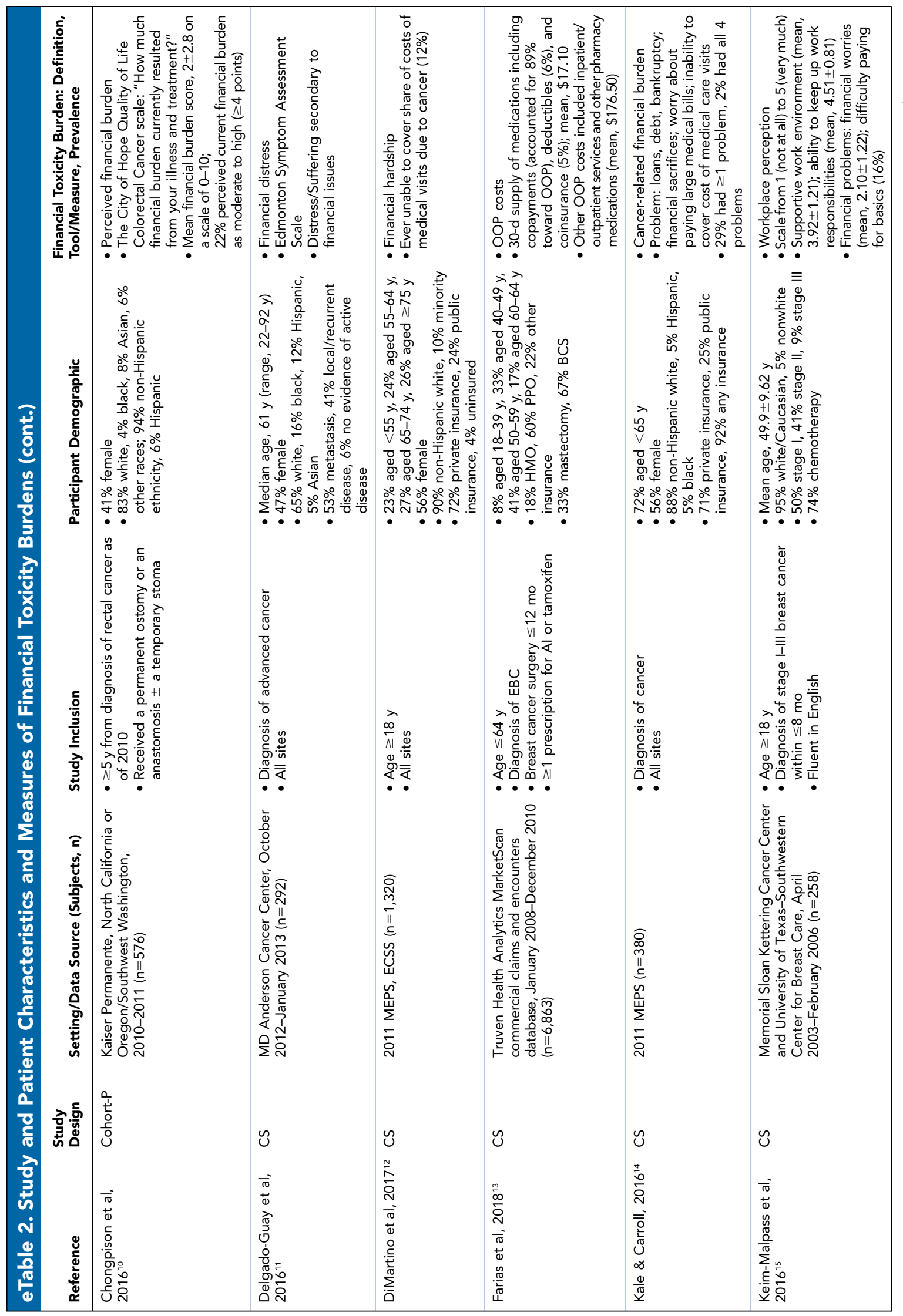

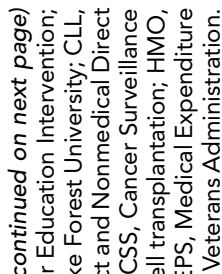

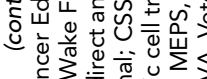

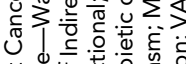

范宁㐘

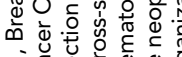

㟧

ه 305

हो

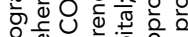

产

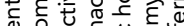

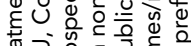

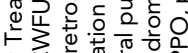

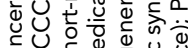

Uึ

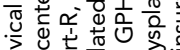

可语

论完

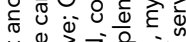

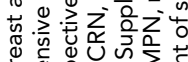

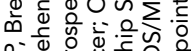

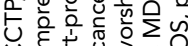

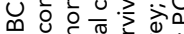

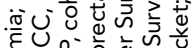

है

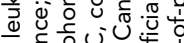

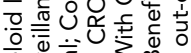

है

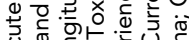

\%

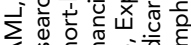

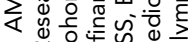

我我

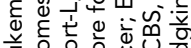

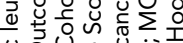

品 O.

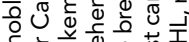

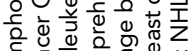

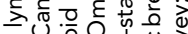

गे 능

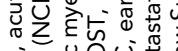

专它记

言记论

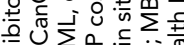

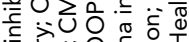

o. 을 >

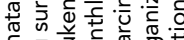

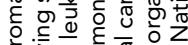

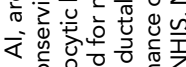

is

당

类

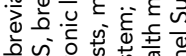

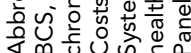




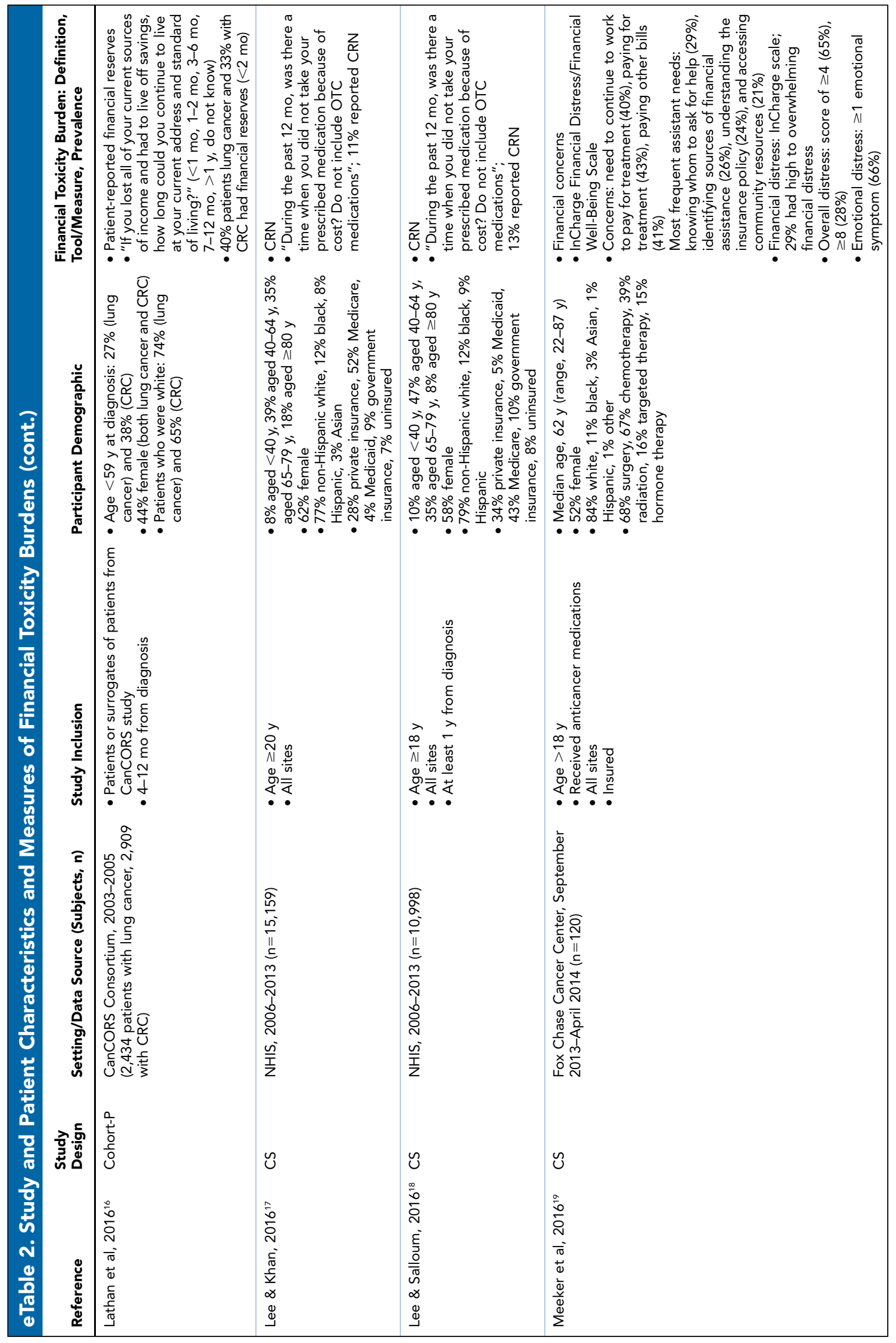

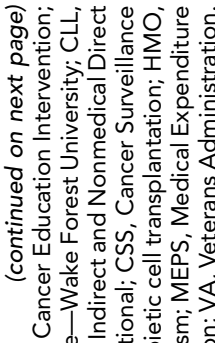

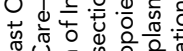

范

画芯记

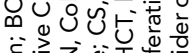

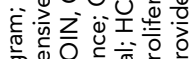

क⿹ 口)

응

屯

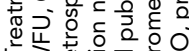

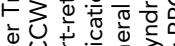

论记

U

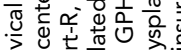

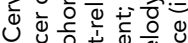

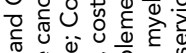

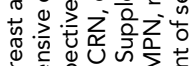

品

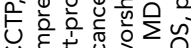

U⿺辶寸

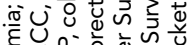

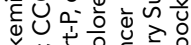

过

응

हैं

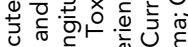

\%

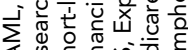

«

है

बे

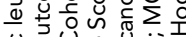

品 0 U

范

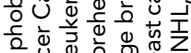

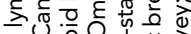

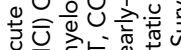

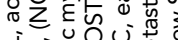

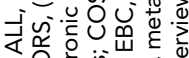

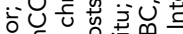

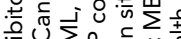

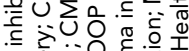

要

范

일.

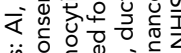

은

.

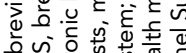

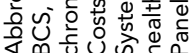



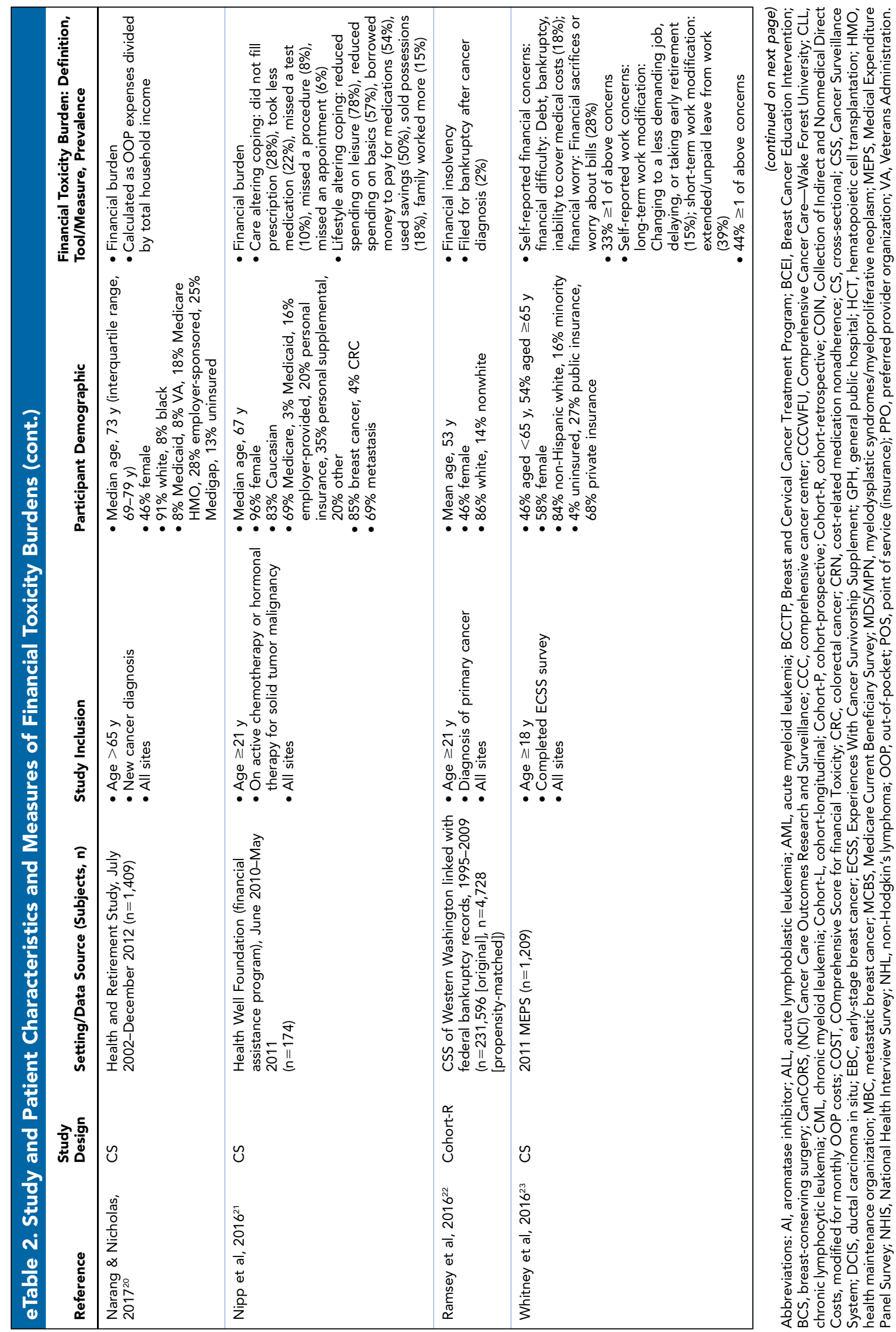


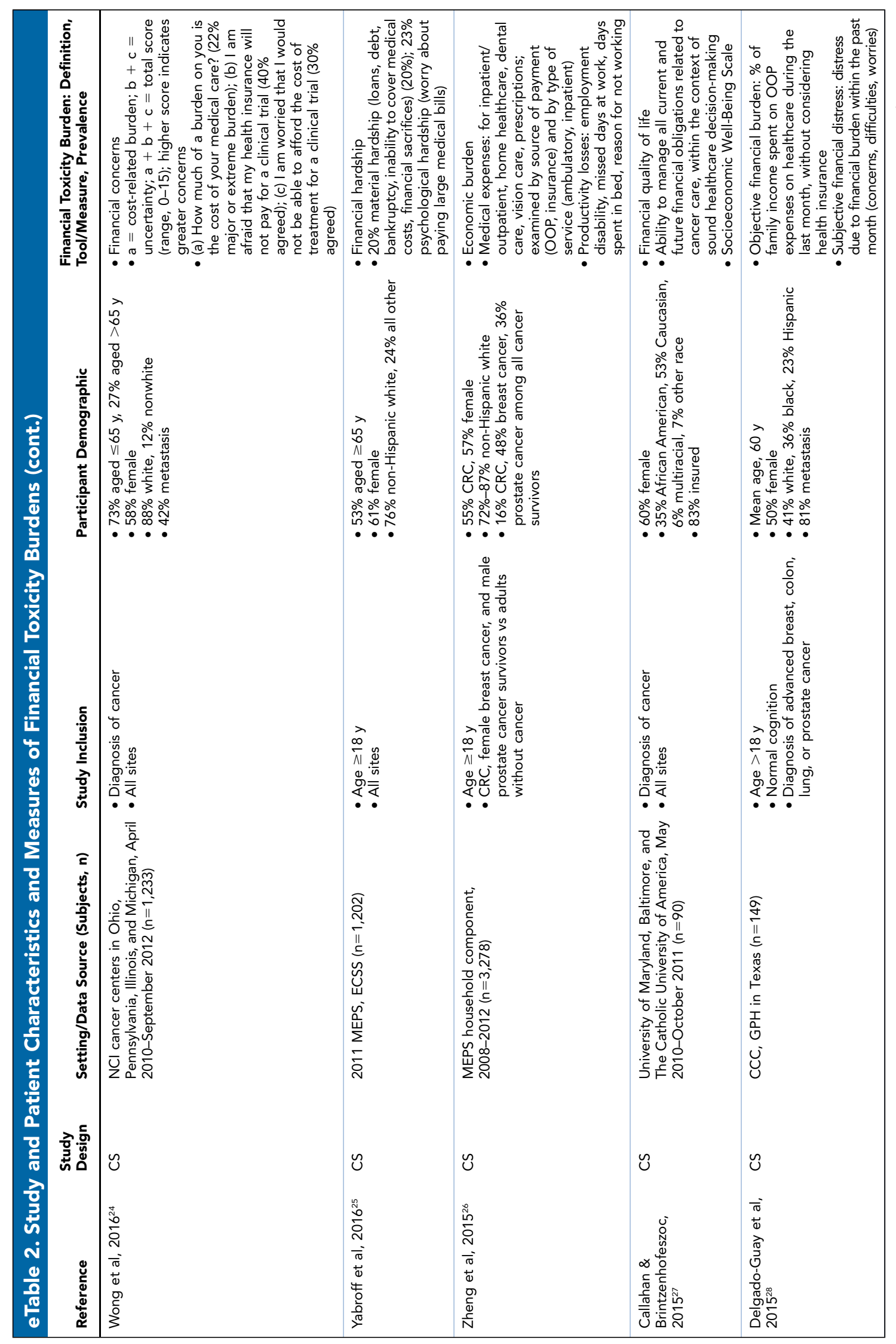

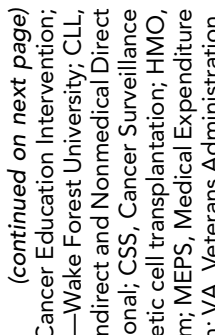

药

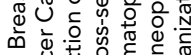

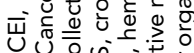

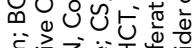

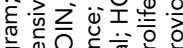

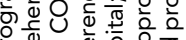

늠

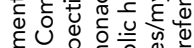

E응

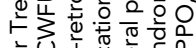

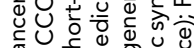

U

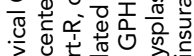

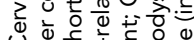

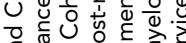

厄.

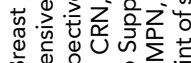

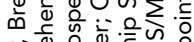

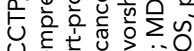

D 0 응

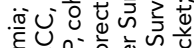

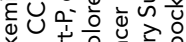

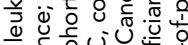

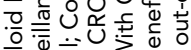

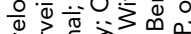

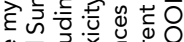

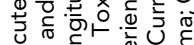

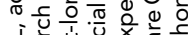

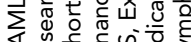

ब⿺辶寸

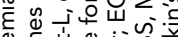

ब

ब

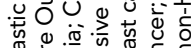

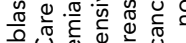

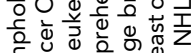

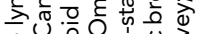

苟论

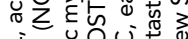

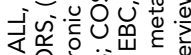

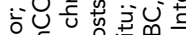

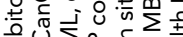

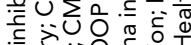
o. $\frac{0}{\varepsilon} \geq 0$

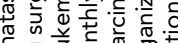

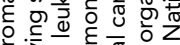

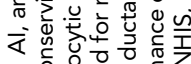
in

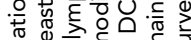

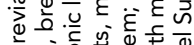

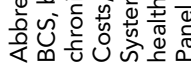




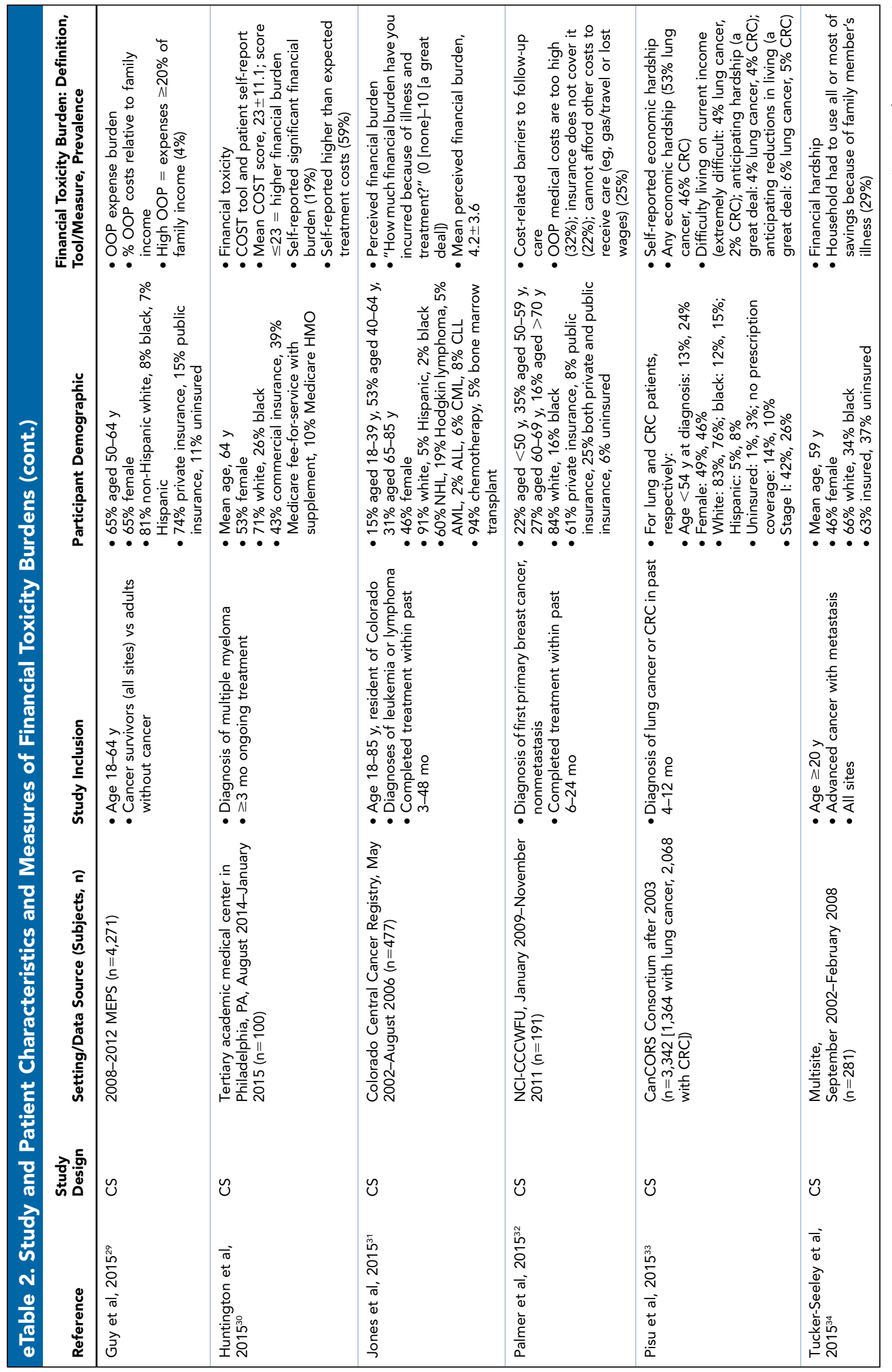

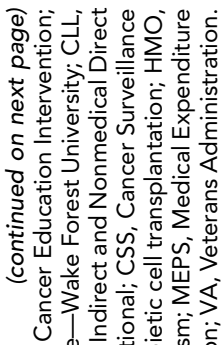

药

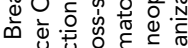

च्山心

ه

ह

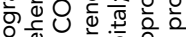

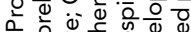

है ह己 월

हن 0

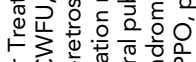

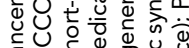

ơ

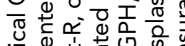

造造

U⿺辶寸

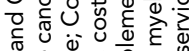

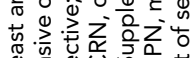

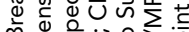

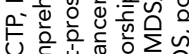

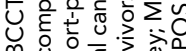

.

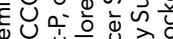

当和实

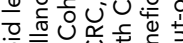

응 $\overline{\bar{\phi}}$

है

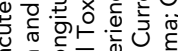

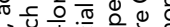

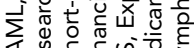

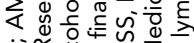

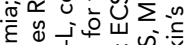

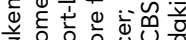

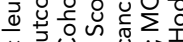

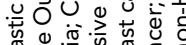

西 语.

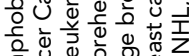

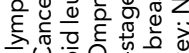

Q

प्रे है

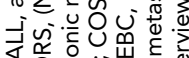

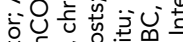

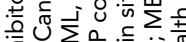

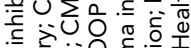

\&

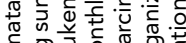

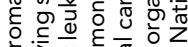

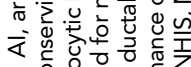

نे

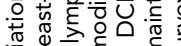

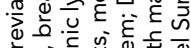

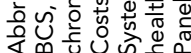



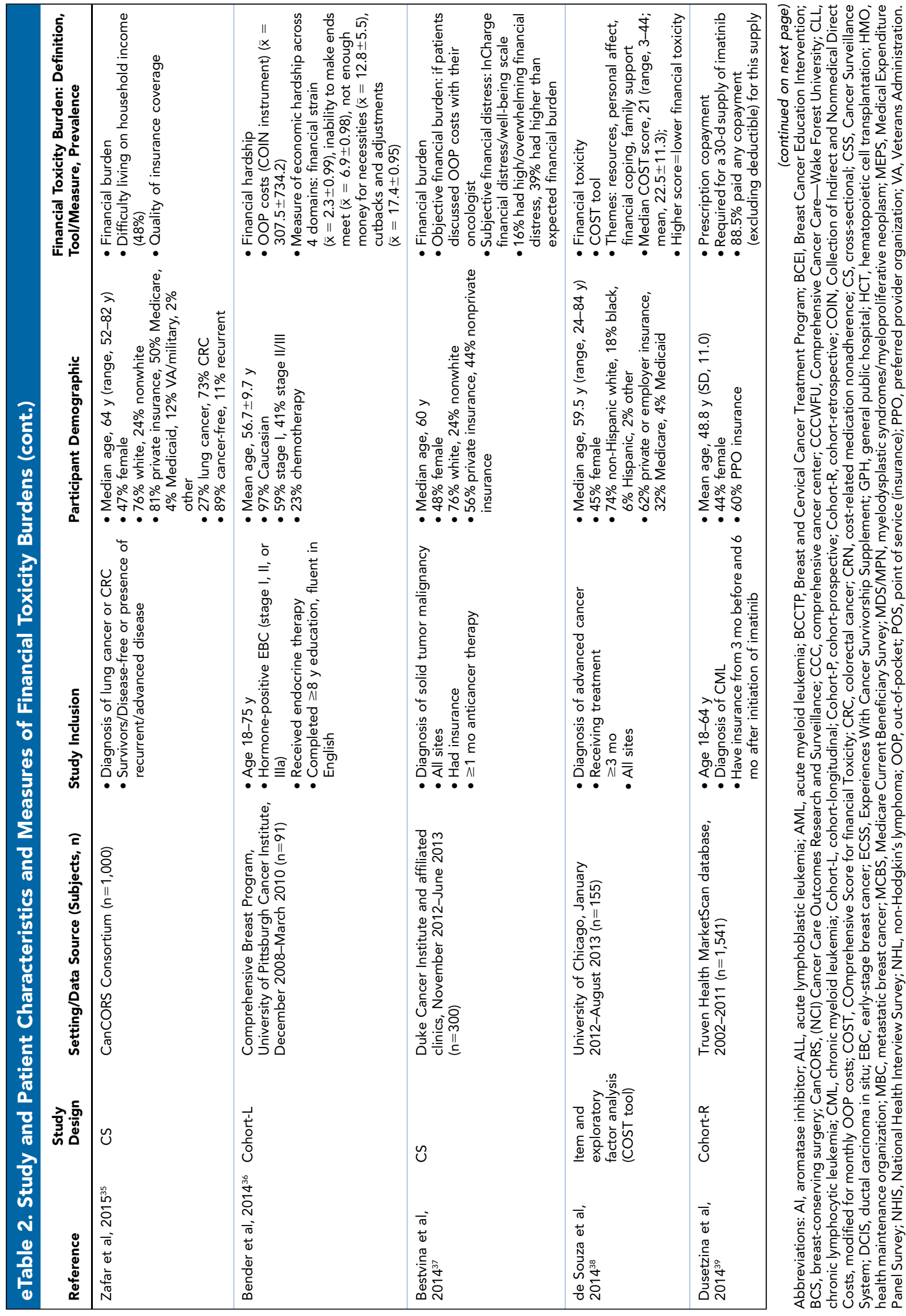


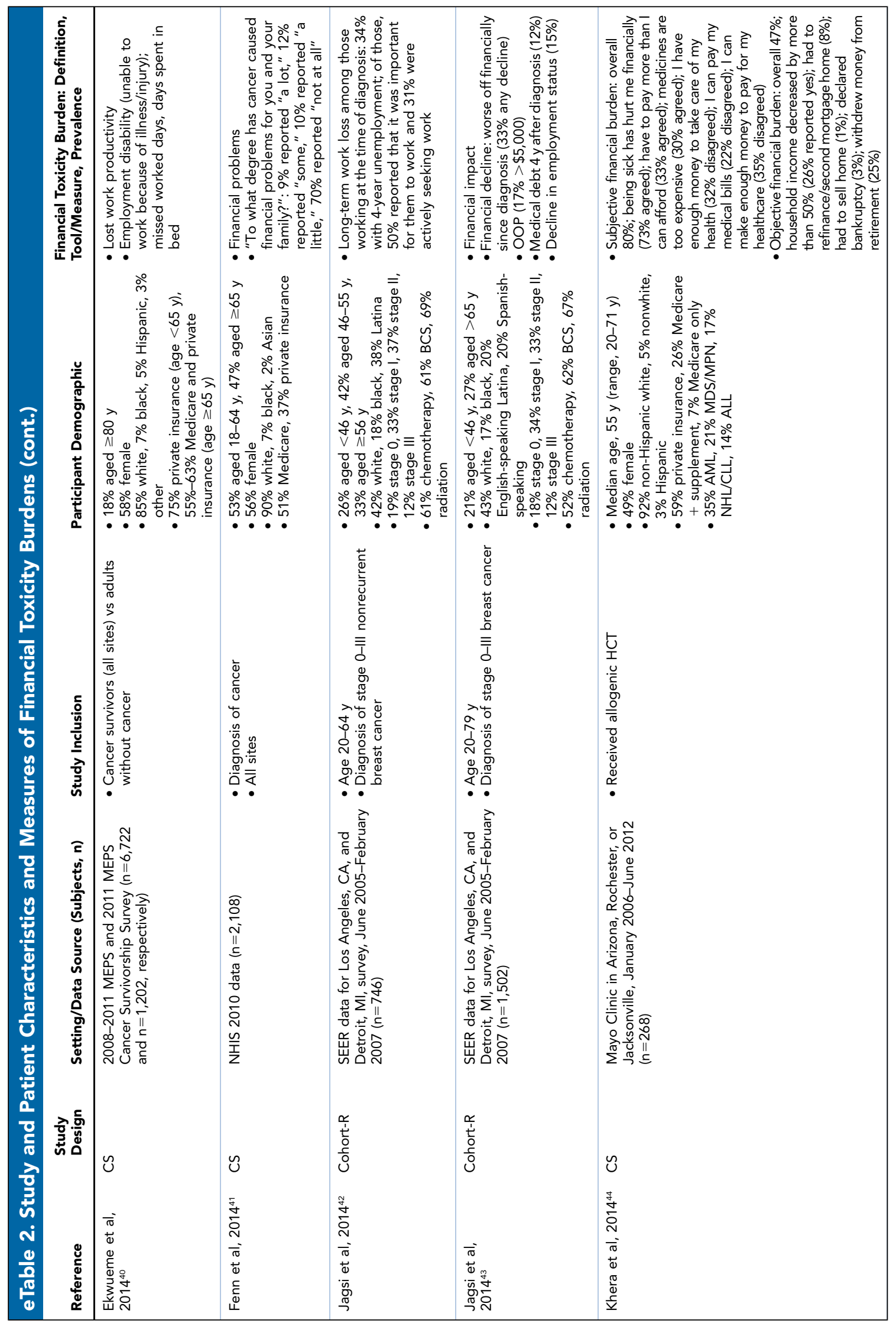

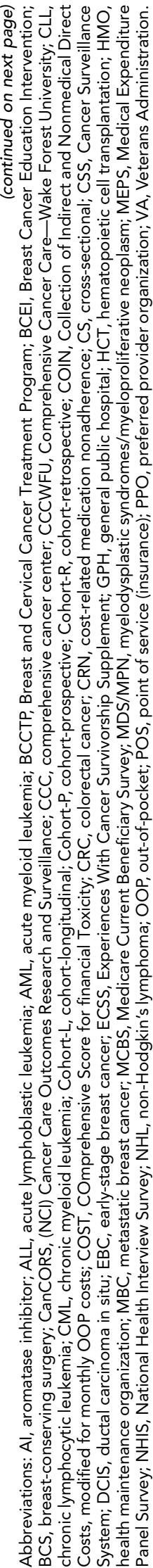



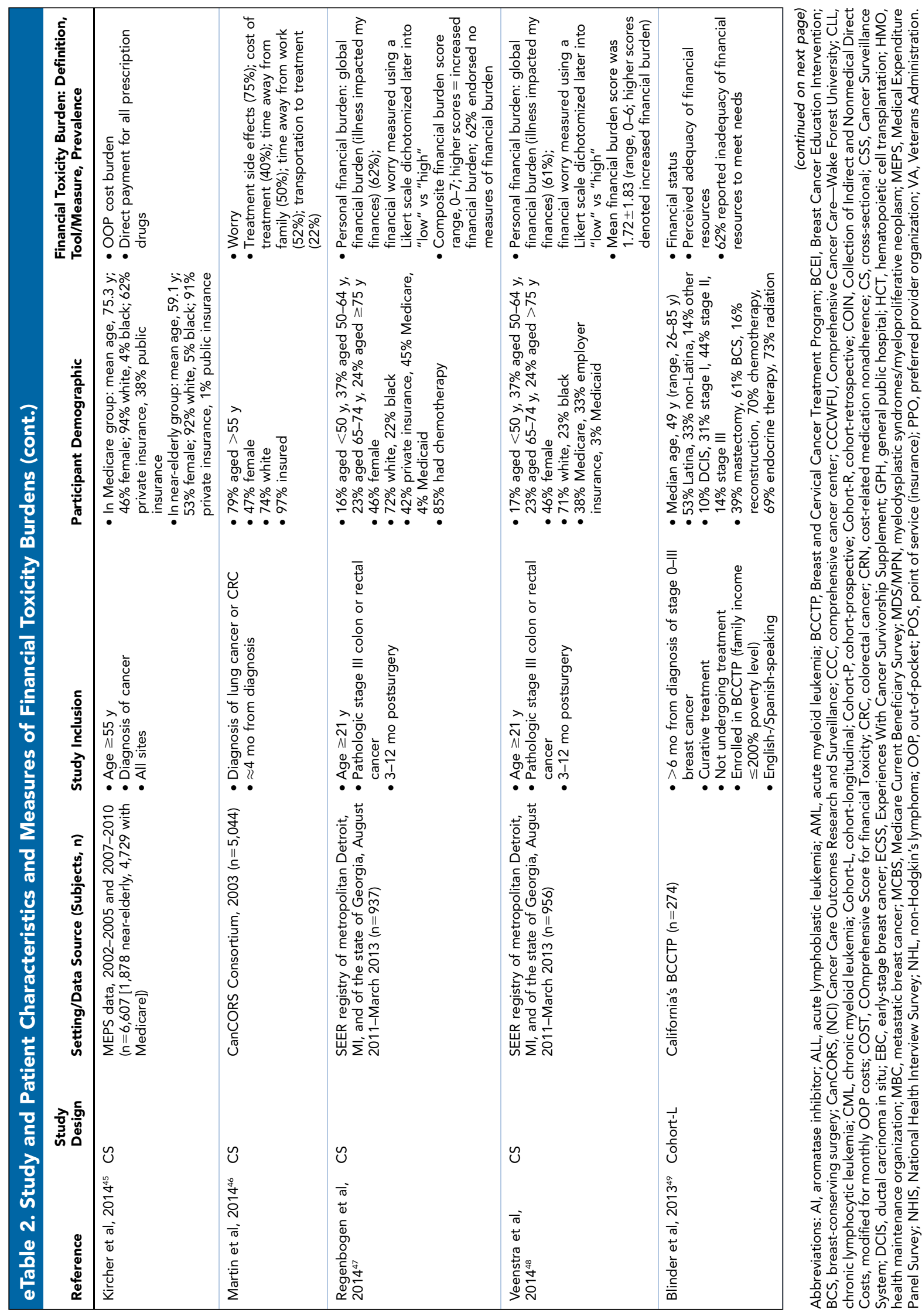

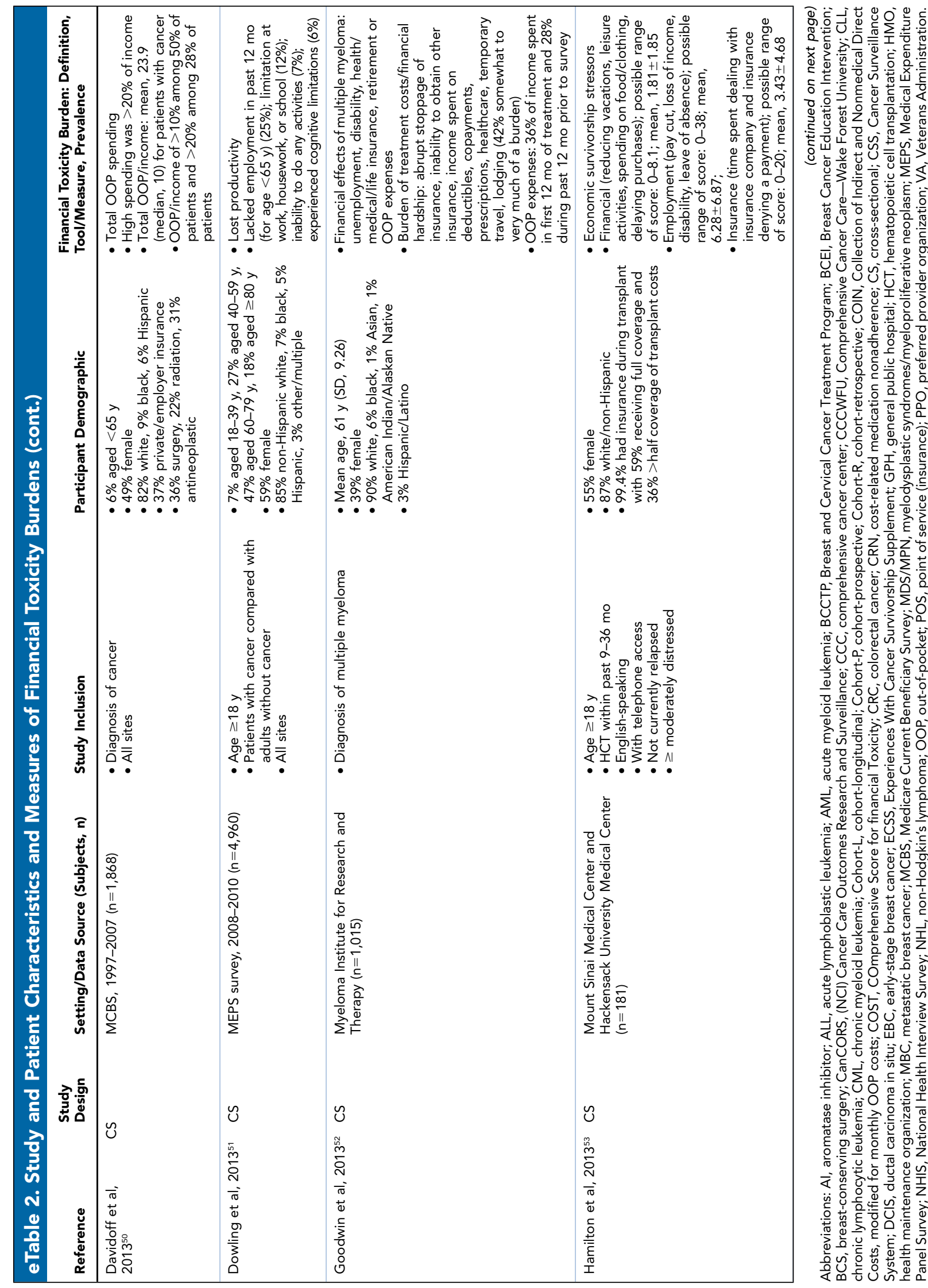


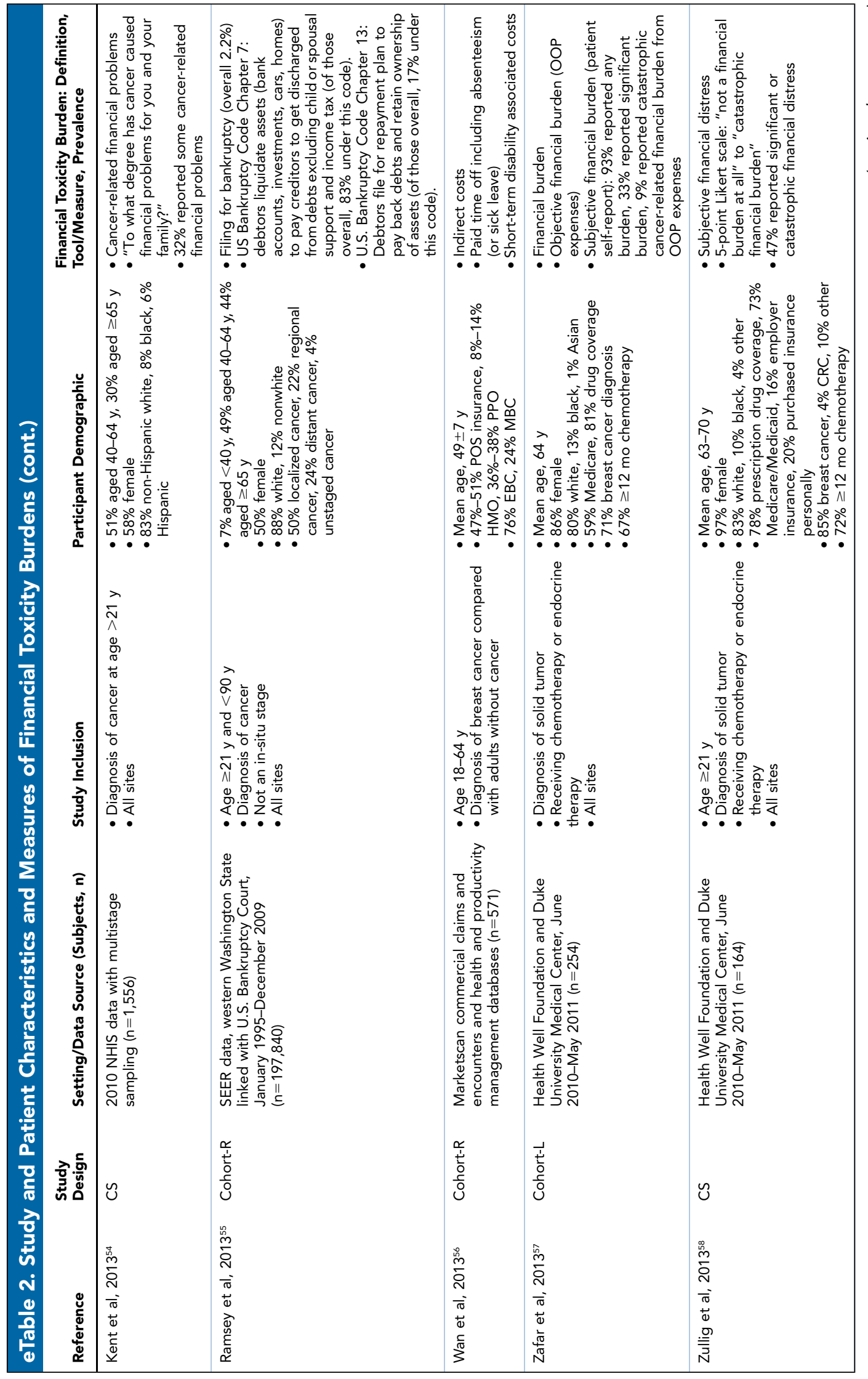

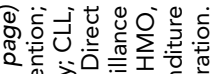

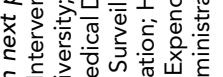
ठ

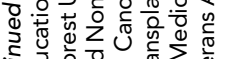

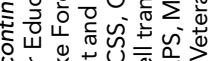

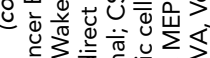
U

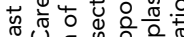

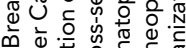

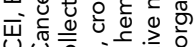
U⿺辶寸

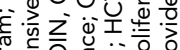

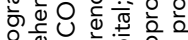

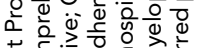
능

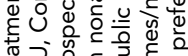

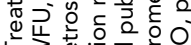

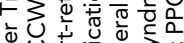
论

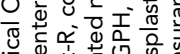

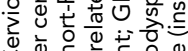

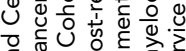

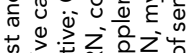

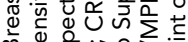
क- क्षे

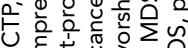
U .

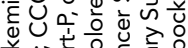

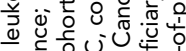

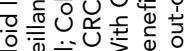
ब西

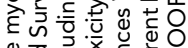

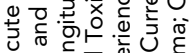

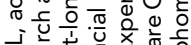

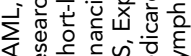

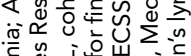
है

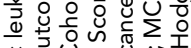

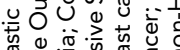

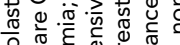
O हो

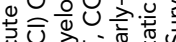

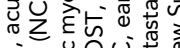

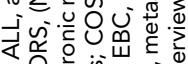

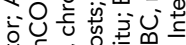

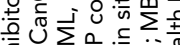

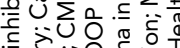
ब

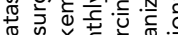

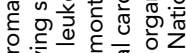
市这.

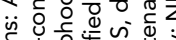

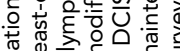
ठै.

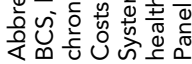




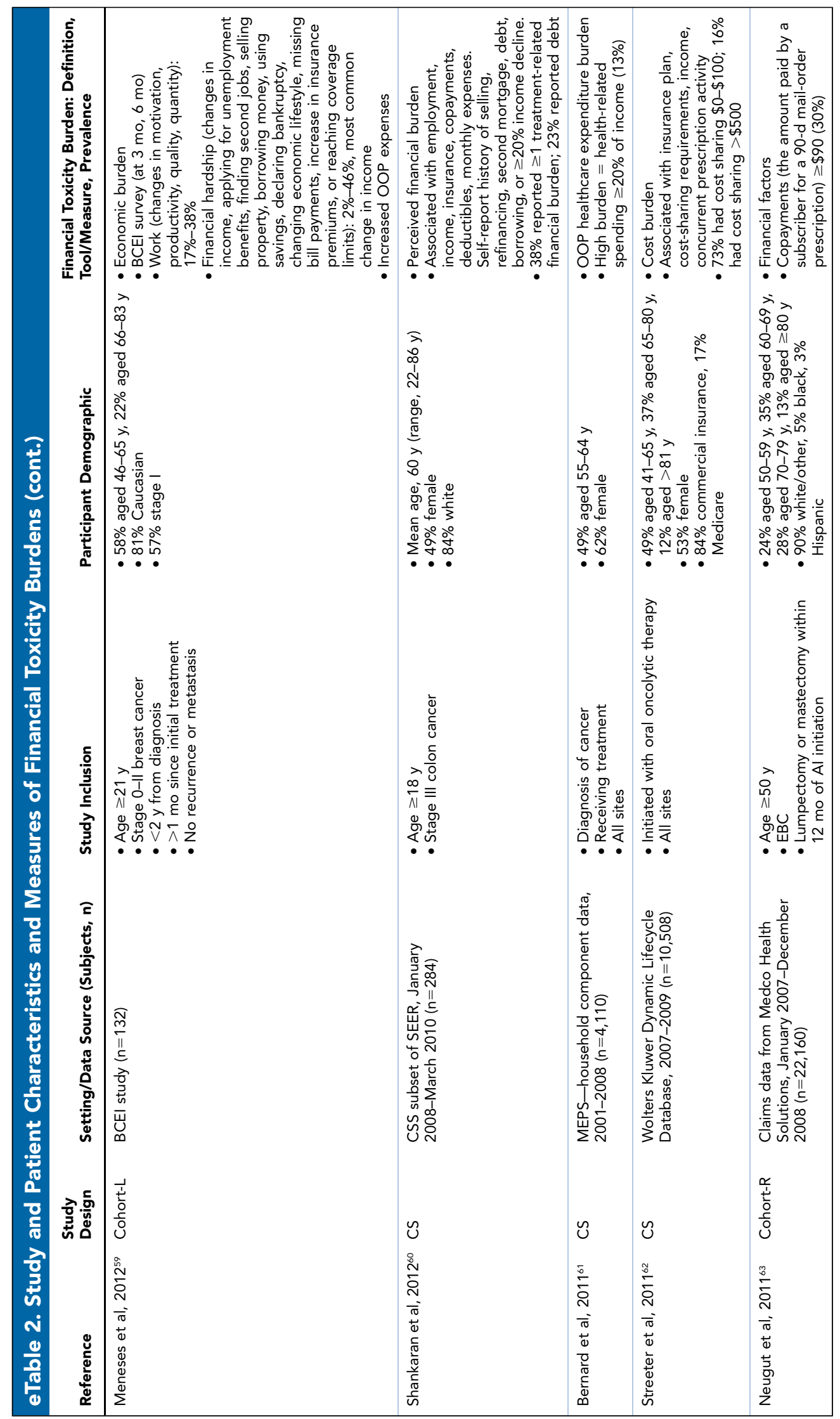

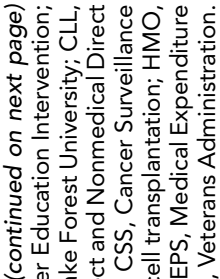

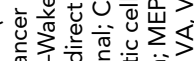

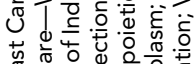

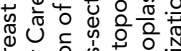

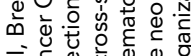

凷而要

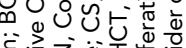

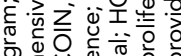

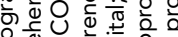

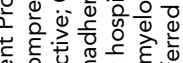

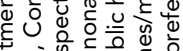

주의

等

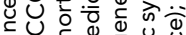

西

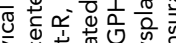

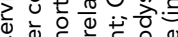

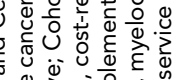

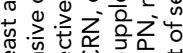

业

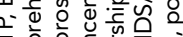

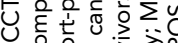

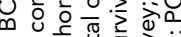

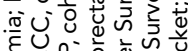

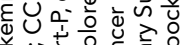

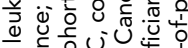

等

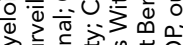

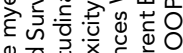

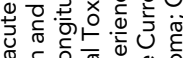

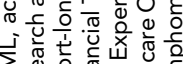

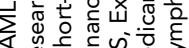

車

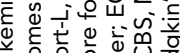

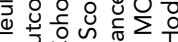

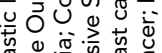

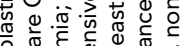

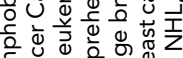

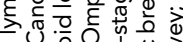

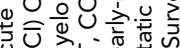

प्र है

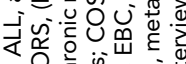

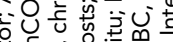

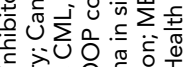

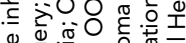

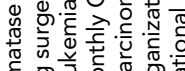

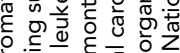

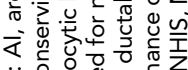

is

年萌

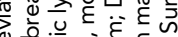

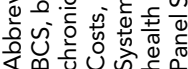




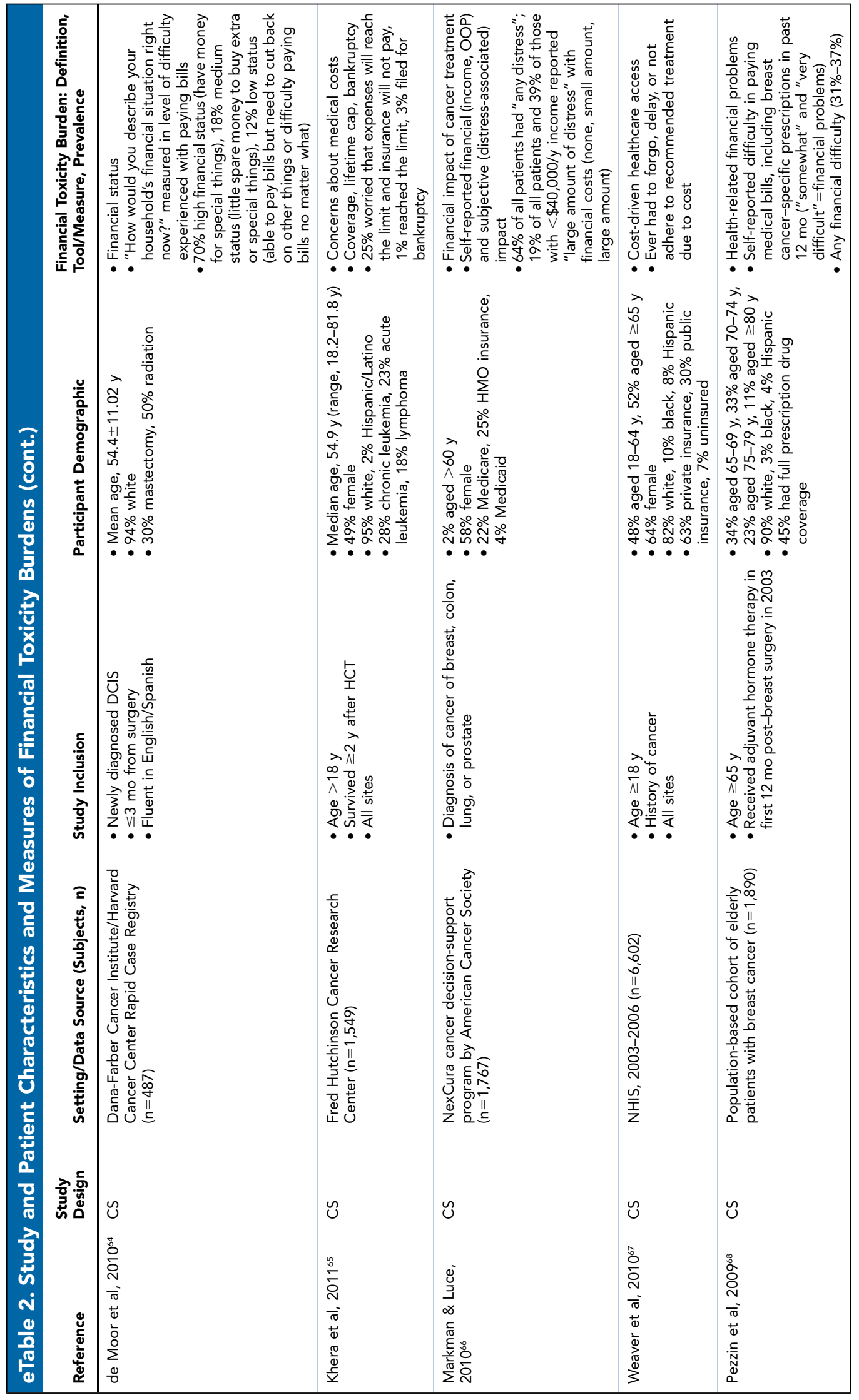

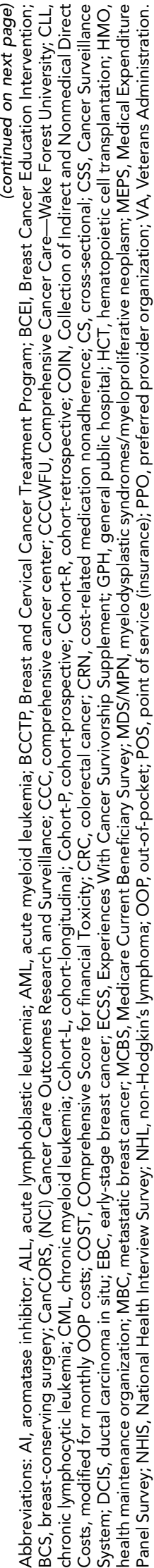




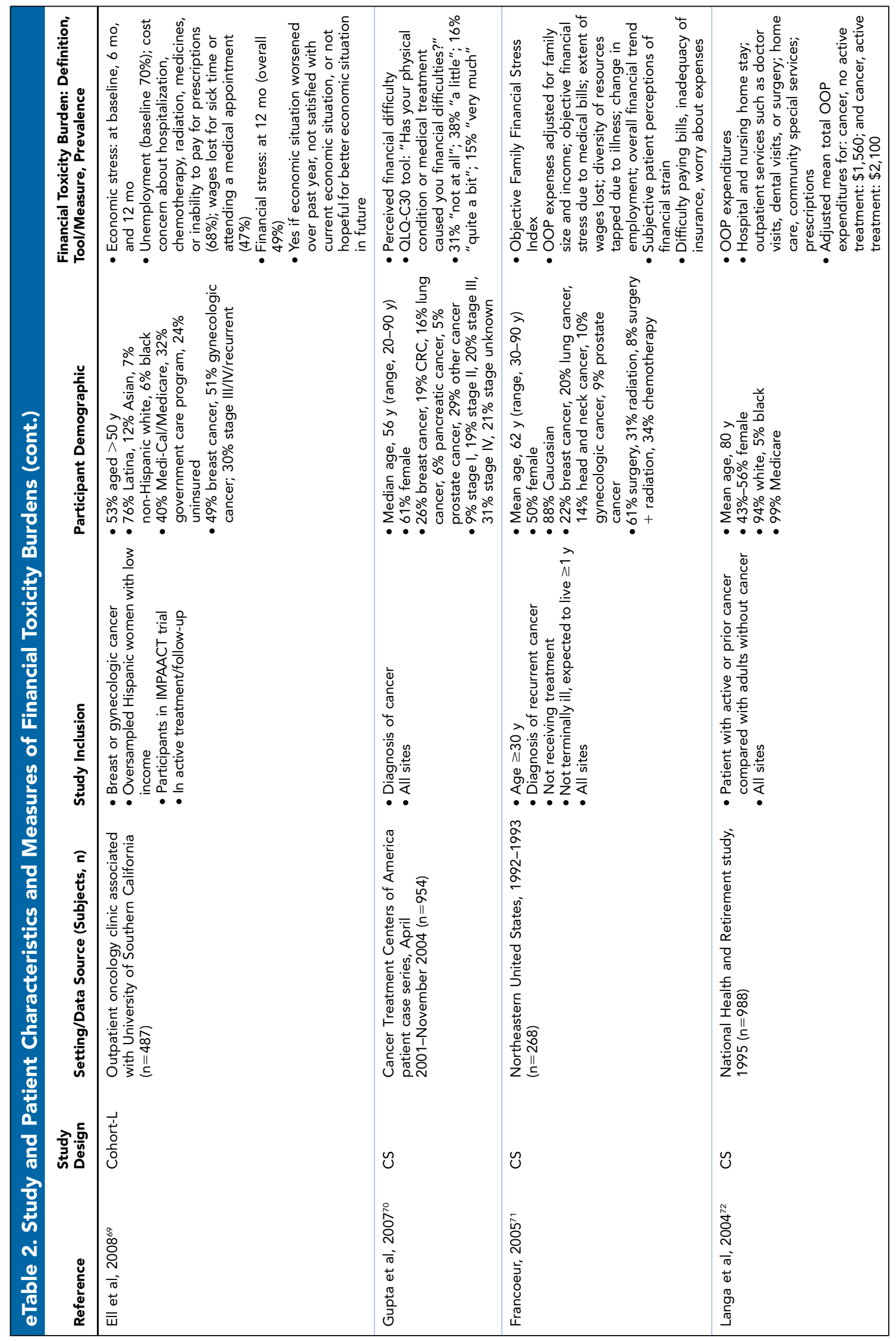

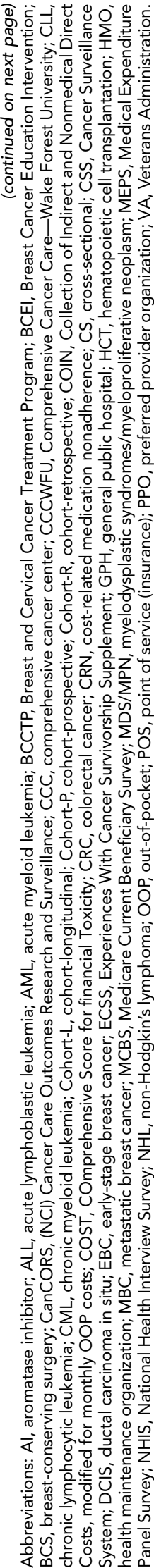



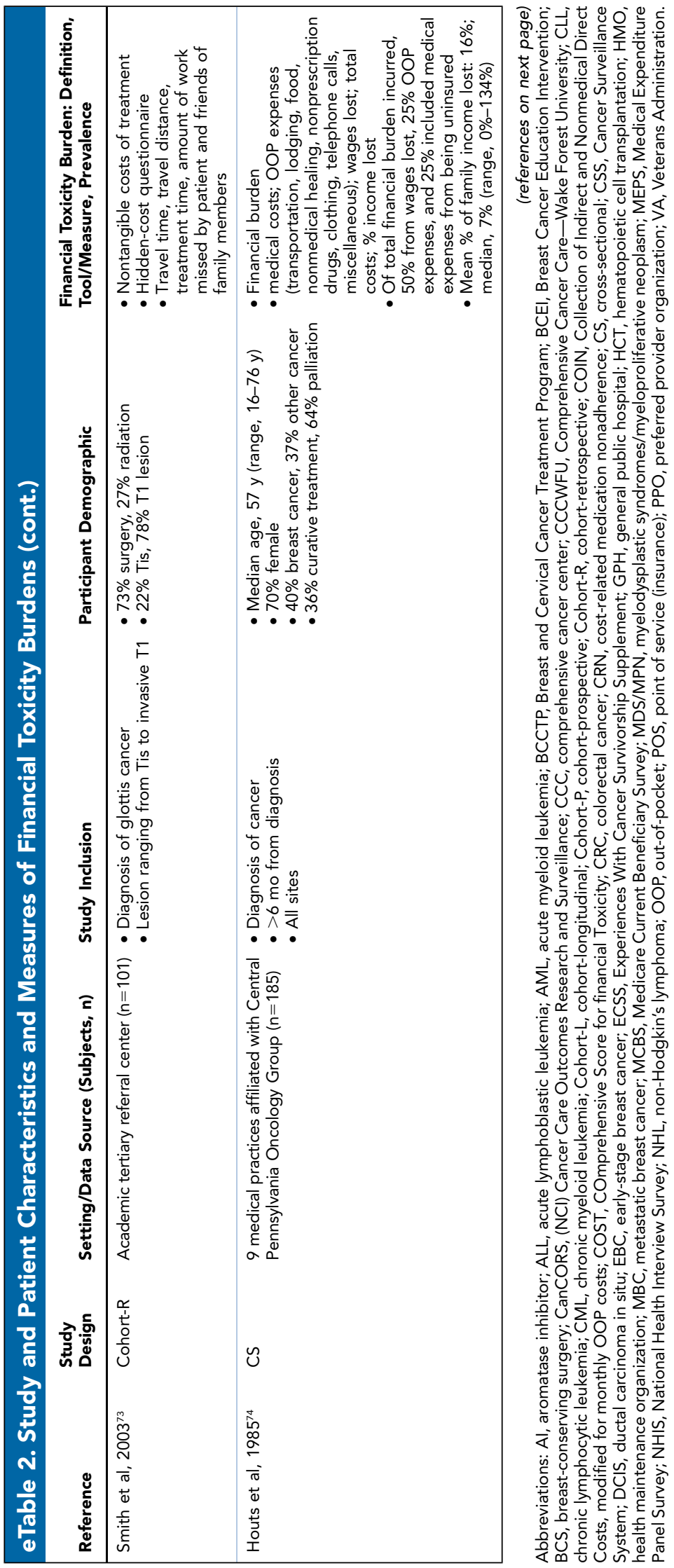

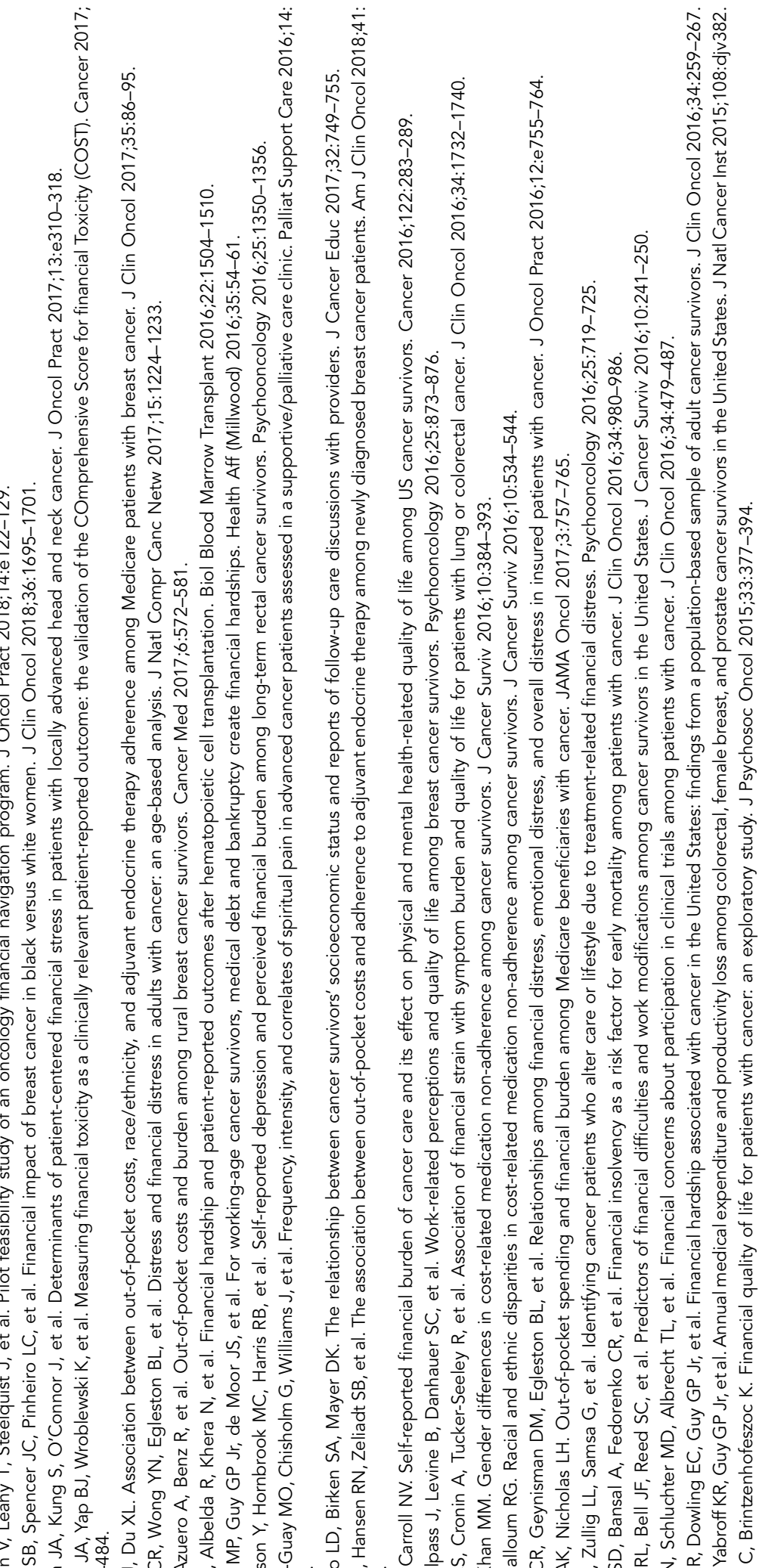

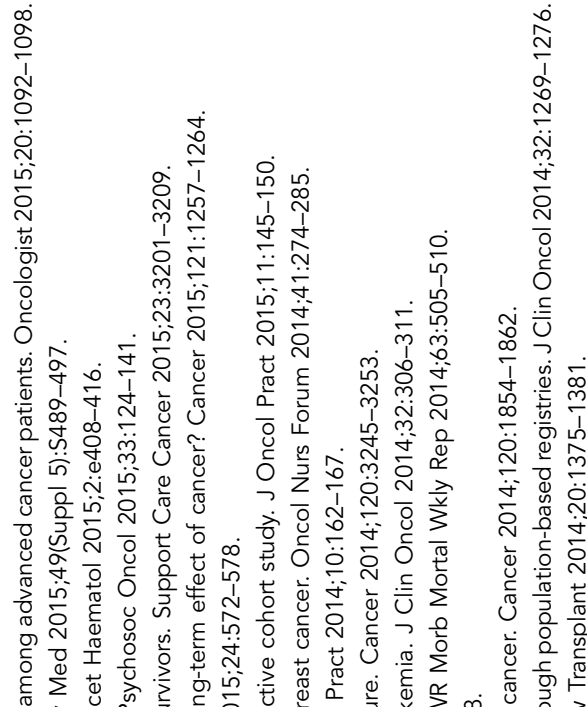

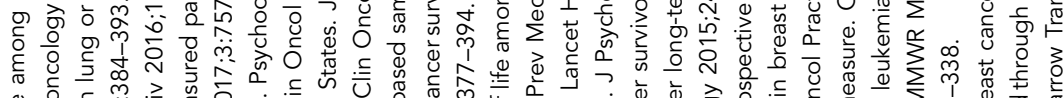

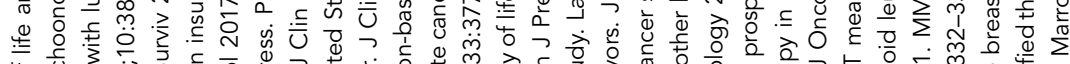

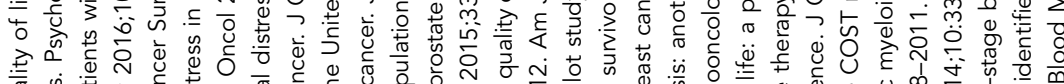

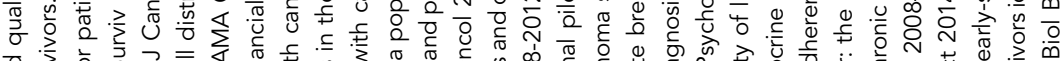

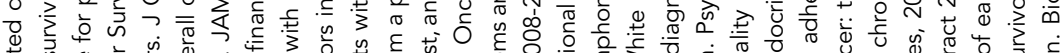

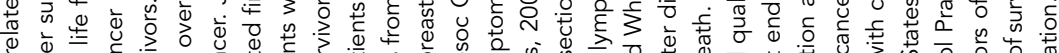

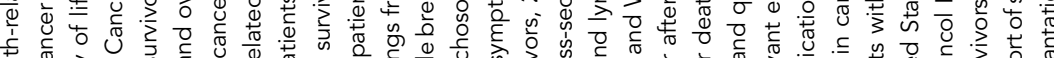

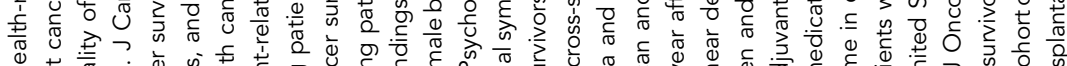

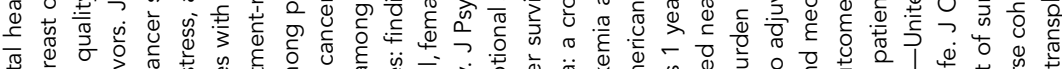

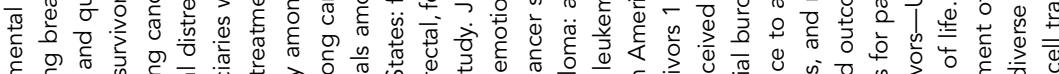

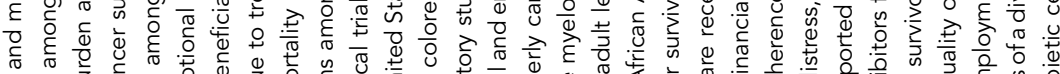

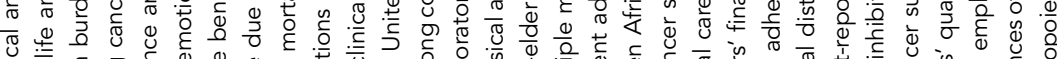

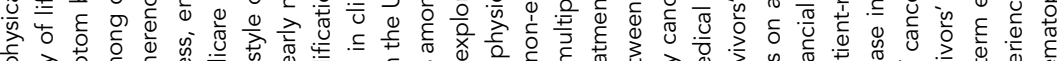

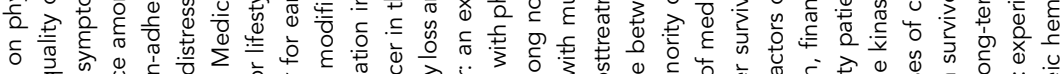

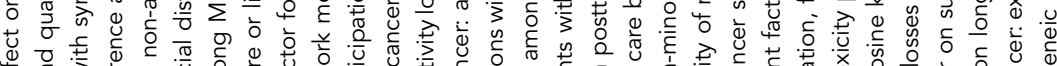

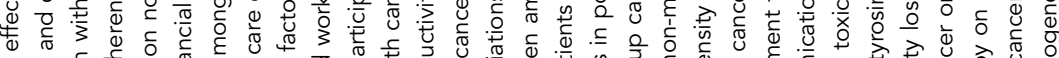

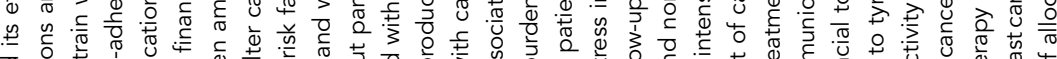

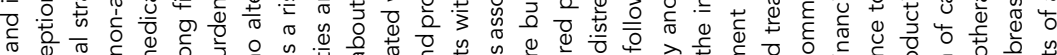

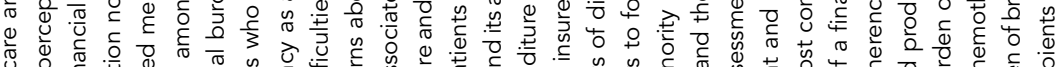

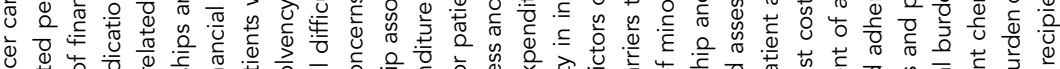

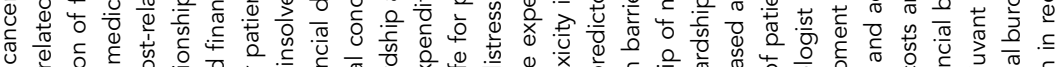

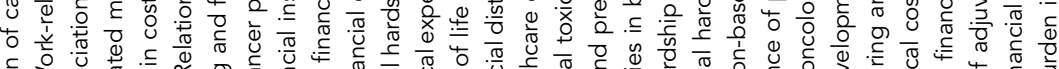

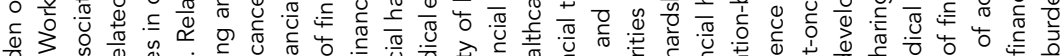

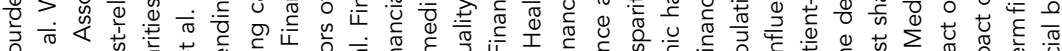

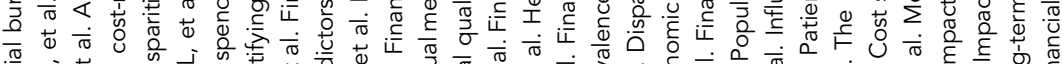

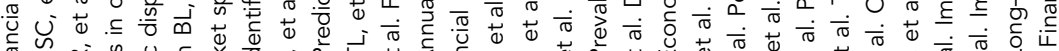

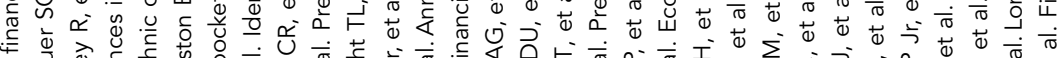

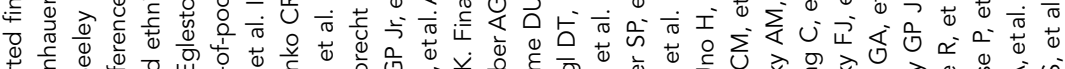

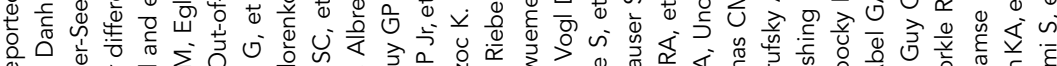

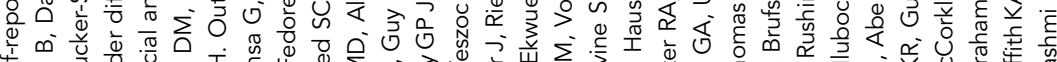

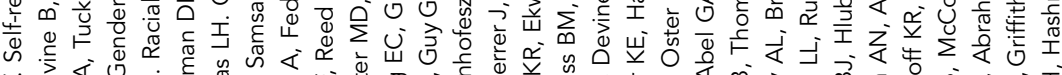

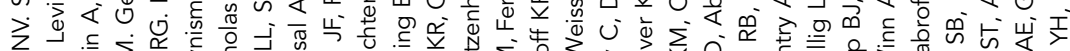

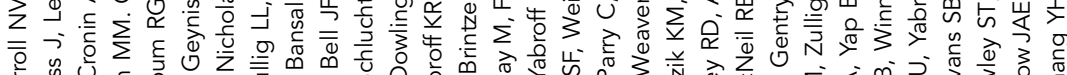

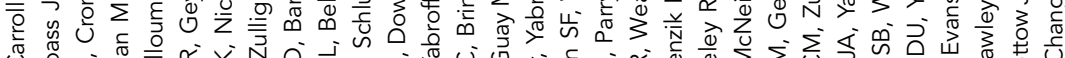

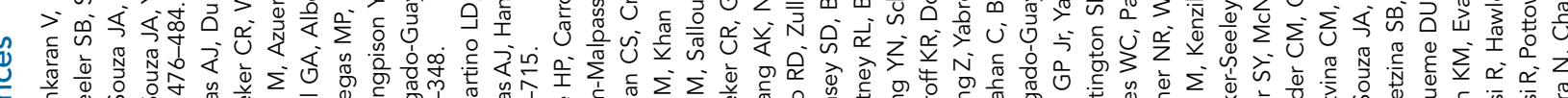

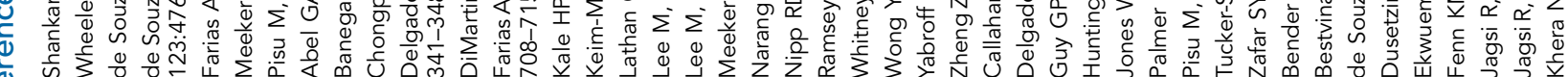
$\frac{\omega}{\Phi}$ 


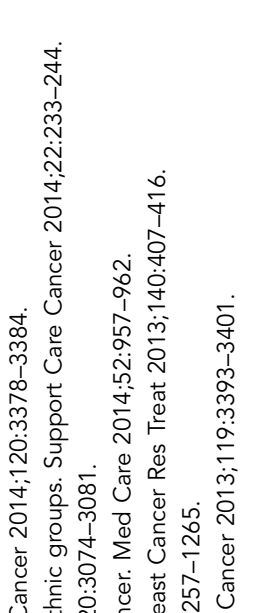

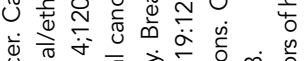

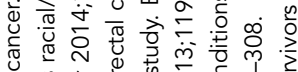

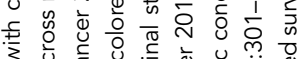

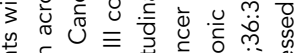

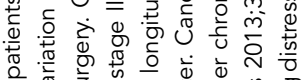

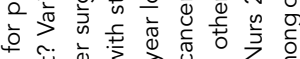

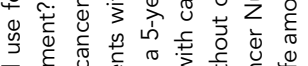

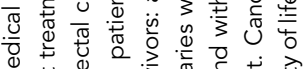

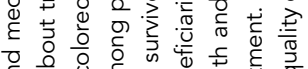

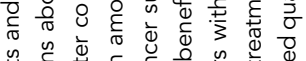

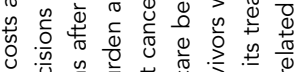

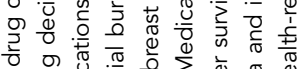

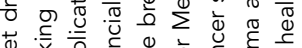

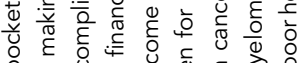

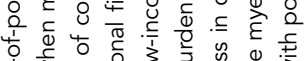

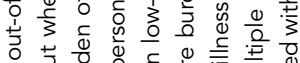

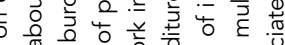

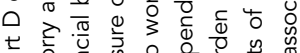
б

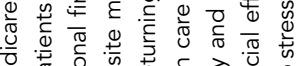

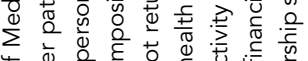

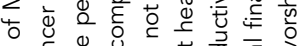

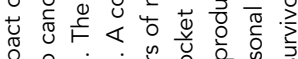

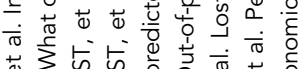

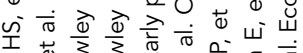
I

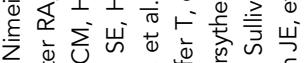

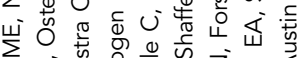

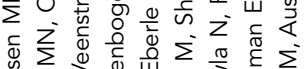

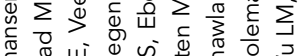

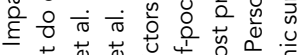

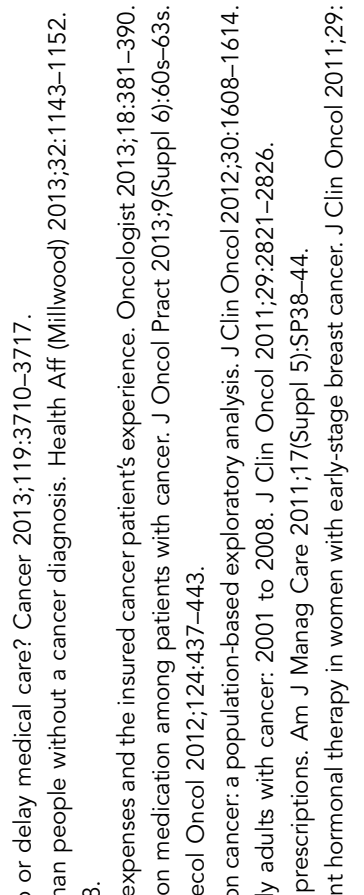

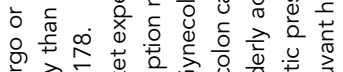

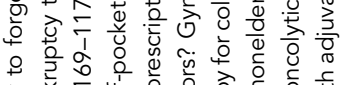
>

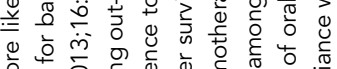

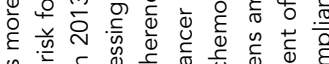
है

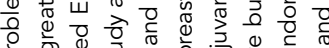

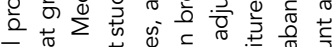

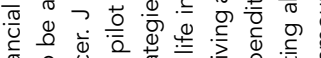

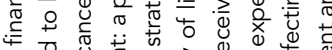

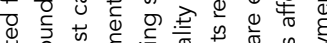
范

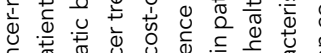

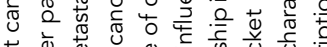

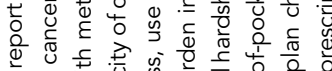

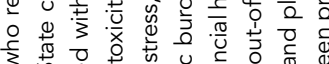

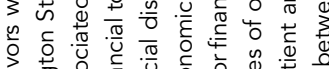

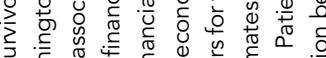

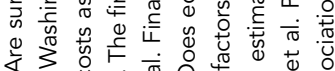

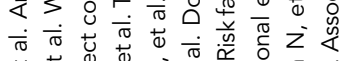

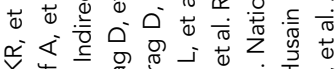

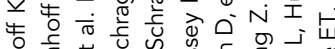

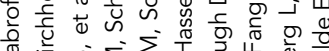

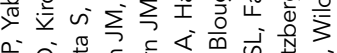

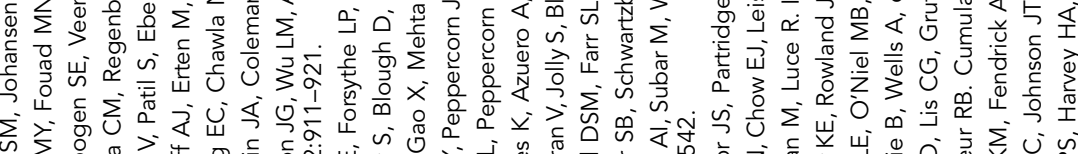

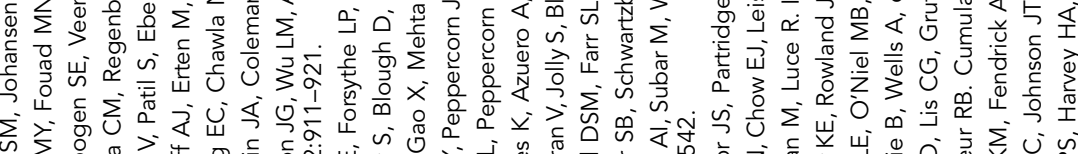

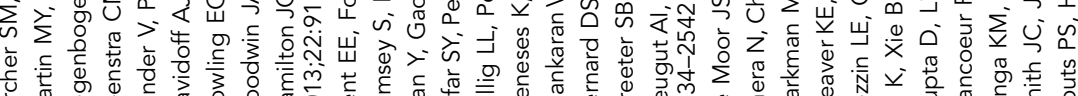

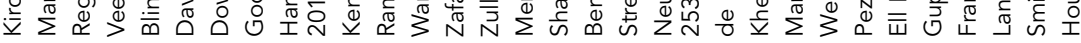

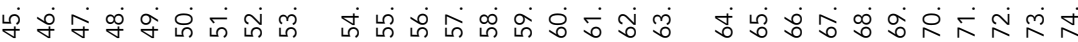

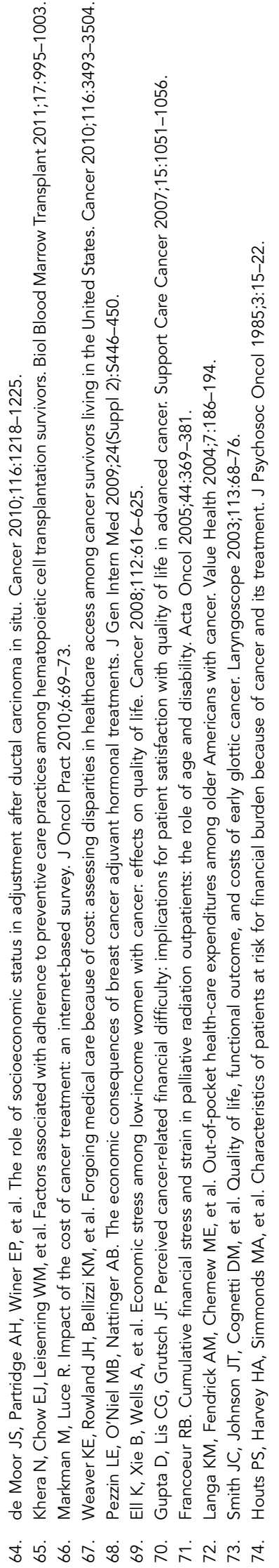




\section{eTable 3. Strength of Evidence Assessment Using GRADE Criteria}

\begin{tabular}{|c|c|c|}
\hline Analysis & Assessment & Other Details \\
\hline \multicolumn{3}{|c|}{ Sample-weighted prevalence of financial burden } \\
\hline Limitations in study design & Downgraded & 8 studies judged "fair" in risk of bias \\
\hline Inconsistency of result & Downgraded & Because of substantial heterogeneity \\
\hline Indirectness of evidence & Downgraded & Because of substantial heterogeneity \\
\hline Imprecision & Not downgraded & \\
\hline Publications of bias & Not downgraded & Not present \\
\hline General assessment & Very low & \\
\hline \multicolumn{3}{|c|}{ Association between insurance status and financial burdens } \\
\hline Limitations in study design & Not downgraded & \\
\hline Inconsistency of result & Downgraded & Because of substantial heterogeneity \\
\hline Indirectness of evidence & Downgraded & Because of substantial heterogeneity \\
\hline Imprecision & Not downgraded & \\
\hline Publications of bias & Not downgraded & Cannot be assessed \\
\hline General assessment & Low & \\
\hline \multicolumn{3}{|c|}{ Association between financial burdens and cancer medication adherence } \\
\hline Limitations in study design & Not downgraded & \\
\hline Inconsistency of result & Downgraded & Because of substantial heterogeneity \\
\hline Indirectness of evidence & Downgraded & Differences in populations and outcomes \\
\hline Imprecision & Downgraded & Large confidence intervals \\
\hline Publications of bias & Not downgraded & Cannot be assessed \\
\hline General assessment & Very low & \\
\hline
\end{tabular}

Abbreviation: GRADE, Grading of Recommendations Assessment, Development, and Evaluation criteria. 

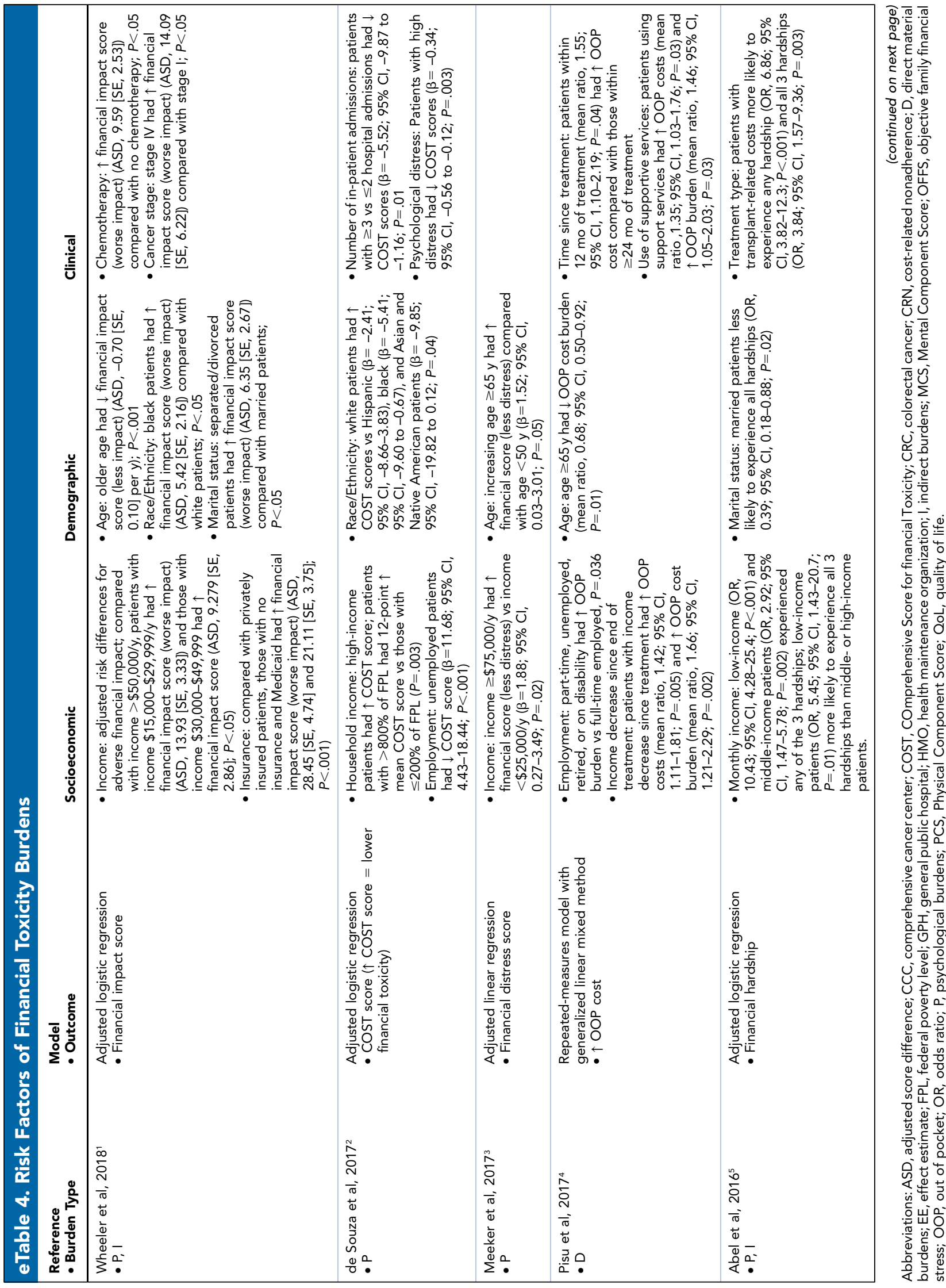


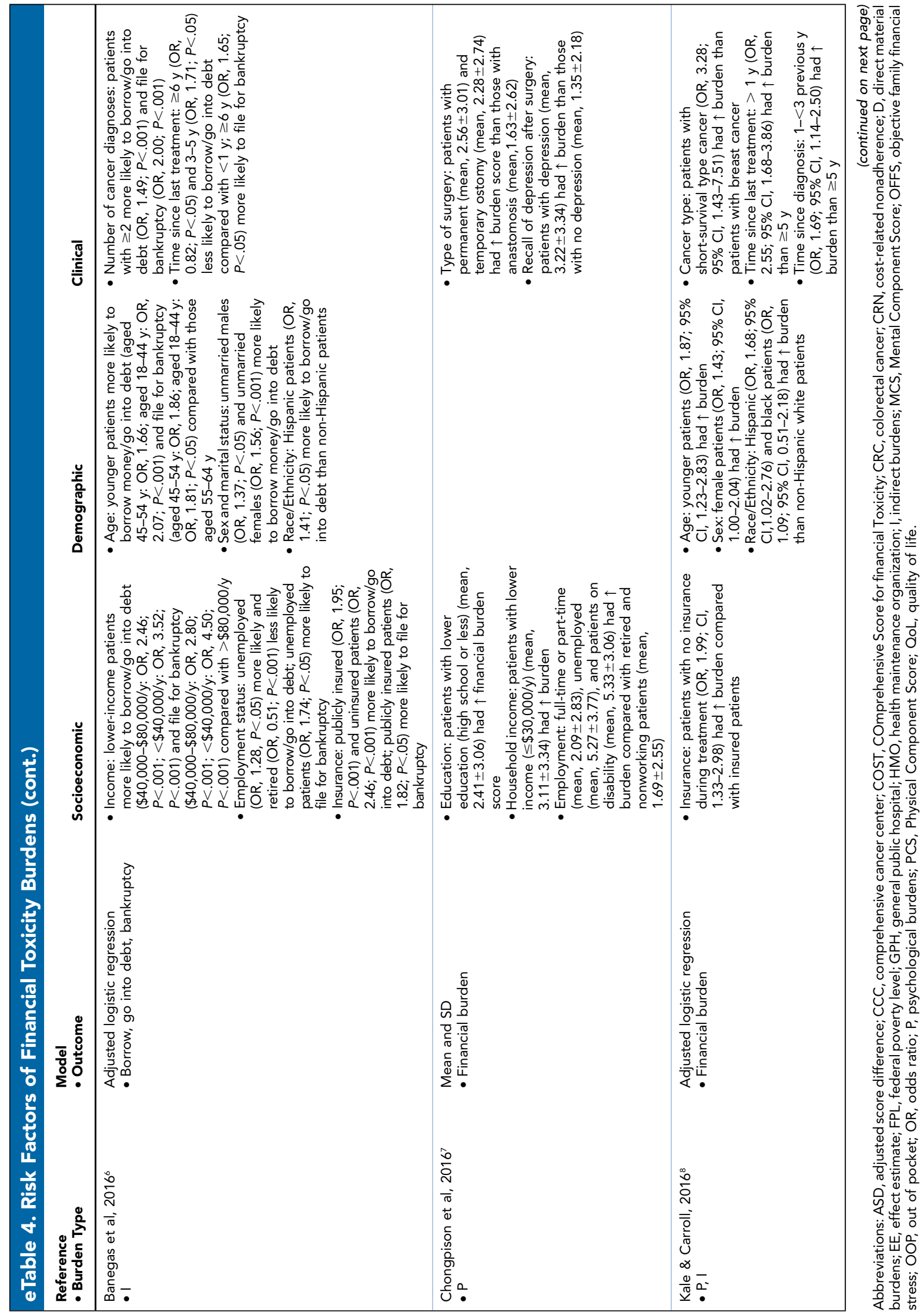



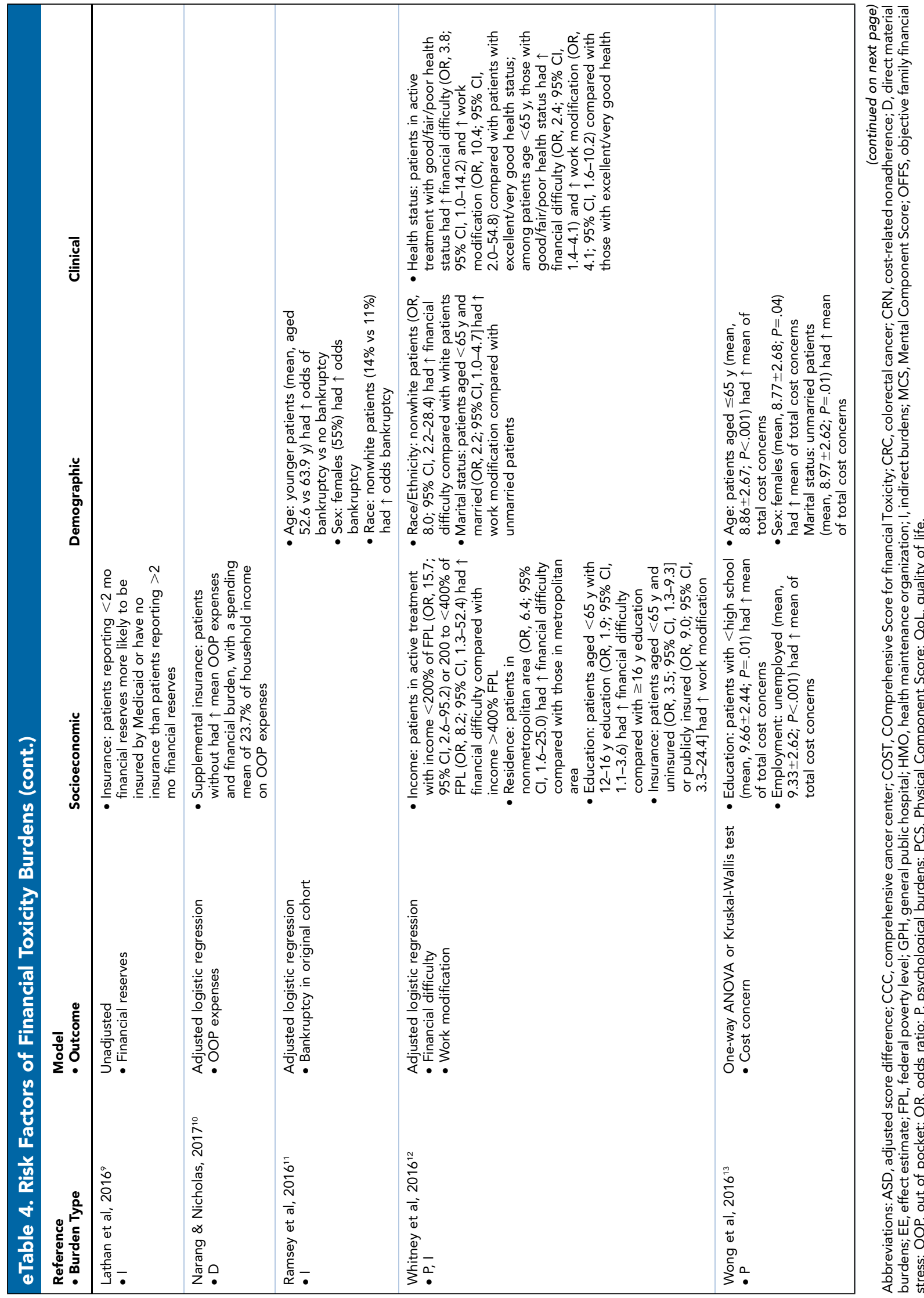


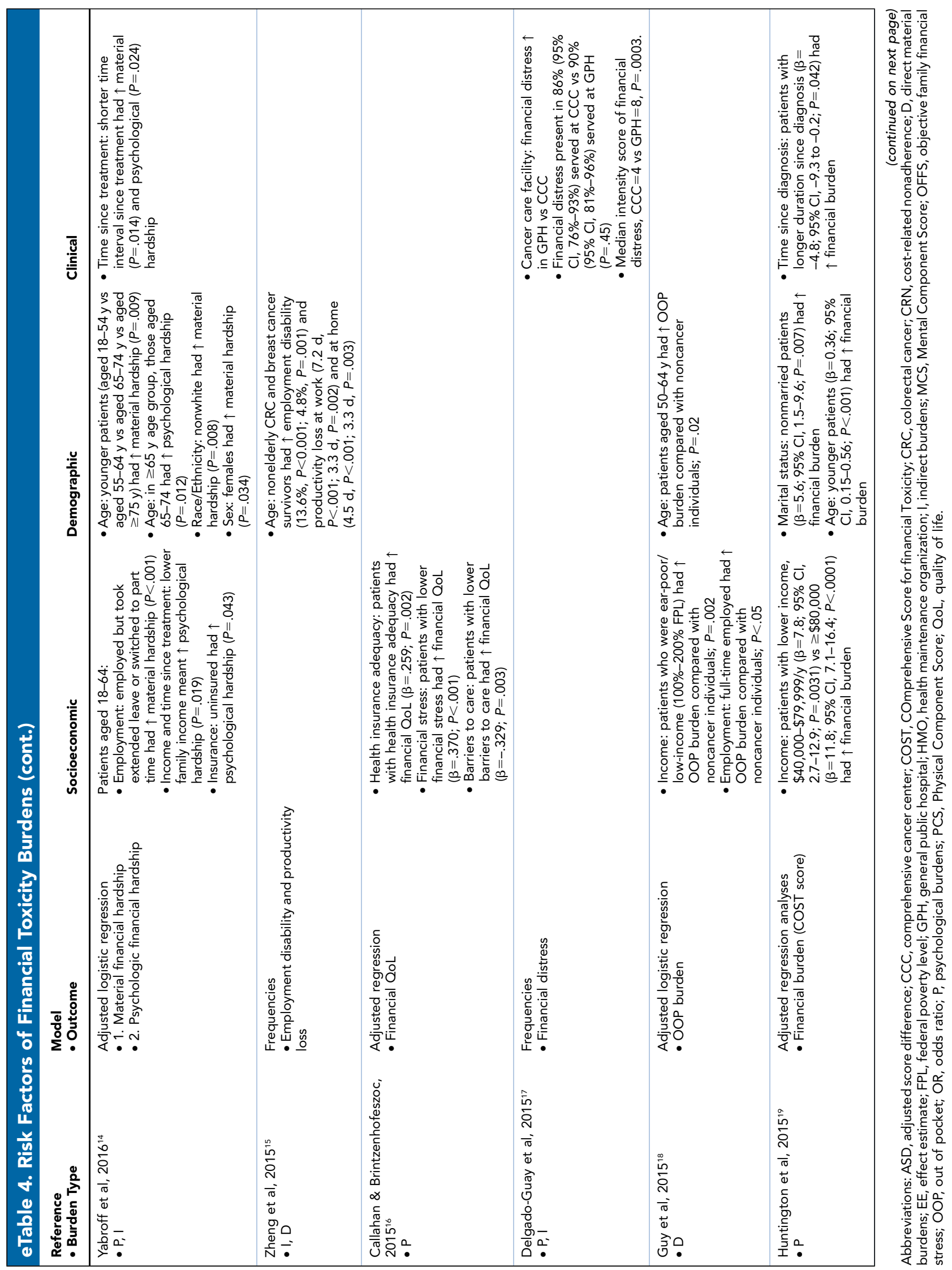




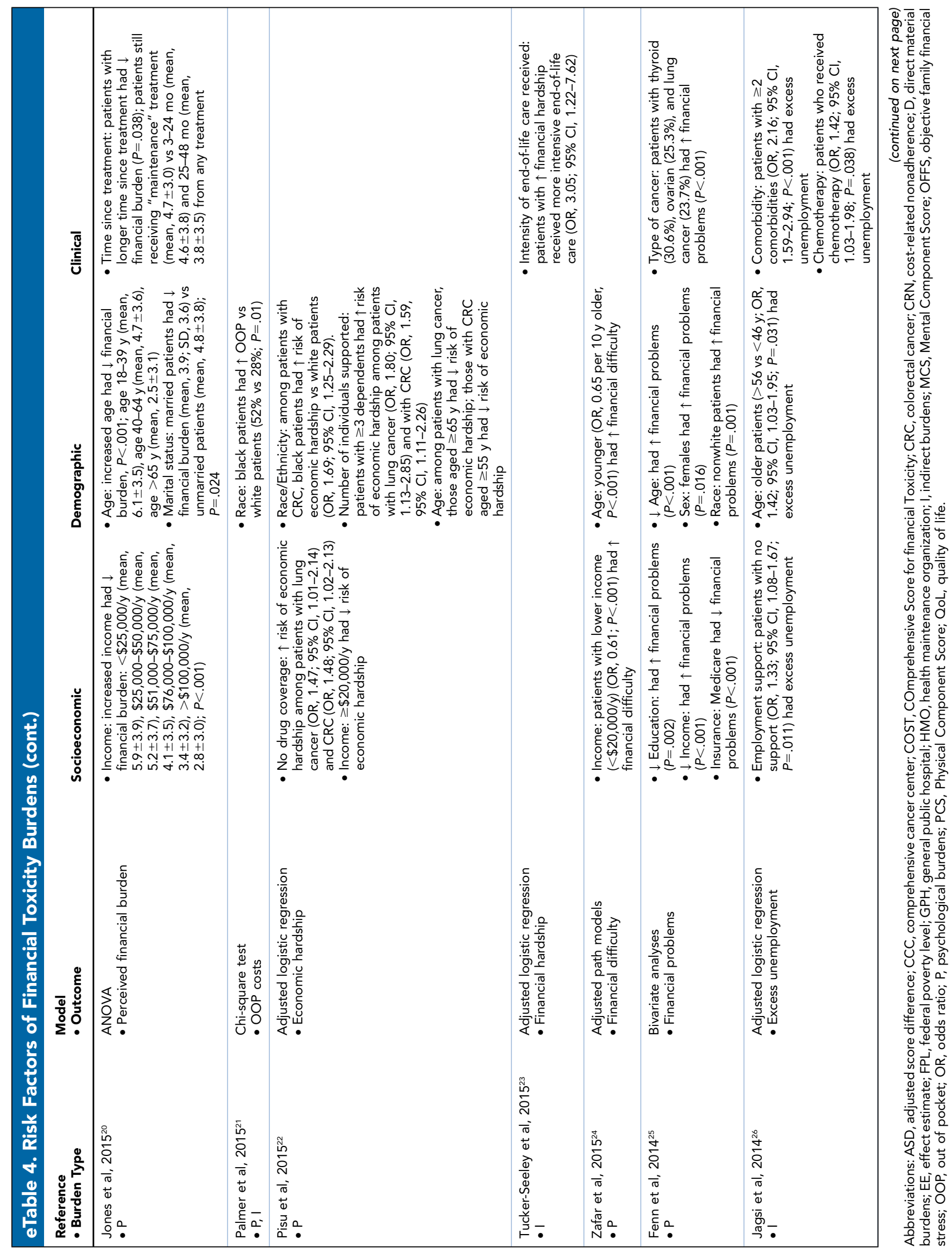



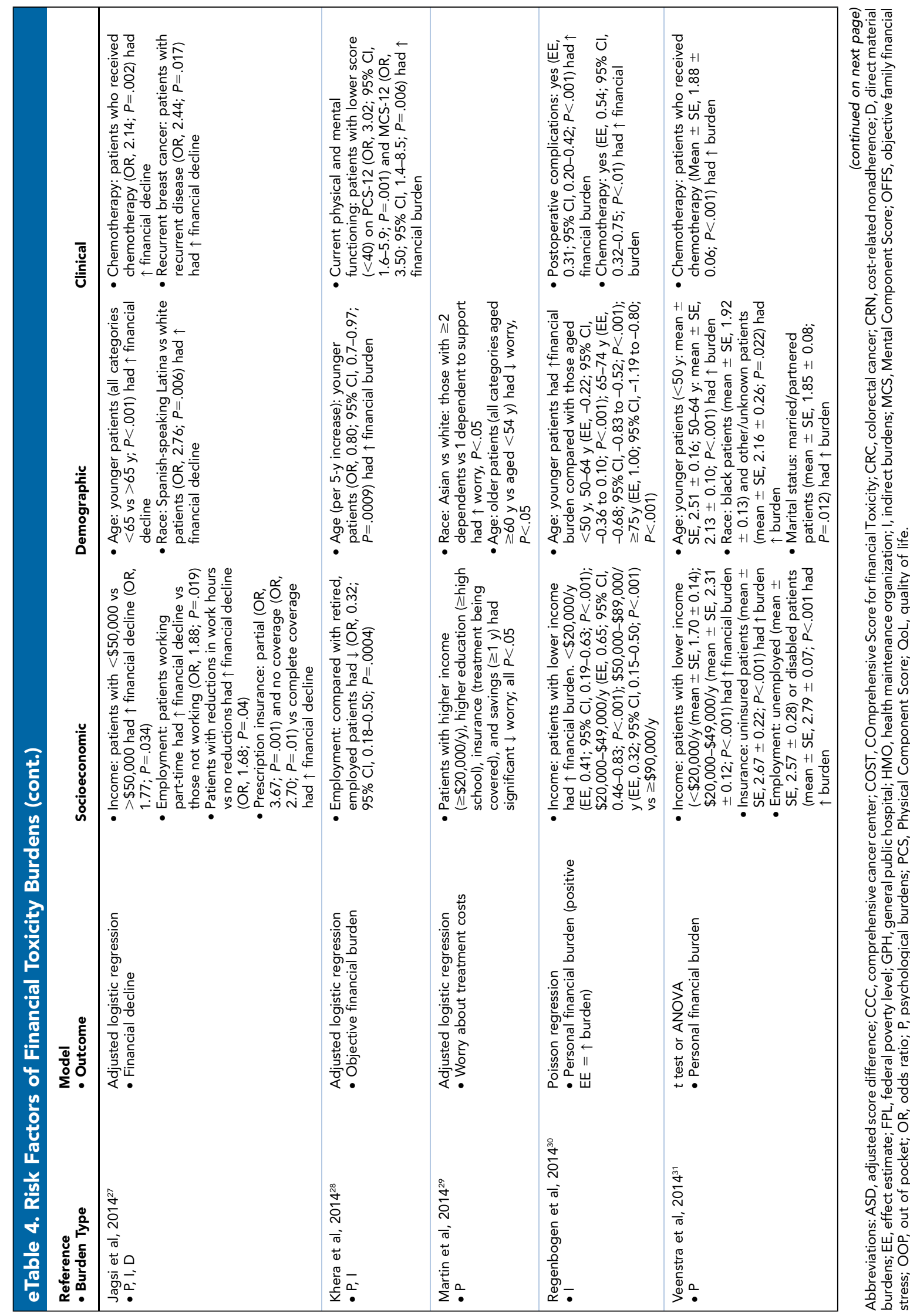


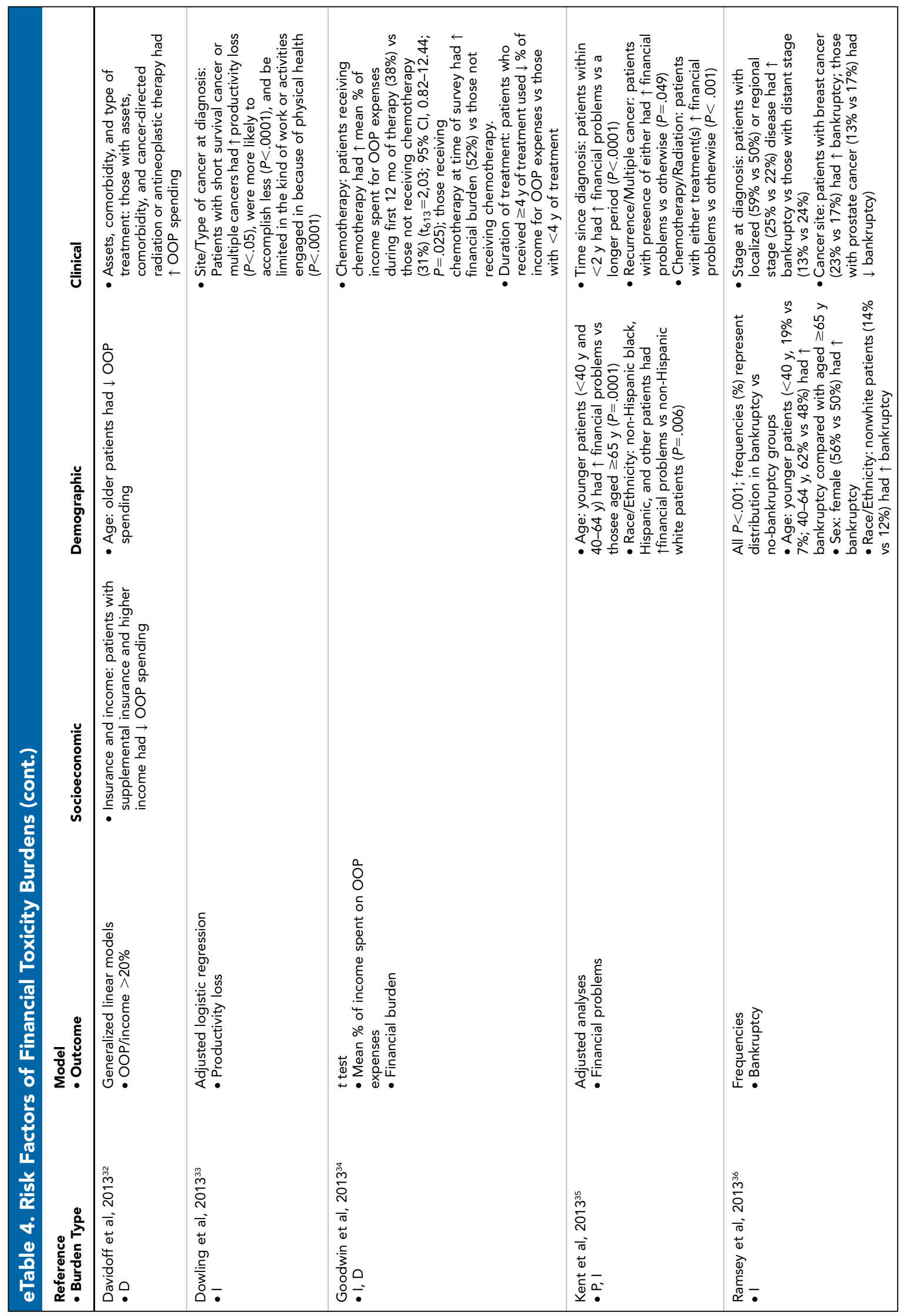

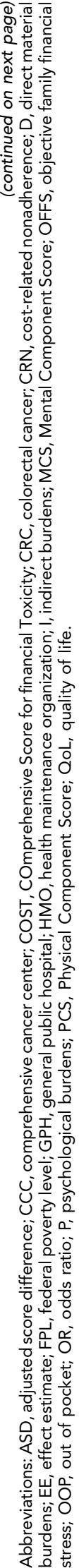




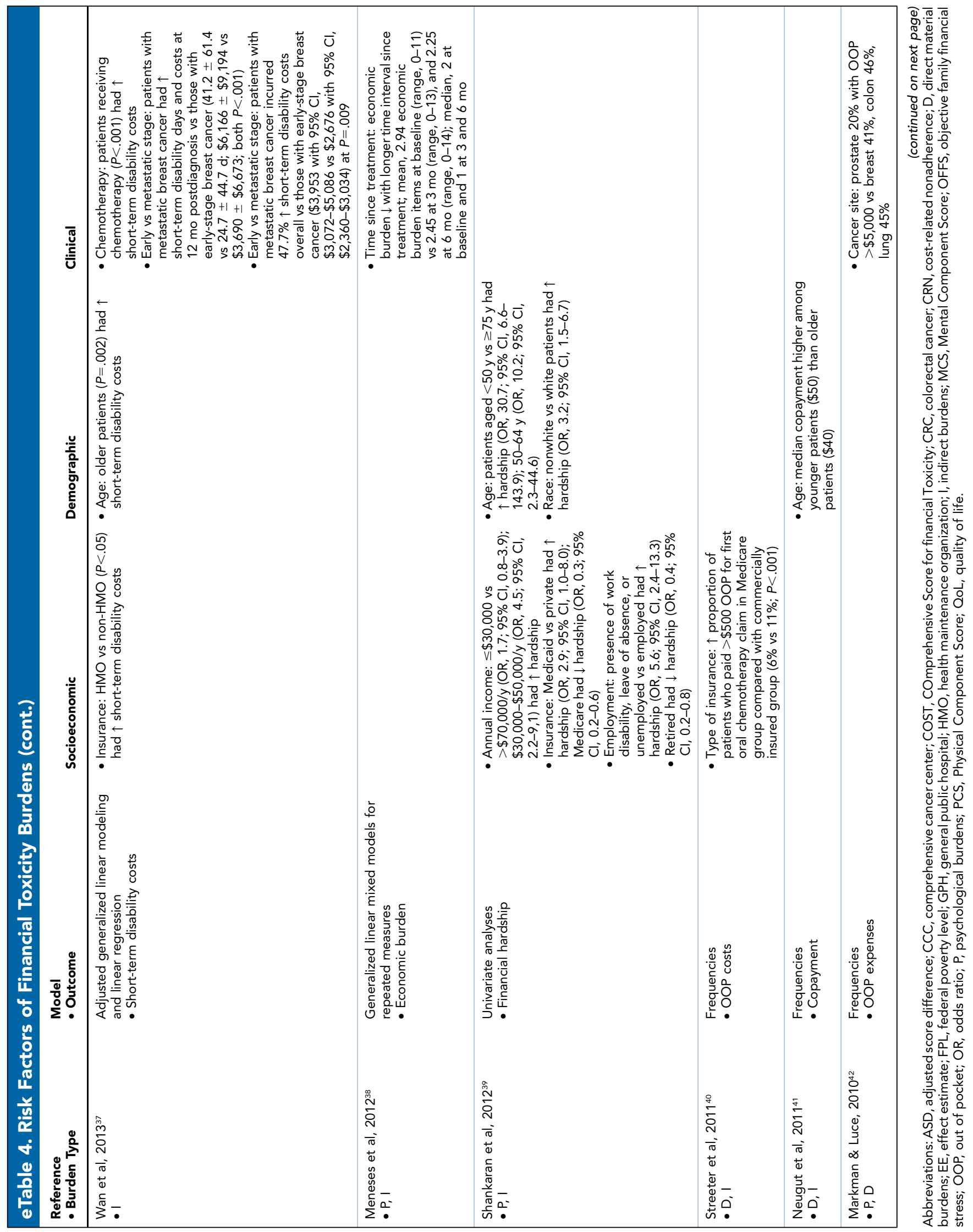




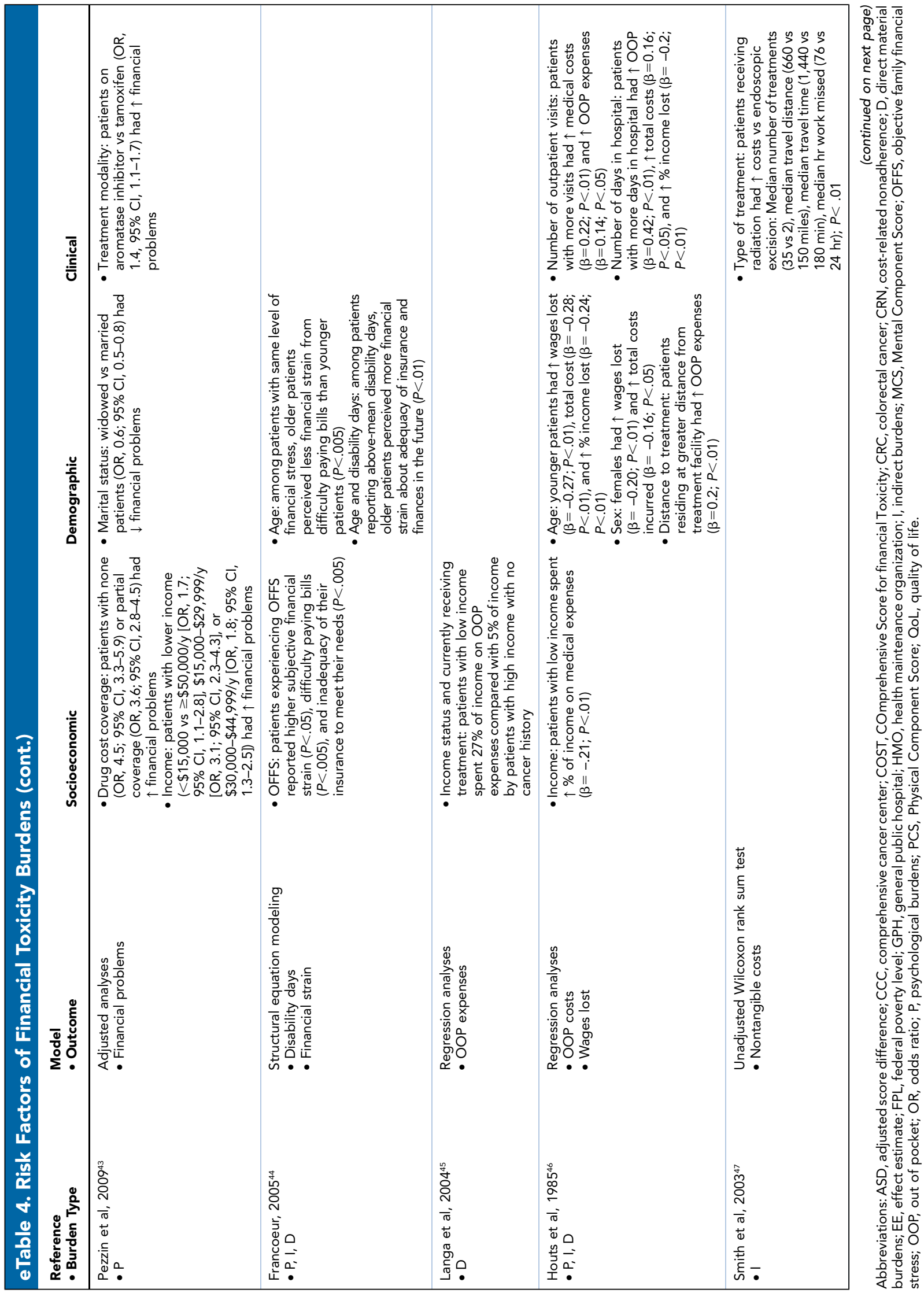




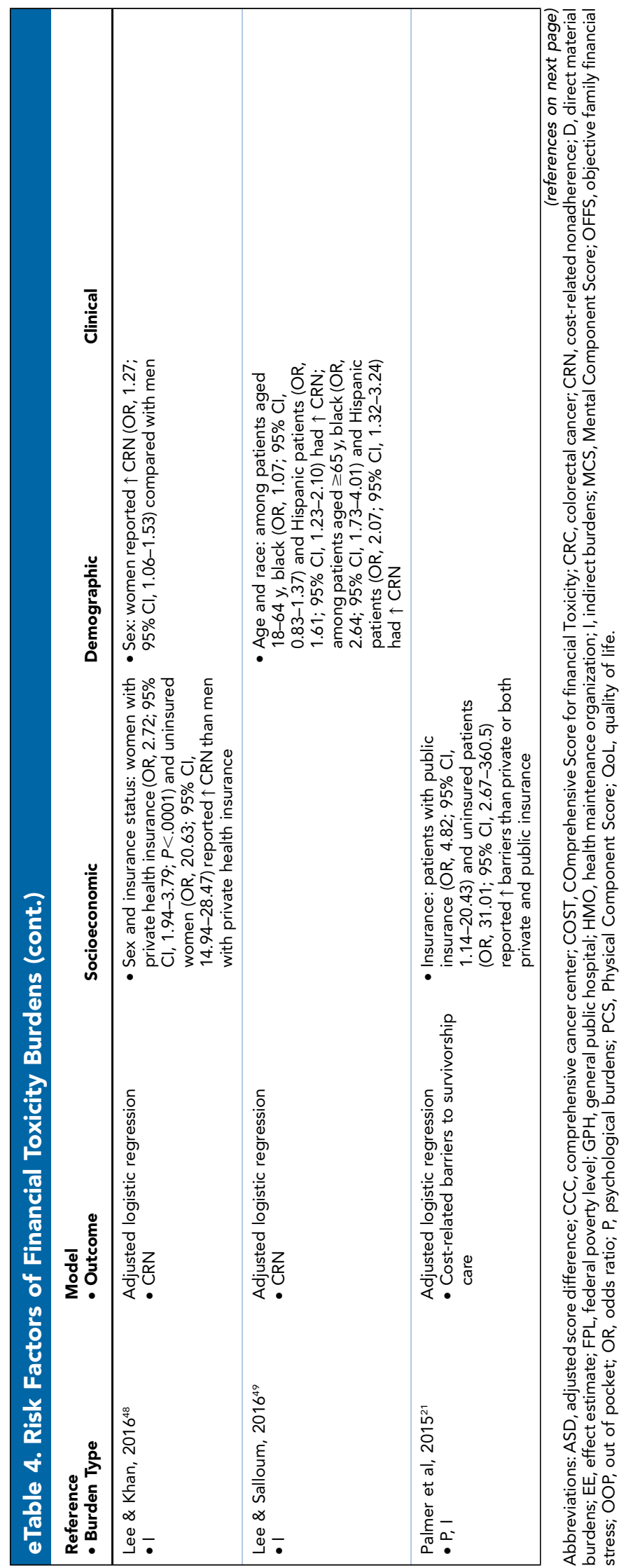




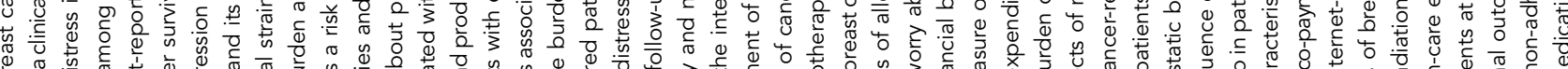

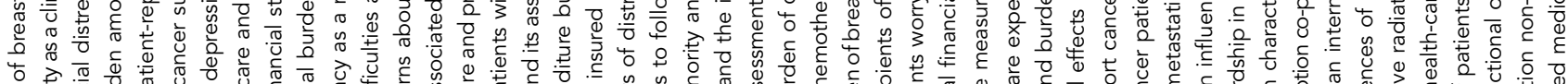

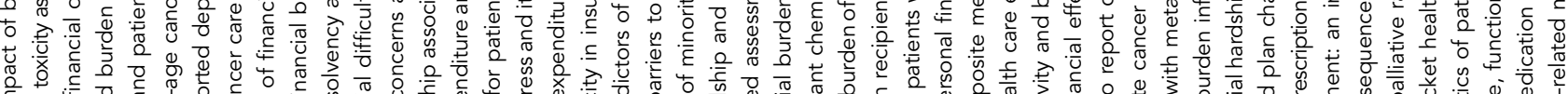

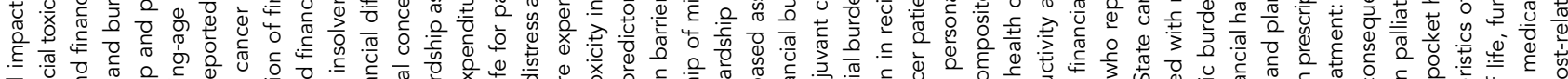

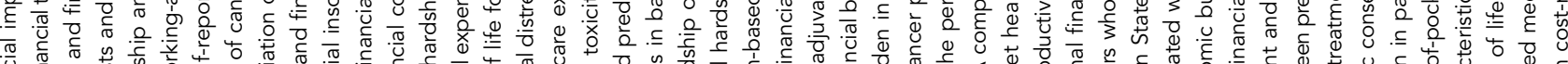

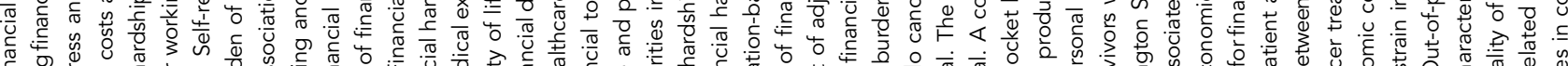

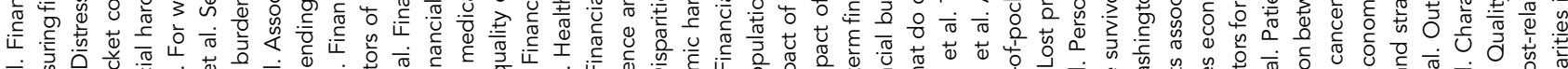

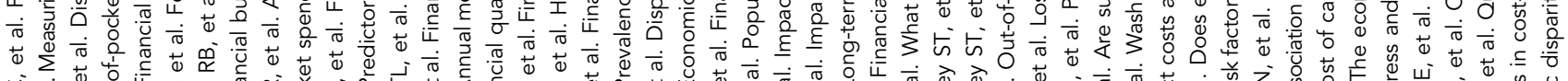

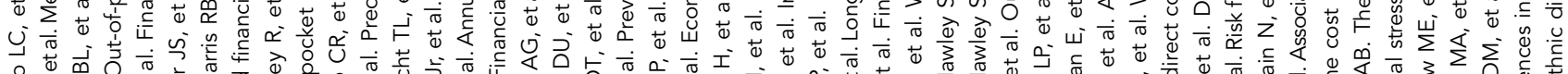

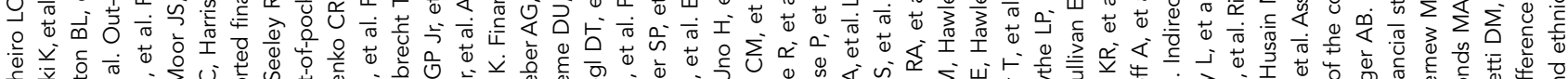

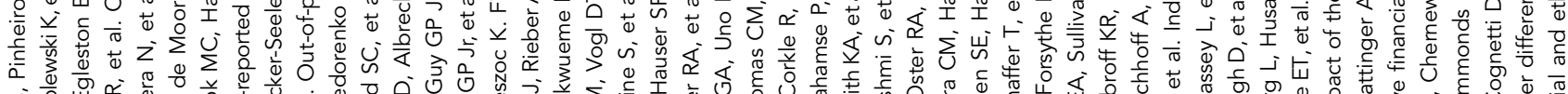

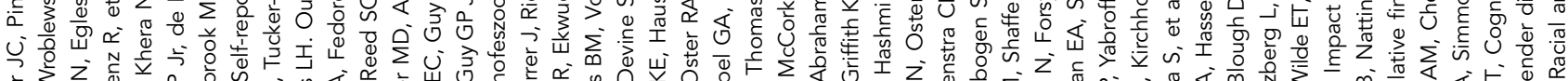

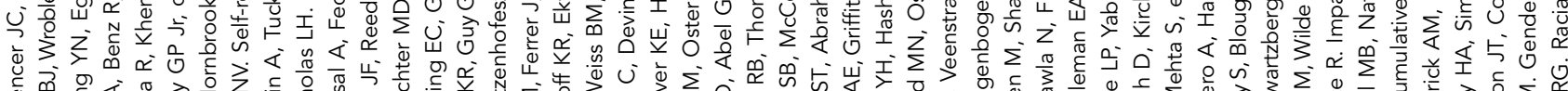
$\begin{array}{lllll} & \\ 0\end{array}$

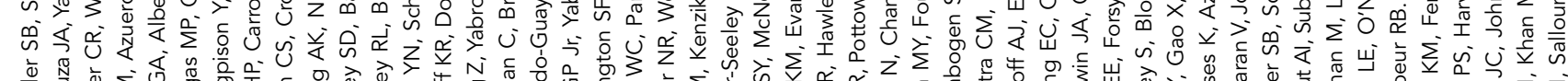

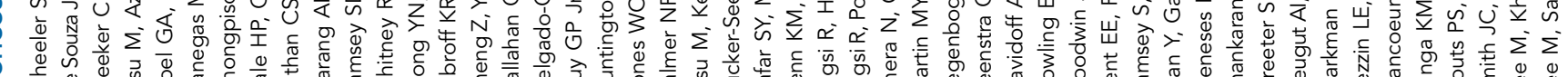

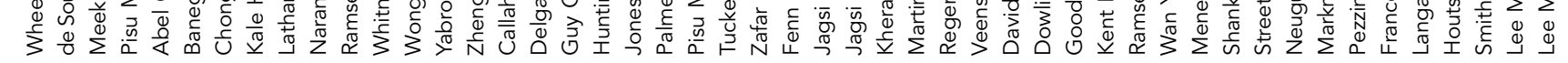

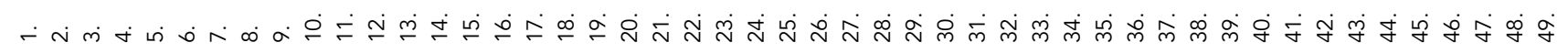




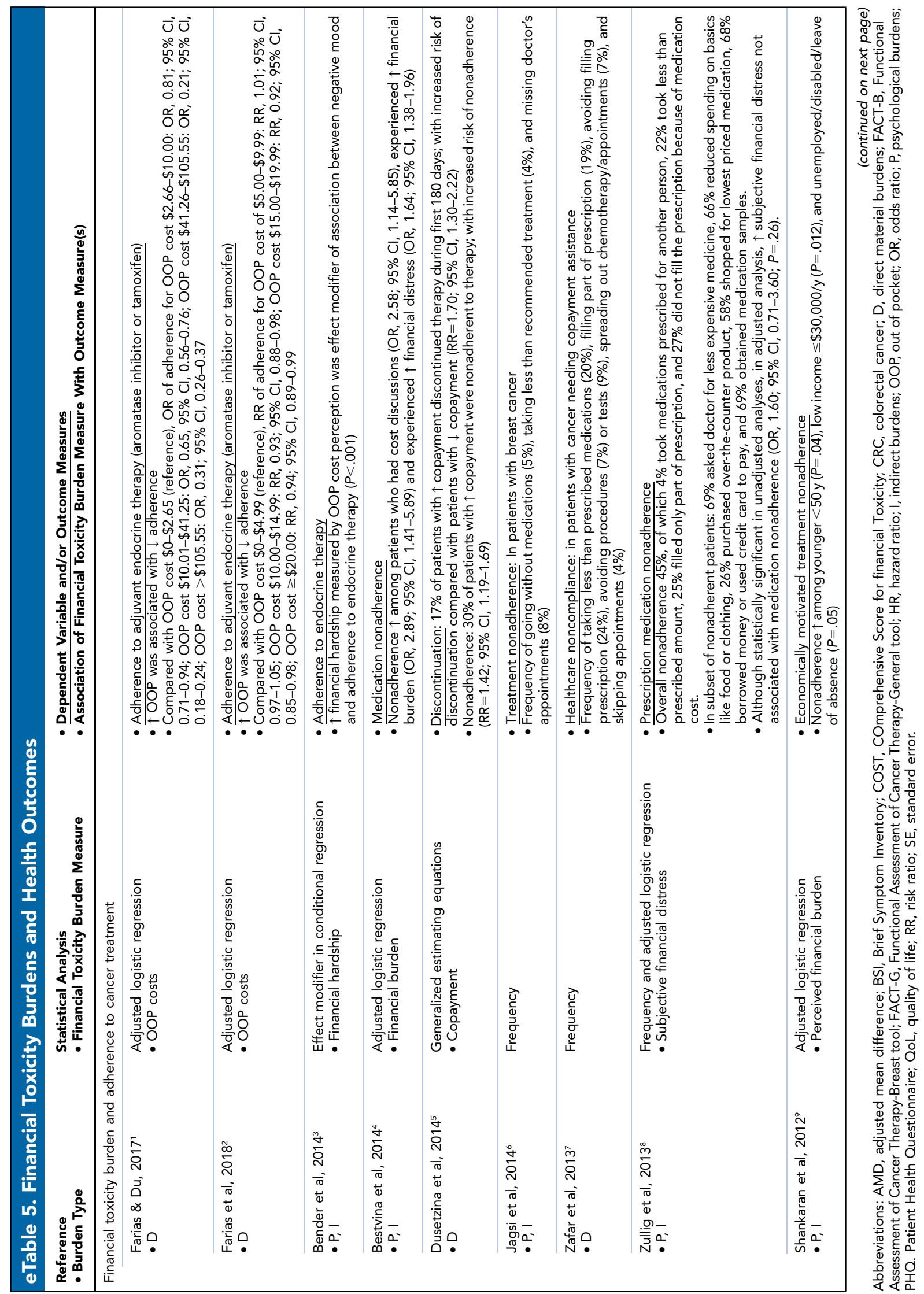




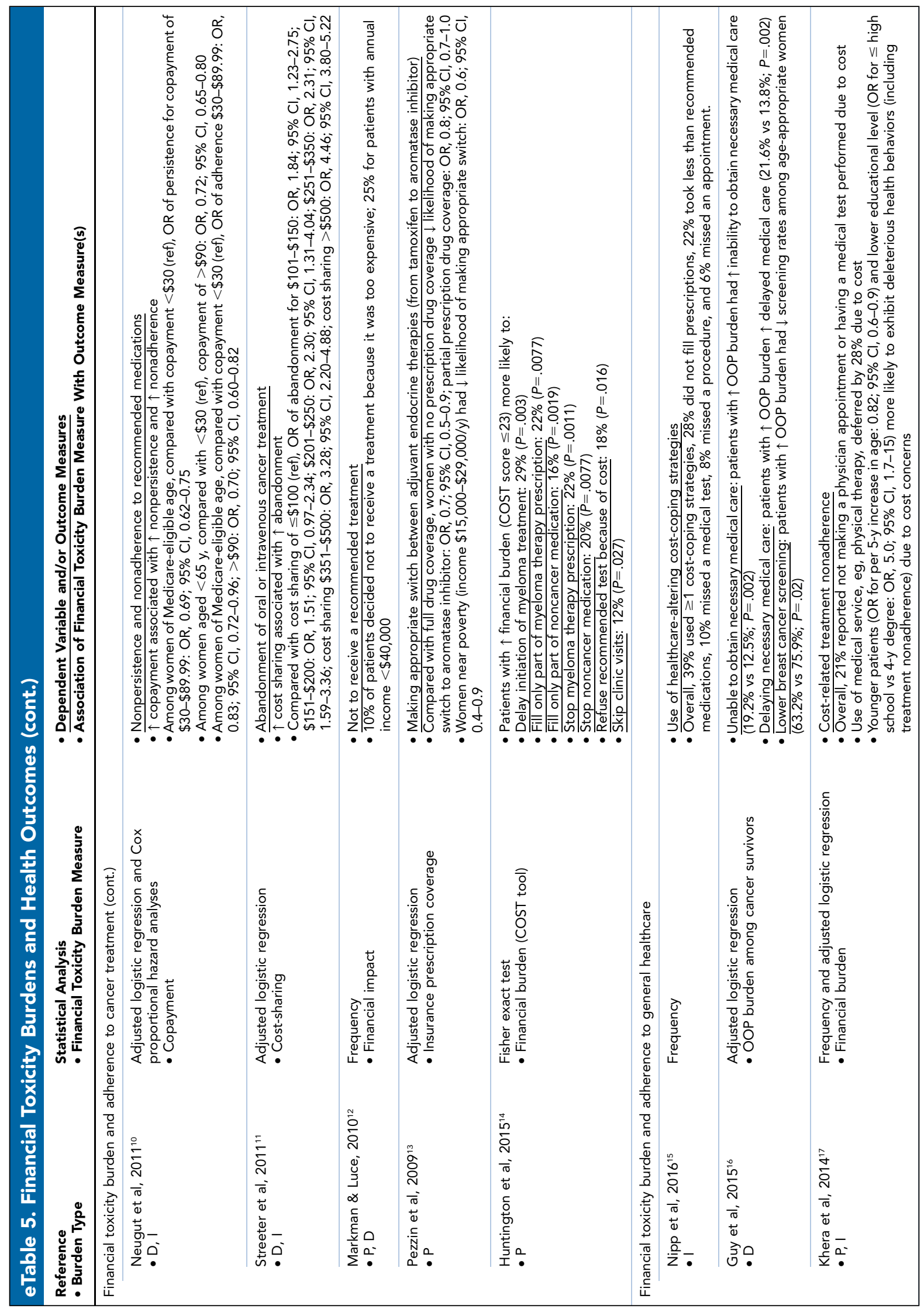

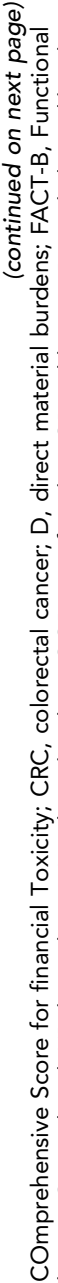

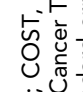

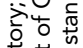

苍莴出

至

을 $\frac{1}{\sigma}$

光

品缐

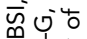

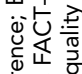

要产

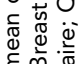

엉 응.

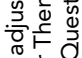

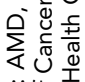

نั่

.

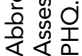




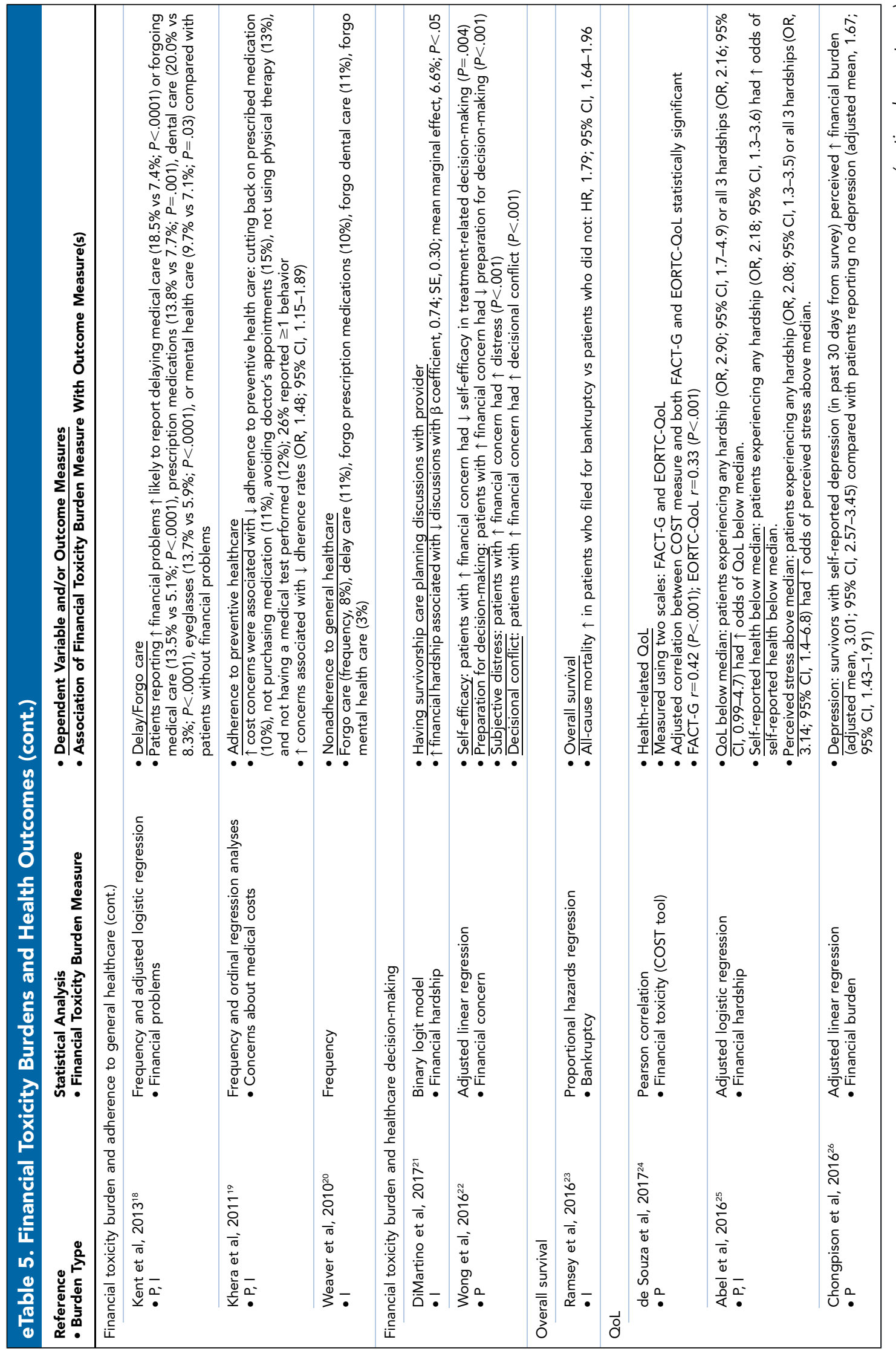

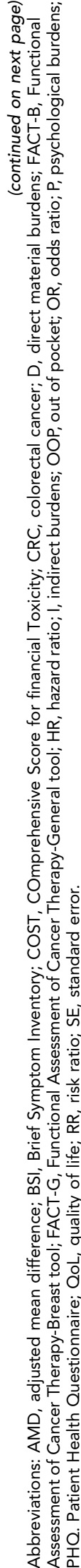




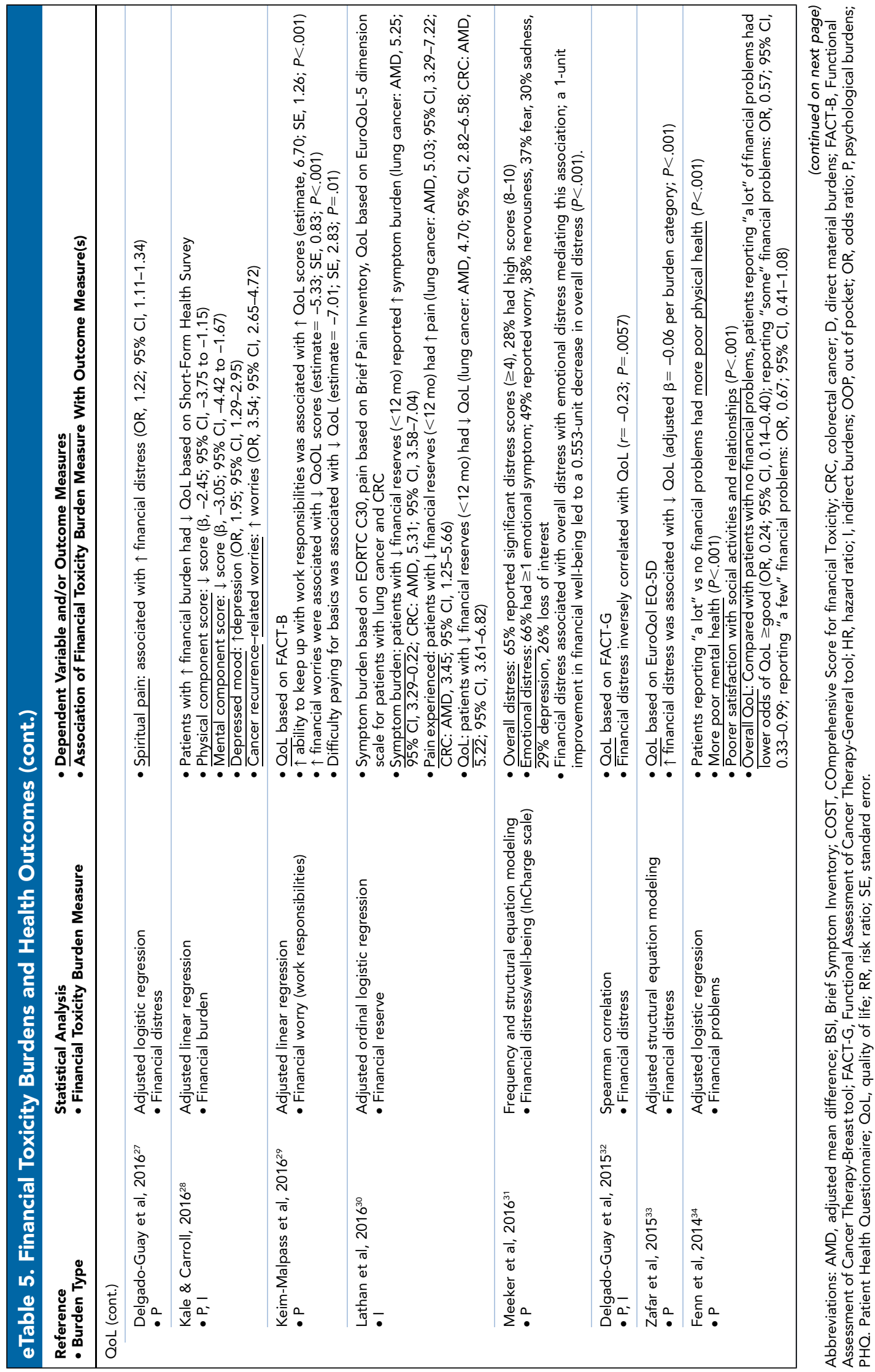



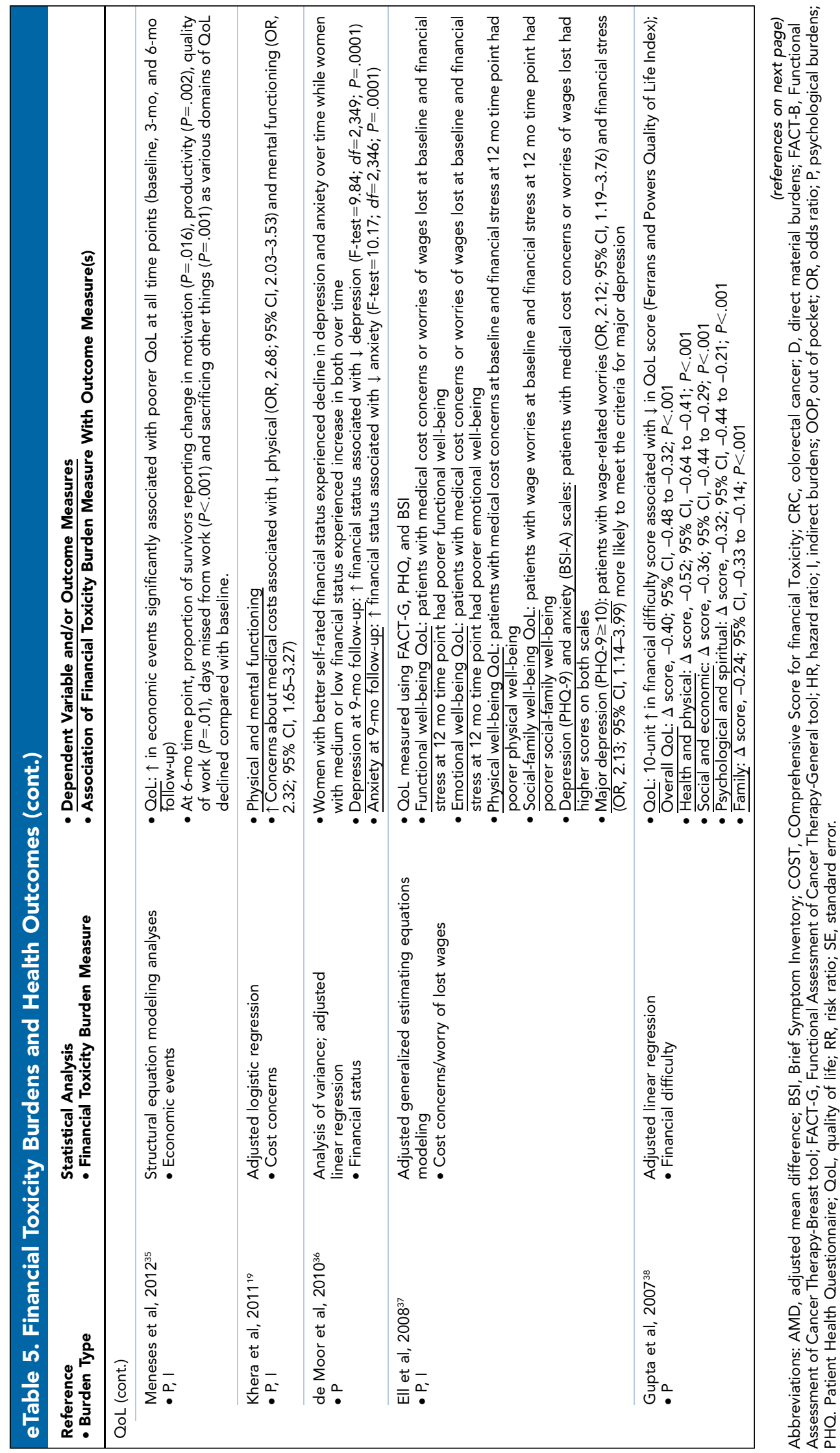


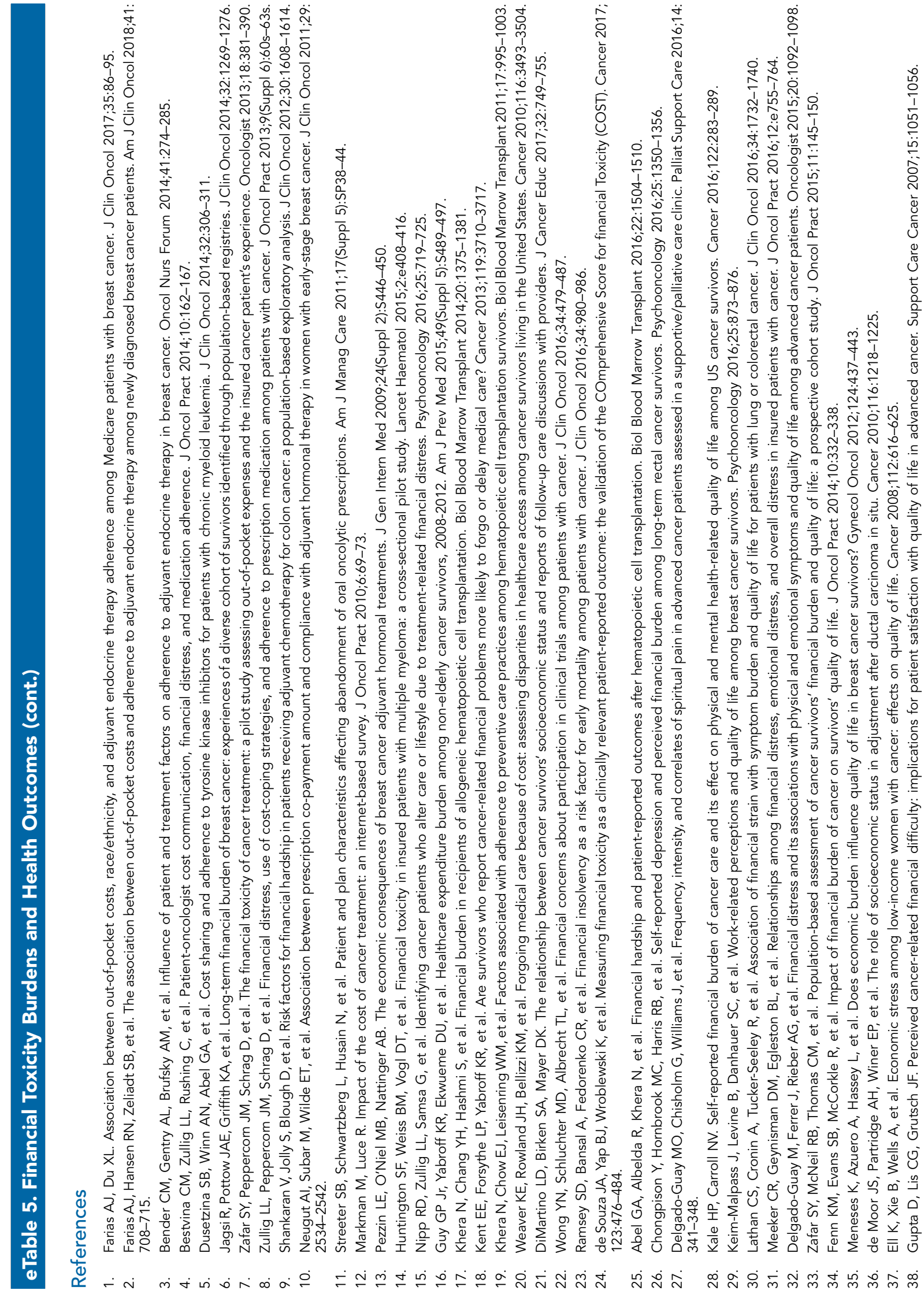




\section{eAppendix 1. Supplementary Results}

\section{Study Characteristics}

Patients with cancer at any disease site (eg, breast, prostate, lung) were eligible in 38 studies (51\%). Single-disease sitespecific studies most commonly focused on breast cancer ( $n=14$ studies, representing 46,033 study subjects) and hematologic cancers ( $n=7$ studies, representing 7,005 study subjects). Assessments of the measure of financial toxicity represented a variety of time points across the cancer survivorship spectrum, from diagnosis to treatment to follow-up; 7 studies focused on financial toxicity within the first 12 months of cancer treatment, ${ }^{1-7}$ and 6 studies were longitudinal in design. ${ }^{8-13}$ A total of 5 studies (74\%) were cross-sectional in design; 3 studies (4\%) focused on subjects aged $\geq 65$ years, ${ }^{14-16}$ and 7 studies oversampled for racial/ethnic minorities or medically underserved patients. ${ }^{4,8,17-21}$ For sample-weighted prevalence estimates, subgroup analyses demonstrating the prevalence of financial burdens ranged from $39 \%$ to $64 \%$. When data were grouped by the specific type of financial burden, prevalence was as follows:

- In 7 studies reporting psychological burdens, 39\% (95\% CI, 25\%-54\%).

- In 13 studies reporting psychological and indirect burdens, 50\% (95\% CI, 39\%-61\%).

- In 1 study reporting indirect and direct burdens, $42 \%$ (95\% CI, 39\%-45\%).

- In 2 studies reporting psychological, indirect, and direct burdens, 59\% (95\% CI, 54\%-63\%).

- In 1 study reporting indirect burdens, $64 \%$ (95\% CI, 62\%-66\%).

- In 1 study reporting psychological and direct burdens, $49 \%$ (95\% CI, $41 \%-56 \%$ ).

Therefore, by type of financial burden, no substantial differences in prevalence were observed (meta-regression $P=.24)$.

\section{Risk of Bias}

There was a risk of recall bias within studies, particularly for studies with cross-sectional or retrospective cohort design in which a subject's financial toxicity was not determined prospectively but instead depended on recall and self-report of financial toxicity that the subject retrospectively attributed as a consequence of cancer treatment. Therefore, temporality of associations between financial toxicity and outcomes could not be confirmed. Not all financial toxicity tools/measures had reliability and validity testing, which could lead to misclassification bias. However, some financial toxicity measures were objective (eg, out-of-pocket [OOP] costs and copays determined by insurance claims records, or bankruptcy as determined by public records and not subject self-reporting) and/or validation-related (eg, the COST tool), and themes between findings from studies using validated measures did not differ categorically from studies using other financial toxicity measures. Selection bias may have occurred with underrepresentation of nonwhite subjects in studies.

Selection bias may have also occurred if nonparticipants systematically differed from participants (eg, if nonparticipants tended to have more severe disease or financial toxicity causing barriers to participation), though in the 56 evaluable studies the participation rate exceeded $50 \%$ in $86 \%$ of studies. Of the 6 longitudinal studies, attrition bias because of deaths from metastatic or advanced cancer could have impacted the generalizability of longitudinal findings to patients with more severe disease.

\section{Measures of Financial Toxicity}

Regarding existing measures of financial toxicity, no single concept, measure, or tool was consistently used across studies. Measures included validated items or tools (the Medical Expenditure Panel Survey ${ }^{22}$ and the COST tool ${ }^{23}$ ), objective quantification or estimation of OOP costs, and subjective questions about the severity of treatment, financial burdens, and/or psychological stress (eg, "How much financial burden currently resulted from your illness and treatment?"). ${ }^{24}$

\section{Additional Quantitative Analyses}

Funnel plot and regression asymmetry tests to assess small-study bias were not feasible because of the small number of studies for quantitative synthesis. For the association between insurance status and odds of financial toxicity, on sensitivity analysis, greater odds were observed in patients with breast cancer aged $>65$ years receiving adjuvant hormonal treatments. Insurance was still associated with financial toxicity when removing the studies evaluating breast cancer (odds rqatio [OR], 1.77; 95\% CI, 1.38-2.25; $I^{2}=31 \%$ ) or any other particular type of cancer (OR, 2.17; 95\% CI, 1.63-2.89; $\left.I^{2}=0 \%\right)$. For the association between financial toxicity and odds of medication nonadherence, the association was still significant after removing the study evaluating leukemia only (OR, 2.22; 95\% CI, 1.25-3.96; $I^{2}=13 \%$ ). 


\section{6 - Smith et al}

\section{References}

1. Kale HP, Carroll NV. Self-reported financial burden of cancer care and its effect on physical and mental health-related quality of life among US cancer survivors. Cancer 2016;122:283-289.

2. Lee M, Salloum RG. Racial and ethnic disparities in cost-related medication non-adherence among cancer survivors. J Cancer Surviv 2016;10:534-544.

3. Zafar SY, McNeil RB, Thomas CM, et al. Population-based assessment of cancer survivors' financial burden and quality of life: a prospective cohort study. J Oncol Pract 2015;11:145-150.

4. Wong YN, Schluchter MD, Albrecht TL, et al. Financial concerns about participation in clinical trials among patients with cancer. J Clin Oncol 2016; 34:479-487.

5. Ramsey SD, Bansal A, Fedorenko $C R$, et al. Financial insolvency as a risk factor for early mortality among patients with cancer. J Clin Oncol 2016;34: 980-986.

6. Delgado-Guay M, Ferrer J, Rieber AG, et al. Financial distress and its associations with physical and emotional symptoms and quality of life among advanced cancer patients. Oncologist 2015;20:1092-1098.

7. Peng $L, Y e X$, Zhou Y, et al. Meta-analysis of incidence and risk of peripheral neuropathy associated with intravenous bortezomib. Support Care Cancer 2015;23:2813-2824.

8. Shankaran V, Jolly S, Blough D, et al. Risk factors for financial hardship in patients receiving adjuvant chemotherapy for colon cancer: a populationbased exploratory analysis. J Clin Oncol 2012;30:1608-1614.

9. Regenbogen SE, Veenstra CM, Hawley ST, et al. The personal financial burden of complications after colorectal cancer surgery. Cancer 2014;120: 3074-3081.

10. Goodwin JA, Coleman EA, Sullivan E, et al. Personal financial effects of multiple myeloma and its treatment. Cancer Nurs 2013;36:301-308.

11. Meeker CR, Wong YN, Egleston BL, et al. Distress and financial distress in adults with cancer: an age-based analysis. J Natl Compr Canc Netw 2017; 15:1224-1233.

12. Zheng Z, Yabroff KR, Guy GP Jr, et al. Annual medical expenditure and productivity loss among colorectal, female breast, and prostate cancer survivors in the United States. J Natl Cancer Inst 2015;108:djv382.
13. de Souza JA, Kung S, O'Connor J, et al. Determinants of patient-centered financial stress in patients with locally advanced head and neck cancer. J Oncol Pract 2017;13:e310-318.

14. Banegas MP, Guy GP Jr, de Moor JS, etal. For working-age cancer survivors, medical debt and bankruptcy create financial hardships. Health Aff (Millwood) 2016;35:54-61.

15. Martin MY, Fouad MN, Oster RA, et al. What do cancer patients worry about when making decisions about treatment? Variation across racial/ethnic groups. Support Care Cancer 2014;22:233-244.

16. Neugut Al, Subar M, Wilde ET, et al. Association between prescription co-payment amount and compliance with adjuvant hormonal therapy in women with early-stage breast cancer. J Clin Oncol 2011;29: 2534-2542.

17. Fenn KM, Evans SB, McCorkle R, et al. Impact of financial burden of cancer on survivors' quality of life. J Oncol Pract 2014;10:332-338.

18. Wheeler SB, Spencer JC, Pinheiro LC, et al. Financial impact of breast cancer in black versus white women. J Clin Oncol 2018;36:1695-1701.

19. Farias AJ, Hansen RN, Zeliadt SB, et al. The association between out-ofpocket costs and adherence to adjuvant endocrine therapy among newly diagnosed breast cancer patients. Am J Clin Oncol 2018;41. 708-715.

20. Shankaran V, Leahy T, Steelquist J, et al. Pilot feasibility study of an oncology financial navigation program. J Oncol Pract 2018;14:e122-129.

21. DiMartino LD, Birken SA, Mayer DK. The relationship between cancer survivors' socioeconomic status and reports of follow-up care discussions with providers. J Cancer Educ 2017;32:749-755.

22. Peng $L, B u Z, Y e X$, et al. Incidence and risk of peripheral neuropathy with nab-paclitaxel in patients with cancer: a meta-analysis. Eur J Cancer Care [Br] 2017;26:e12407.

23. Chongpison Y, Hornbrook MC, Harris RB, et al. Self-reported depression and perceived financial burden among long-term rectal cancer survivors. Psychooncology 2016;25:1350-1356.

24. Wan Y, Gao X, Mehta S, et al. Indirect costs associated with metastatic breast cancer. J Med Econ 2013;16:1169-1178. 